Florida International University FIU Digital Commons

\title{
Comparison of Linear Functions in Middle Grades Textbooks from Singapore and the United States
}

Linda D. Fowler

Florida International University, donna_fowler@pba.edu

DOI: $10.25148 /$ etd.FI15032190

Follow this and additional works at: https://digitalcommons.fiu.edu/etd

Part of the Cognition and Perception Commons, Cognitive Psychology Commons, Curriculum and Instruction Commons, Curriculum and Social Inquiry Commons, Educational Assessment, Evaluation, and Research Commons, Educational Psychology Commons, Educational Sociology $\underline{\text { Commons, International and Area Studies Commons, International and Comparative Education }}$

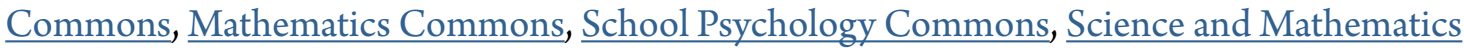
Education Commons, and the Social Psychology Commons

\section{Recommended Citation}

Fowler, Linda D., "Comparison of Linear Functions in Middle Grades Textbooks from Singapore and the United States" (2015). FIU Electronic Theses and Dissertations. 1799.

https://digitalcommons.fiu.edu/etd/1799 


\section{FLORIDA INTERNATIONAL UNIVERSITY}

Miami, Florida

\section{COMPARISON OF LINEAR FUNCTIONS IN MIDDLE GRADES TEXTBOOKS \\ FROM SINGAPORE AND THE UNITED STATES}

A dissertation submitted in partial fulfillment of

the requirements for the degree of

DOCTOR OF EDUCATION

in

CURRICULUM AND INSTRUCTION

by

Linda Donnell Fowler

2015 
To: Dean Delia C. Garcia

College of Education

This dissertation, written by Linda Donnell Fowler, and entitled Comparison of Linear Functions in Middle Grades Textbooks from Singapore and the United States, having been approved in respect to style and intellectual content, is referred to you for judgment.

We have read this dissertation and recommend that it be approved.

Janice Sandiford

Hilary Landorf

Maria Fernandez, Co-Major Professor

George E. O'Brien, Co-Major Professor

Date of Defense: March 27, 2015

The dissertation of Linda Donnell Fowler is approved.

Dean Delia C. Garcia

College of Education

Dean Lakshmi N. Reddi

University Graduate School

Florida International University, 2015 


\section{ACKNOWLEDGMENTS}

First of all, I want to acknowledge my Lord and Savior Jesus Christ, without whom, I would never have gotten this degree. He is the ultimate cause of all things.

I would next like to thank my family and friends for their love and support throughout this process: my parents, John and Brenda, sisters Amy and Diane, brother Johnny, husband Tom, daughter Ashley, and parents in law: Big Tom and Ginny.

A big thank you goes to my sister Diane whose editing comments pushed me forward when I was at a standstill.

A big thank you goes to my husband Tom who suffered through the loathsome task of being my second coder in the study. Thank you for your sacrifice.

I give a big thank you to Ashley who sacrificed the most time-wise throughout this process. Thank you, Ashley.

I also give Marsha Guntharp a big thank you for being the third judge needed to find the content validity index values for the study.

A big thank you goes to my co major professors: Dr. O’Brien, Dr. Fernandez, without whom, I would never have gotten my extensions. Thank you for all your work.

A big thank you goes to my committee members Dr. Sandiford and Dr. Landorf for all the work you put in.

I also gives thanks to my former advisor Dr. Alacaci for leading me to this topic of study, to Dr. Tashakkori who taught my first class at FIU, and to Dr. Banya who volunteered to teach an independent study for me.

I also thank the Palm Beach County school district and Conniston Middle School for the use of one series of U.S. textbooks for the study. 


\title{
ABSTRACT OF THE DISSERTATION \\ COMPARISON OF LINEAR FUNCTIONS IN MIDDLE GRADES TEXTBOOKS \\ FROM SINGAPORE AND THE UNITED STATES
}

by

\author{
Linda Donnell Fowler
}

Florida International University, 2015

Miami, Florida

\section{Professor George E. O’Brien, Co-Major Professor \\ Professor Maria Fernandez, Co-Major Professor}

Many U.S. students do not perform well on mathematics assessments with respect to algebra topics such as linear functions, a building-block for other functions. Poor achievement of U.S. middle school students in this topic is a problem.

U.S. eighth graders have had average mathematics scores on international comparison tests such as Third International Mathematics Science Study, later known as Trends in Mathematics and Science Study, (TIMSS)-1995, -99, -03, while Singapore students have had highest average scores. U.S. eighth grade average mathematics scores improved on TIMMS-2007 and held steady onTIMMS-2011. Results from national assessments, PISA 2009 and 2012 and National Assessment of Educational Progress of 2007, 2009, and 2013, showed a lack of proficiency in algebra. Results of curriculum studies involving nations in TIMSS suggest that elementary textbooks in high-scoring countries were different than elementary textbooks and middle grades texts were different with respect to general features in the U.S. 
The purpose of this study was to compare treatments of linear functions in Singapore and U.S. middle grades mathematics textbooks. Results revealed features currently in textbooks. Findings should be valuable to constituencies who wish to improve U.S. mathematics achievement.

Portions of eight Singapore and nine U.S. middle school student texts pertaining to linear functions were compared with respect to 22 features in three categories: (a) background features, (b) general features of problems, and (c) specific characterizations of problem practices, problem-solving competency types, and transfer of representation. Features were coded using a codebook developed by the researcher. Tallies and percentages were reported. Welch's $t$-tests and chi-square tests were used, respectively, to determine whether texts differed significantly for the features and if codes were independent of country.

U.S. and Singapore textbooks differed in page appearance and number of pages, problems, and images. Texts were similar in problem appearance. Differences in problems related to assessment of conceptual learning. U.S. texts contained more problems requiring (a) use of definitions, (b) single computation, (c) interpreting, and (d) multiple responses. These differences may stem from cultural differences seen in attitudes toward education. Future studies should focus on density of page, spiral approach, and multiple response problems. 


\section{TABLE OF CONTENTS}

CHAPTER

PAGE

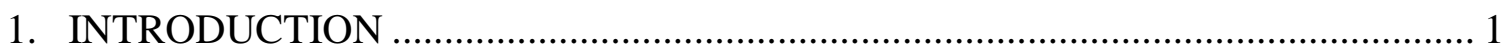

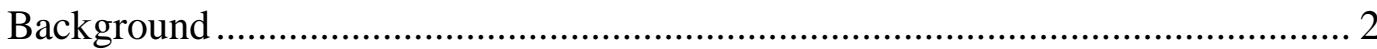

Rationale for a Textual Analysis Concerning Linear Functions ......................... 4

Rationale for Comparison of Singapore and U.S. Middle School Texts ......... 15

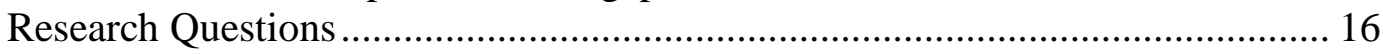

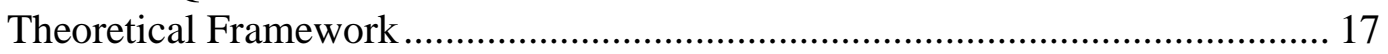

Potential Usefulness of Textbook Research .................................................. 18

Historical Background ......................................................................... 18

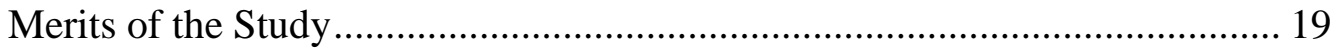

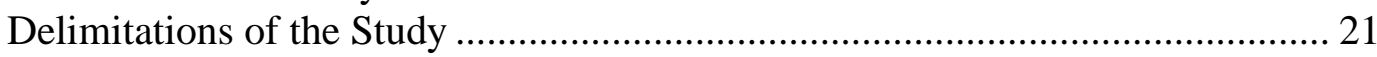

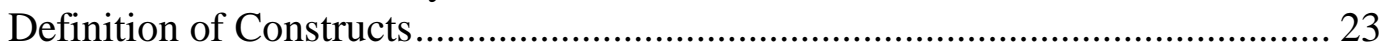

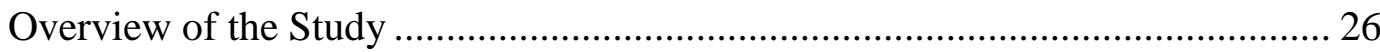

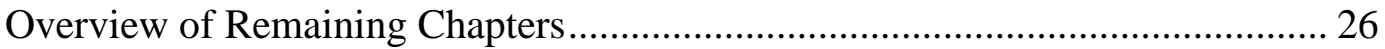

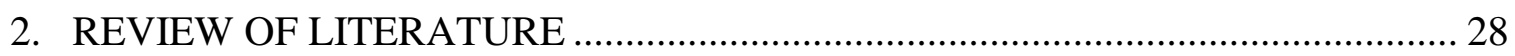

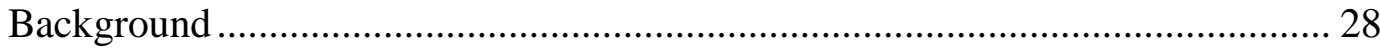

Textbook Features ………………………………............................... 34

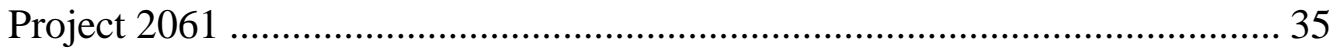

Aspects of Problems ................................................................................. 36

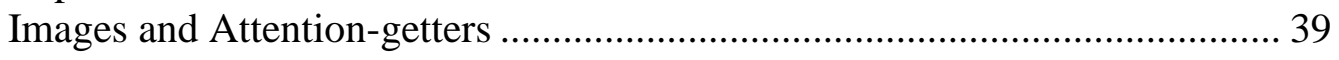

Goals and Development of Concepts ............................................................. 40

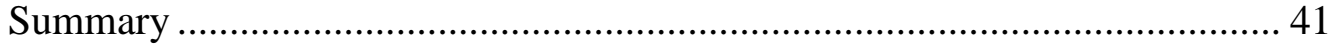

Textbooks within a Larger Mathematical System ............................................... 42

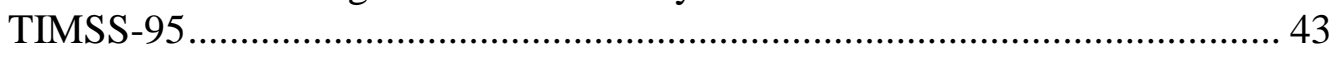

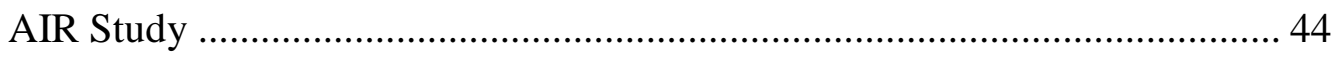

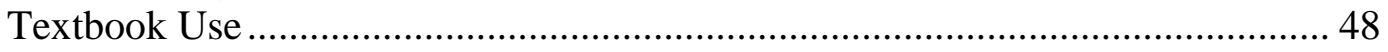

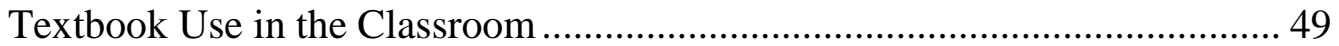

Textbook Use and Teaching Strategy …………………................................ 50

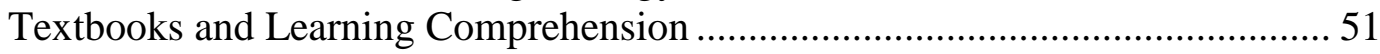

Effects on Learning When the Textbook is Altered.......................................... 52

Types of learning inherent in the text ......................................................... 56

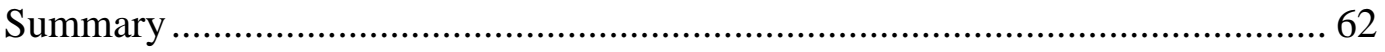

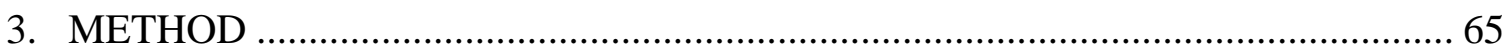

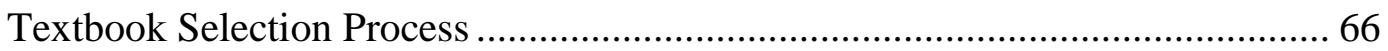

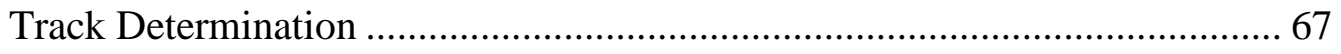

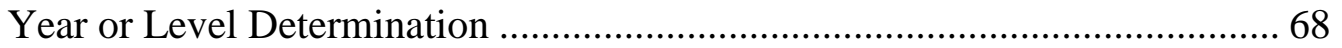

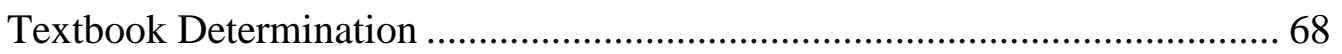

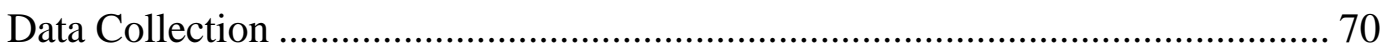

Analysis of Coding Scheme.............................................................................. 74

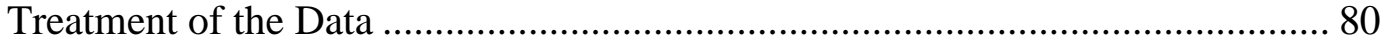




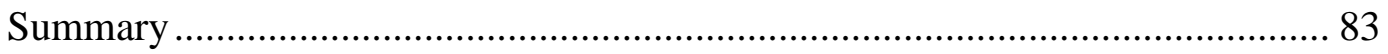

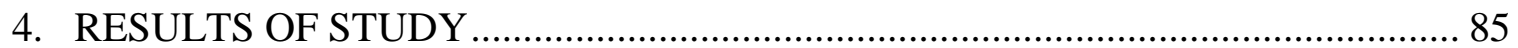

Results from Data Collection.................................................................... 85

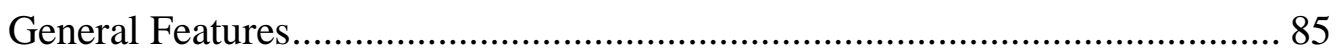

Problem Features............................................................................. 89

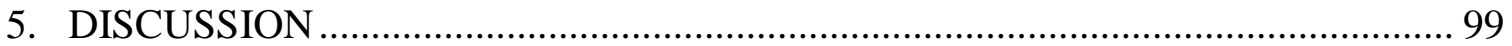

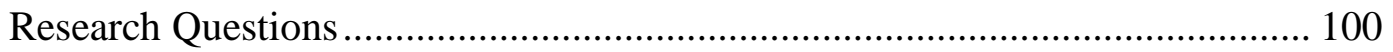

Examination of General Features.......................................................... 100

Examination of Problem Features .............................................................. 106

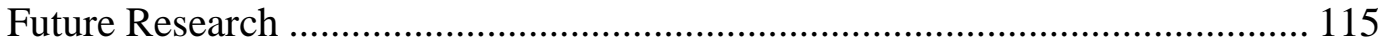

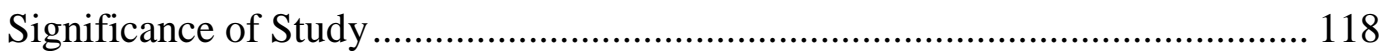

Implications for Practice ....................................................................... 122

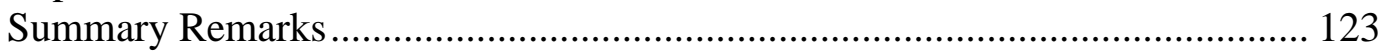

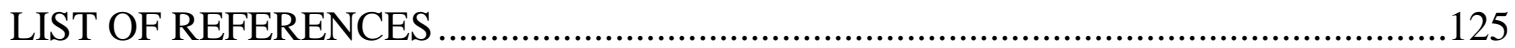

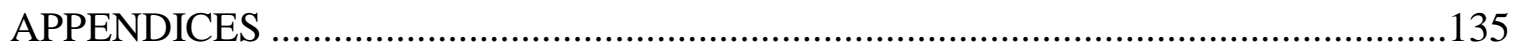

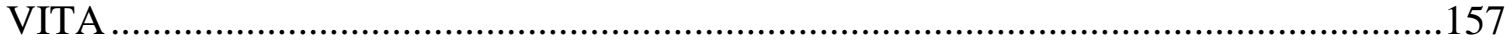




\section{LIST OF TABLES}

TABLE

PAGE

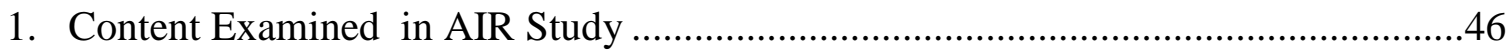

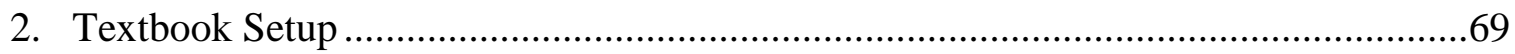

3. Final Inter-Rater Reliability Coefficients for Categories Coded in Text...................78

4. Comparison of Data for General Characteristics of the Text ................................79

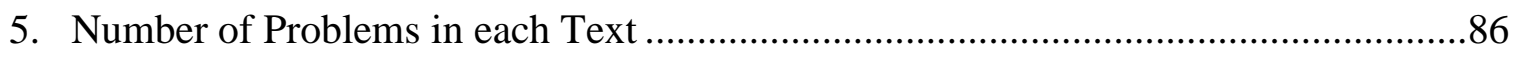

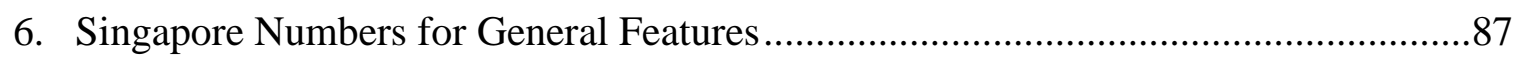

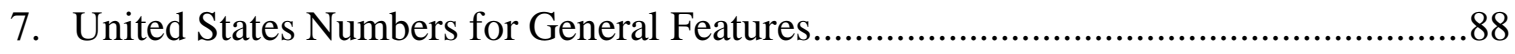

8. Average Values for General Features for Each Country ......................................89

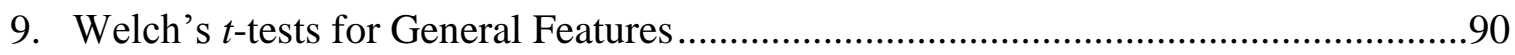

10. Welch's $t$-tests for Codes of Problem Features....................................................92

11. Values for $\chi^{2}$ Test of Independence for Problem Features .......................................95

12. Overlap in Glencoe Math Connects Textbooks ...................................................104 


\section{LIST OF FIGURES}

FIGURE

PAGE

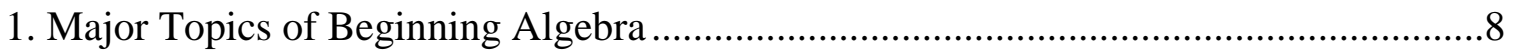

2. Linear Functions within Algebra and School Mathematics......................................9

3. Concept Map for Linear Functions ..................................................................... 11

4. Example of a Linear Function in Different Representations ...................................25

5. Cognitive Requirement Sample Problems ..........................................................77

6. Similarities and Differences of General Features of Textbooks ...............................101

7. Significantly Different Codes for Problem Features .............................................107

8. U.S. "Other" and "Does Not Apply' Problems..................................................111

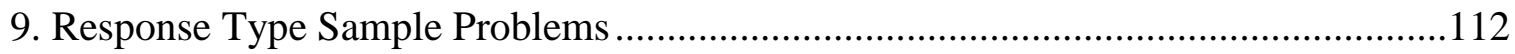




\section{CHAPTER I}

\section{INTRODUCTION}

While teaching mathematics classes, such as college algebra, that satisfy college and university minimum graduation requirements, the researcher observed that many students do not do well on algebra-related topics. Upon conducting a preliminary literature search about student success in college algebra in the United States, the researcher found that based upon meeting ACT's college readiness benchmarks, only $40 \%$ of high school graduates were ready for their first course in college algebra (ACT, 2004). Also, only $34 \%$ of eighth graders were projected to be ready for enrollment in college algebra courses upon high school graduation. By 2009, the number of high school graduates ready for college algebra was $42 \%$ (ACT, 2009). Results from the Nation's Report Card — the National Assessment of Educational Progress (NAEP) from 2009 showed that while the percentage of students in eighth grade at or above proficiency levels was the largest ever for mathematics, this percentage was only $34 \%$ (U.S. Department of Education, 2010b). In 2011, the percentage of eighth graders at or above proficiency levels on the NAEP had increased to 35\% and remained the same in 2013 (National Center for Education Statistics. 2013).

The continuing low achievement in mathematics for most American high school graduates is a major concern to business, economic, and political leaders, due to the fact that a "strong grasp of algebra is essential for successful preparation in the contemporary American workforce" (Fennell et al., 2008, p. 3-1). Additionally, educators are concerned since college algebra is necessary for entry into higher education and the pursuit of advanced mathematics in general (Fennell et al., 2008). The lack of proficiency in 
mathematics is also seen as an issue of national safety (Fennell et al., 2008). In the Final Report by the National Mathematics Advisory Panel, the panel discussed the critical importance of teaching mathematics in the middle grades, and how this might be pivotal to achieving the national goal of a mathematically-literate nation (Fennell et al., 2008).

\section{Background}

Historically, U.S. students have demonstrated weak performances on state, national, and international assessments (Kilpatrick, Swafford, \& Findell, 2001). Particularly important to this study, weakness of U.S. middle school students in the area of mathematics can be seen in the results of assessments such as (a) the eighth-grade portion of the Third International Mathematics and Science Study of 1995 (TIMSS-95;

Beaton et al., 1996); (b) the Trends in Mathematics and Science Study (TIMSS) in 1999, 2003, 2007, and 2011 (Gonzales et al., 2000; Gonzales et al., 2004; U.S. Department of Education, 2009; Provasnik et al., 2012); (c) Program for International Student Assessment (PISA) for 15-year-olds (Baldi, Jin, Skemer, Green, \& Herget, 2007; Kelly, Xie, Nord, Jenkins, Chan, \& Kastberg, 2013); and (d) the Nation's Report Card—the National Assessment of Educational Progress (NAEP) (Fennell et al., 2008; Lee, Grigg, \& Leon, 2007; National Center for Educational Assessment, 2013; U.S. Department of Education, 2010b) for eighth-graders. The results showed that U.S. students were below average or just above average as compared to other nations in the assessments and showed a lack of proficiency in the area of algebra.

The Third International Mathematics and Science Study (TIMSS) of 1995 showed that U.S. eighth graders had average mathematics achievement score, 500, below the mean of the international average mathematics achievement score, 513, across the 41 
nations that took the test (Beaton et al., 1996; Schmidt et al., 2001; Zhu \& Fan, 2004). Students of the same age in East Asian countries had the highest average mathematics achievement scores with Singapore students having the highest average score, 643, of all the countries. After 1995, the international comparison continued at 4-year intervals with the new name, Trends in Mathematics and Science Study (TIMSS). Subsequent TIMSS tests in 1999 (Gonzales et al., 2000) and 2003 (Gonzales et al., 2004) showed similar results with U.S. average scores, 502 and 504, slightly above the international TIMSS scale average of 500, respectively. The TIMSS in 2007 showed some improvement in the U.S. eighth grade students' average score as compared to the averages of the 47 other nations who participated (U.S. Department of Education, 2009). The U.S. average score, 508 , was above the average scores of 39 other countries and below the average scores of eight nations including Singapore. In 2011, U.S. eighth grade students' average score, 509 , remained about the same with 11 education systems scoring higher and 32 nations scoring below the U.S. score (Provasnik et al., 2012). While these results showed an improvement in mathematics achievement as compared to other nations since 1995, in light of the NAEP results and the U.S. status as a business, economic, and higher education leader, the fact remains that the mathematics achievement in the U.S. needs to continue to improve.

One topic that U.S. middle school students have difficulty in is the topic of linear functions. An example of middle school students' lack of proficiency in the topic of linear functions can be seen in one of the published results from the Nation's Report Card: Mathematics 2007 (Lee et al., 2007). The results demonstrated that $54 \%$ of eighth graders correctly determined a symbolic representation of a linear function when given 
the function in table form, but only $25 \%$ of eighth graders were able to identify the graph of a linear equation. This result is indicative of a more general lack of success of U.S. middle school students to be able to transition from arithmetic to algebra in topics such as linear functions (Kilpatrick et al., 2001). On the 2013 Nation's Report Card assessment, U.S. students showed improvement in being able to find the symbolic representation of a line as $67 \%$ were able to find the equation of a line when given a table of values (National Center for Educational Assessment, 2013). However, students still struggled with some problems pertaining to linear functions as only $20 \%$ of students were able to interpret slope from a verbal description. This lack of proficiency in linear functions by eighth-graders continues as students proceed to take more advanced mathematics classes as is evidenced by AP Calculus students' difficulty with concepts of linear rate of change (Teuscher \& Reys, 2010).

\section{Rationale for a Textual Analysis Concerning Linear Functions}

The results from the landmark international comparison study, TIMSS-95, served as the catalyst for a plethora of studies comparing the educational practices of the nations participating in the TIMSS-95 (Kaiser, Luna, \& Huntley, 1999; Zhu \& Fan, 2004).

Within curriculum studies involving these nations, textbooks have been examined in an attempt to identify differences that could possibly help explain the disparity in achievement. The results of these studies have suggested that textbooks in countries that placed at the top of the TIMSS were different than textbooks in the U.S. (Schmidt et al., 2001). Also, researchers such as Fan (2011) have posited that the first step towards improving the quality of mathematics education is to know what is in the textbook and to make comparisons to other textbooks. 
Schmidt and colleagues (2001) examined the mathematics curriculum contained in eighth-grade textbooks used in the 37 countries, including East Asian countries, which participated in the TIMSS-95. Schmidt et al. (1997) described the United States' intended curriculum as repetitive when compared to the other nations' curricula and coined the phrase "a mile wide and an inch deep" (Schmidt et al., 2001,p. 301) to describe the U.S. curricula. U.S. textbooks and the textbooks of other nations in that study were seen to have general differences in topics covered. However, Schmidt and colleagues only examined topics generally without considering individual problems within a topic. This study was undertaken because it has been noted in the field ( $\mathrm{Li}, 2000)$ that research that focuses on the problems pertaining to one particular topic was needed.

Research has also shown the effectiveness of a textual analysis in revealing things that are unclear in the text (Neuendorf, 2002) and in highlighting aspects of the curriculum which need to be changed (Schoen \& Clark, 2007). Fan and Kaeley (1998) demonstrated that textbooks affect instructional practices in the classroom. Also, Österholm (2005) and Tieso (2005) demonstrated that altering the text in the textbooks students read changes student achievement. The details concerning these studies are presented in Chapter 2 of this dissertation. In light of research that says that the textbook is the most widely-used resource in the classroom as obtained from teacher self-reporting data in the TIMSS-95 report (Schmidt et al., 2001) and from teacher questionnaires in Singapore (Zhu \& Fan, 2002), changes in the text of the textbooks will potentially have an effect on several aspects of student achievement. Thus, finding out the content and how that content is presented in a textbook will assist those making curricula changes to find things in the text which, if altered, may affect what is taught in the classroom and 
what is learned by students. Furthermore, research on curriculum can be complex due to the interplay of relationships between different curricula such as (a) ideal, (b) intended, (c) implemented, (d) textbook, (e) tested, and (f) achieved curricula (Usiskin, 2008). Different research programs are needed to study these different curricula. The researcher chose to focus on textbook curriculum by doing a textbook comparison in this study.

Additionally, past textual analyses have shown that there are many differences in elementary textbooks from the U.S. and countries that showed the highest mathematics achievement on the TIMSS tests (Ginsburg, Leinwand, Anstrom, \& Pollock, 2005; Harries \& Sutherland, 2000) and a few, general differences in the middle school texts of these countries (Schmidt, Houang \& Cogan, 2002). The differences found in the middle school texts were based upon a general examination of topics without considering individual problems within a topic. Therefore, the researcher has helped make up for this lack by doing a textual analysis that emphasizes the problems within a particular topic as suggested by $\mathrm{Li}$ (2000). The particular topic that the researcher has chosen to focus on is linear functions. The reasons why this topic was chosen are presented next.

In the following paragraphs, the researcher presents a visual pathway and overview of the most critical elements of mathematics in relation to the study. Algebra is a branch of mathematics that consists of six major topics, (a) symbols and expressions, (b) linear equations, (c) quadratic equations, (d) functions, (e) algebra of polynomials, and (f) combinatorics and finite probability (Fennell et al., 2008). Of these six major topics, the first four are within the curriculum of beginning algebra. Furthermore, three of the four major topics of beginning algebra have two or more sub-topics that include linear 
functions (see Figure 1). Hereafter, these sub-topics, particularly linear functions, will be referred to as topics.

A diagram of how linear functions fit into the algebra curriculum is presented in Figure 2. The diagram was created by considering the details about algebra as seen in K12 Mathematics: What Should Students Learn and When Should They Learn It? (Center for the Study of Mathematics Curriculum, 2007) and Principles and Standards for School Mathematics (NCTM, 2000). Analysis of Figure 2 shows the topic of linear functions is pervasive in the subject area of algebra. In Figure 2, algebra is shown to be made up of general concepts found in the upper-right box and major topics found in the second-fromthe-bottom-right box. The general concepts of algebra represent the essence or nature of algebra, that is, what algebra is. The major topics of algebra represent the linguistic vehicles of algebra, that is, how algebra is done. The arrows going from these two fundamental components of algebra to the middle box on the right-hand side depict that the general concepts and major topics of algebra both affect the development of the learning outcomes contained in the box. The arrow coming from this middle box to the bottom box illustrates that the topic of linear functions intersects with all three of the components of algebra, the (a) general concepts, (b) major topics, and (c) learning outcomes. This intersection can be seen in linear functions representation in the major topics of beginning algebra as listed in the bottom box in Figure 2. The three major topics, (a) symbols/variables and expressions, (b) equations, inequalities, and systems, and (c) functions correlate exactly to the major topics listed in Figure 1 when the two topics linear equations and quadratic equations from Figure 1 are combined in the title Equations, Inequalities, and Systems in Figure 2. The bottom box of Figure 2, thus, 
Symbols and Expressions

- Polynomial expressions

○ Rational expressions

- Arithmetic and finite geometric series

Linear Equations

$\circ$ Real numbers as points on the number line

- Linear equations and their graphs

- Solving problems with linear equations

- Linear inequalities and their graphs

$\circ$ Graphing and solving systems of linear equations

Quadratic Equations

- Factors and factoring of quadratic polynomials with integer coefficients

- Completing the square in quadratic expressions

Functions

○ Definition

- Linear functions

Figure 1. Major Topics of Beginning Algebra.

${ }^{a}$ The list was informed by the major topics in school mathematics contained in The Report of the Task Group on Conceptual Knowledge and Skills from Foundations for Success: Report of the National Mathematics Advisory Panel (Fennell et al., 2008). The list was created by omitting topics in Algebra II and adding topics which coincide more directly with the standards from the state department of education websites in Appendix A. 


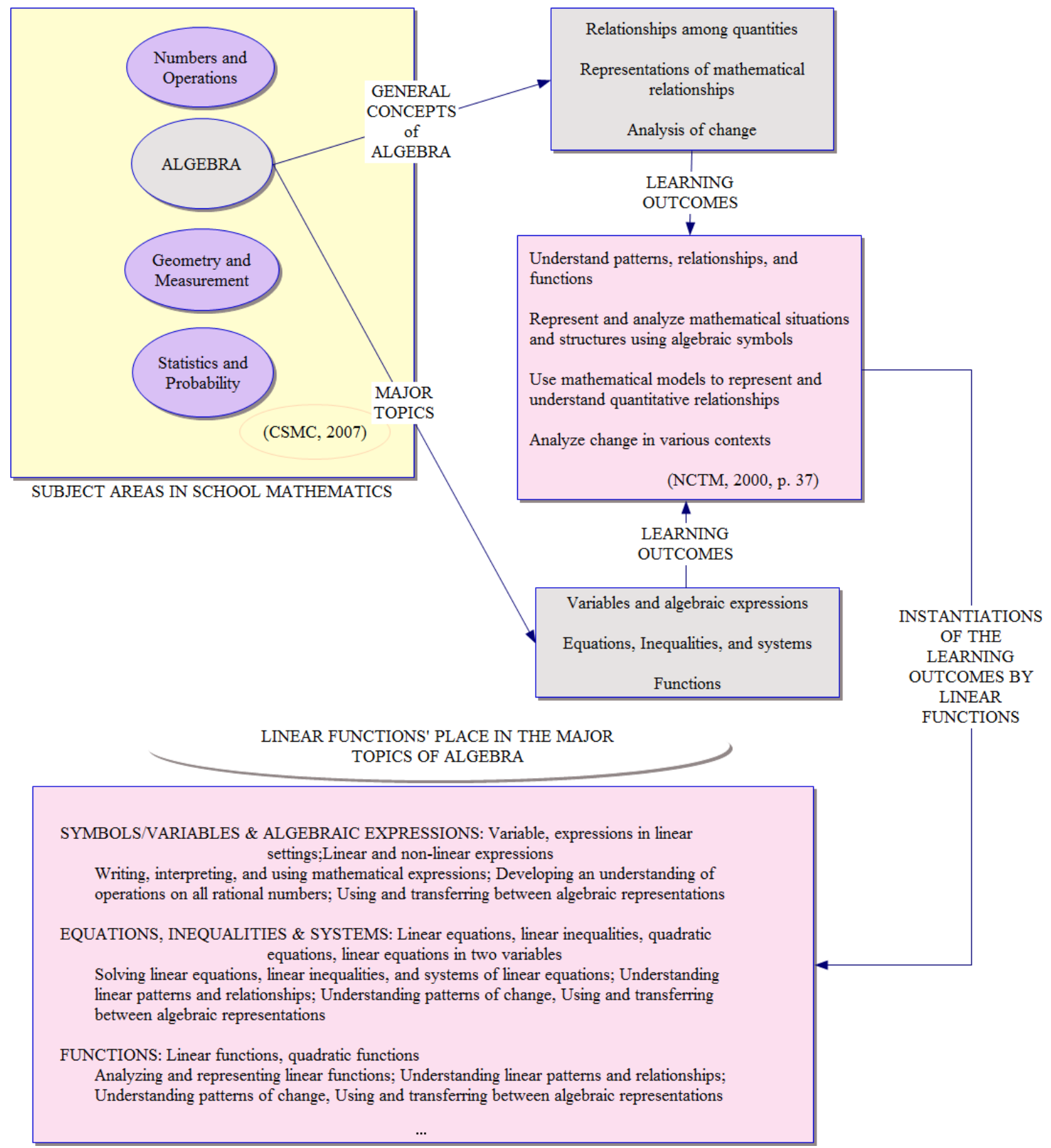

Figure 2. Linear Functions within Algebra and School Mathematics. 
shows how the topic of linear functions is pervasive in all the general concepts, major topics, and learning outcomes within algebra.

Moreover, the representation of linear functions within the major topics of algebra is more clearly seen as one studies a Concept Map for Linear Functions the researcher created in Figure 3. The concept map shows the different representational forms of a linear function and how one can transfer from one representation to another. Also, the map shows how regardless of the representation, a person can analyze and model real world situations that are major themes within the major topics of algebra.

Furthermore, the interconnectedness between the general concepts and major topics is evidenced by the way linear functions are represented within each of the major topics of algebra. Linear functions is (a) specifically classified under the major topic of functions, (b) made up linear equations and has linear patterns and relationships within the major topic equations, inequalities, and systems, and (c) represented by symbols and algebraic expressions. Thus, linear functions as a topic spans more than one major topic. Henceforth in this dissertation, the term linear functions will represent the label for the concepts that are unique to that topic. Note, a formal definition and illustrated example of linear functions (see Figure 4) are presented in the definition of terms section of Chapter 1.

With the lack of success in algebra by U.S. middle school students and the importance of this topic to their future mathematical literacy development, the National Mathematics Advisory Panel began to address this concern of preparation for success in algebra by examining (a) the major topics of algebra, (b) the skills and concepts needed 


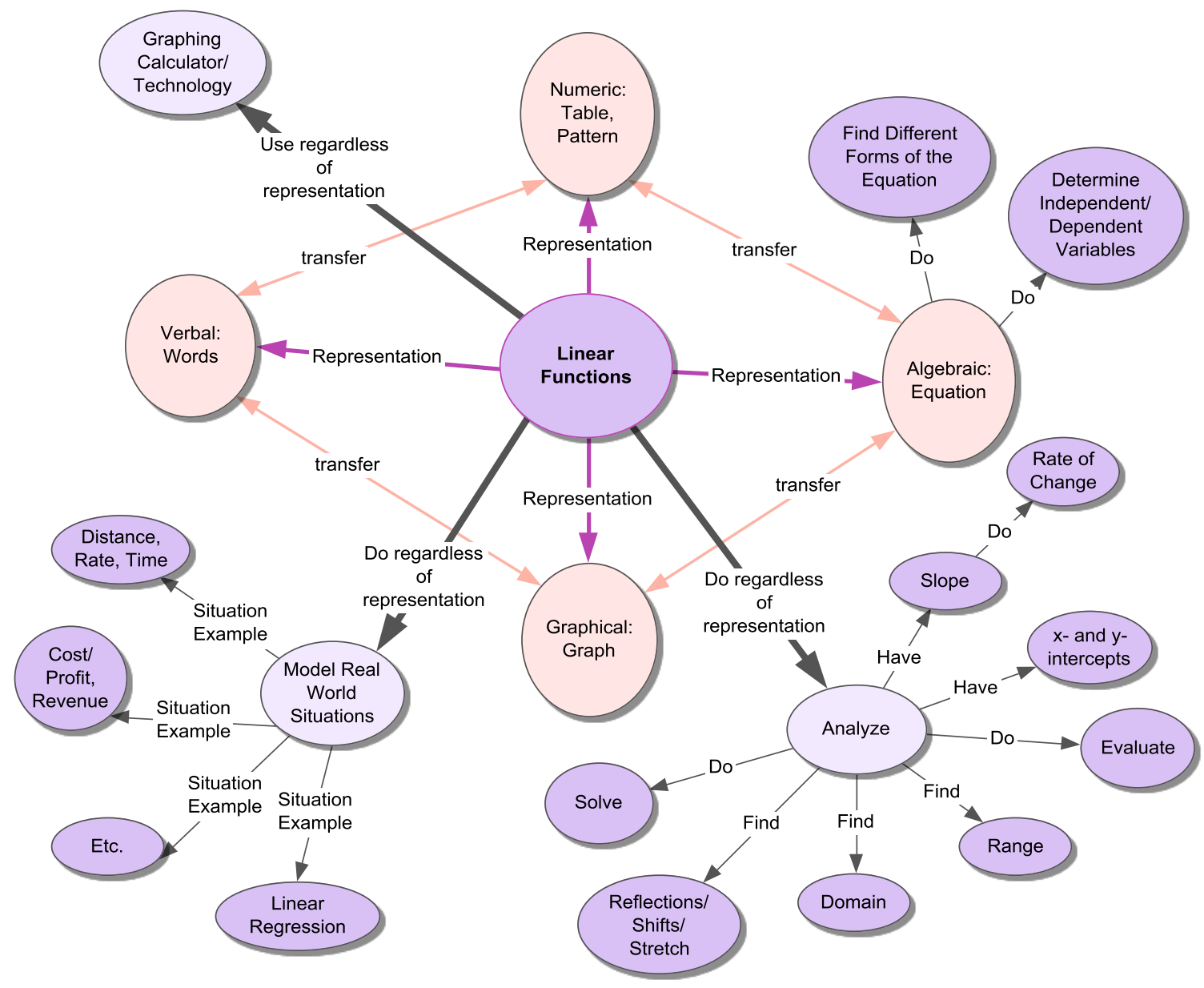

Figure 3. Concept Map for Linear Functions.

for success in algebra, and (c) the sequence of topics needed prior to and while taking algebra (Fennell et al., 2008, p. 3-2). The Center for the Study of Mathematics Curriculum

(CSMC, 2007) addressed this issue on a broader scale in a 2007 conference: K-12 Mathematics: What Should Students Learn and When Should They Learn It? Of the four areas of mathematics that were emphasized in the national mathematics standards documents the CSMC examined, algebra was the most heavily emphasized area when excluding the area of statistics. 
While the standards documents reviewed by the CSMC (2007) had different grade level foci, for example 6-12, K-8, 7-12, each document except for the Guidelines for Assessment and Instruction in Statistics Education (GAISE) Report allowed for algebra to be taught within Grades 6-8. The Common Core States Standards in Mathematics (CCSSM), the voluntary national standards recently introduced to the U.S., also has algebra being taught in Grades 6-8 (National Governors Association Center for Best Practices, 2010). Algebra being taught in Grades 6-8 was in consensus with the 1997 nationwide decision to include algebra as a graduation requirement with the goal that all students will take algebra by eighth grade (Riley, 1997, p. 5). This was due to algebra being considered a "gatekeeper" of student access to higher mathematics and that taking algebra in eighth-grade would allow more mathematical literacy in the U.S. (Spielhagen, 2006). The National Mathematics Advisory Panel (Fennell et al., 2008) recommended that all school districts prepare more eighth-grade students for an "authentic algebra course" (p. 23) than are currently being prepared. Thus, the trend is for algebra, including the topic of linear functions, to be taught in eighth grade.

Linear functions is the dominant topic in beginning algebra (Wu, 2001) and is "primary to the study of algebra" (Cunningham, 2005, p. 74). This can be seen through its prevalence among the concepts within algebra. Within algebra, functions are a tool to describe natural phenomena (Fennell et al., 2008). Specifically, linear functions are used to describe common relationships such as price of $x$ gallons of gas at $\$ 4.00$ per gallon which can be represented by the linear function $f(x)=4 x$. With the increase in technological tools in the study of mathematics (Garofalo, Drier, Harper, Timmerman, \& Shockey, 2000; Steen, 1990), the study of linear functions has been extended "to include 
the data-analysis technique called linear regression" (Garofalo et al., 2000, p. 77). Hence, another common use for linear functions is finding a line-of-best fit or linear regression line for a set of data (Garofalo et al., 2000). The line of best fit becomes a helpful and commonly-used modeling tool. Also, linear functions of the form $f(x)=c x, c \neq 0$ allow students to understand proportional reasoning (Fennell et al., 2008).

Linear functions represent the simplest of all functions and are used as a foundation on which other functions are built (National Council of Teachers of Mathematics [NCTM], 2000). Not only is the topic of linear functions the foundation for the study of entire families of functions, that is, quadratic, exponential, and cubic, the topic also has a place of prominence in the middle school Algebra Standards as presented by the National Council of Teachers of Mathematics (NCTM, 2000). Linear functions' prominence in Grades 6-8 is also seen in the recently created Common Core States Mathematics Standards (National Governors Association Center for Best Practices, 2010).

In the Algebra Standard Expectations section for Grades 6 through 8 in The Principles and Standards for School Mathematics [PSSM] (NCTM, 2000), the emphasis is on the study of patterns and relationships related to linear functions. This emphasis is found in the Expressions and Equations sections of the CCSSM (National Governors Association Center for Best Practices, 2010). Students are expected to recognize nonlinear functions and then compare them to linear functions. Within the middle school Algebra Standards of the PSSM (NCTM, 2000), all functions are first distinguished as linear or nonlinear, and, consequently, all nonlinear functions are then compared and contrasted to the characteristics, patterns, and appearance of linear functions. Hence, the 
topic of linear functions is considered a "mainstay and an important building block of secondary mathematics" (Garofalo et al., 2000, p. 77).

The prominence of the topic of linear functions within algebra can also be found in U.S. Algebra I textbooks as seen from the results of a project on the topic of linear functions the researcher completed in the spring of 2007. That project entailed the examination of the topic of linear functions in three U.S. Algebra I textbooks, (a) Algebra I: An Integrated Approach (Larson, Kanold, \& Stiff, 1997), (b) Discovering Algebra: An Investigative Approach, Teacher's Edition (Murdock, Kamischke, \& Kamischke, 2002), and (c) Cognitive Tutor Algebra I Student Text, (Hadley, Pflueger, \& Covatto, 2006). The results revealed that the total number of pages which contained the topic of linear functions/linear equations was approximately $25 \%$ of the pages in each text. This somewhat large percentage of the texts devoted to linear functions suggested that linear functions is a prominent topic in beginning algebra.

Review of the research on textual analyses (see Appendix B) indicated that the topic of linear functions has not been widely emphasized in textbook comparisons. There are not many studies which focus on problems pertaining to the topic of linear functions. Researchers who have examined middle school curriculum have examined middle school addition/subtraction problems (Li, 2000; Mayer, Sims, \& Tajika, 1995), middle school instructional criteria (American Association for the Advancement of Science [AAAS], 1999), and general features of the text (Schmidt et al., 2001). Linear functions has been included as one topic among many in Mesa's (2004) study in which she characterized problem types. After Mesa classified the problems by the concepts contained within the tasks, she reported the percentage of textbooks that contained these problem types. Also, 
Schmidt et al. (2001) examined linear functions as one topic among many in their examination of textbooks from countries that participated in the TIMSS of 1995. However, they did not focus on particular problems within the text, but examined broad categories of topics within texts. Thus, due to the limited amount of research on problems pertaining to linear functions, the researcher chose to study linear functions.

\section{Rationale for Comparison of Singapore and U.S. Middle School Texts}

Preliminary research (Ginsburg et al., 2005; Schmidt et al., 2001) has indicated that textbooks of the U.S. and countries that scored close to the top of the TIMSS-95, that is, East Asian countries, differ in various ways. In subsequent years, 2003, 2007, and 2011, East Asian countries continued to score close to the top of the TIMSS (Gonzales et al., 2004; U.S. Department of Education, 2009; Provasnik et al., 2012). Singapore's students consistently demonstrated mathematics achievement above every nation on the TIMSS eighth-grade tests (Gonzales et al., 2004), until 2007 when Singapore's average score was below China's average score and Korea's average score (U.S. Department of Education, 2009). In 2011, only Korea was above Singapore on the eighth grade portion of the TIMSS (Provasnik et al., 2012). Of these East Asian countries, only Singapore's mathematics textbooks are written in English. Thus, Singapore's textbooks seemed ideally suited for comparison to the U.S. texts. In summary, because (a) Singapore was the top-achieving country on the eighth-grade portion of the TIMSS tests until falling to third in 2007, (b) Singapore's textbooks are written in English, and (c) previous research has shown that there are differences in the two nations' textbooks, the researcher chose to focus on a comparison of Singapore textbooks to U.S. textbooks with respect to the topic of linear functions. 
A review of the literature indicated that middle school textbooks from Singapore and the U.S. have not been widely studied (see Appendix B). Several researchers have examined elementary textbooks from Singapore and the U.S. (Cai, Lo, \& Watanabe, 2002; Ginsburg et al., 2005). Many researchers (Cai et al., 2002; Li, 2000; Mayer, Sims, \& Tajika, 1995; Zhu \& Fan, 2004) have compared texts from the U.S. and a country other than Singapore. Of the studies between Singapore and the U.S. (Ginsburg et al., 2005; Harries \& Sutherland, 2000; Schmidt et al., 2001), two of the three have examined primary texts, and the third study was a general examination of topics within middle grades textbooks with no consideration of individual exercise problems. Thus, based on this body of research, the present study compared a variety of U.S. middle school textbooks to Singapore textbooks to reveal how Singapore and U.S. textbooks were similar and different in the middle grade years.

\section{Research Questions}

The research questions on which the study was based are:

1. How do the treatments of the topic of linear functions in middle grades mathematics textbooks of Singapore compare to the treatments of the topic of linear functions in middle grades mathematics textbooks of the U.S.?

Treatments of the topic refer to the ways linear functions are presented in general in the text and how the topic is represented in the problems of the text particularly with regard to the 22 features the researcher examined.

2. What are the similarities and differences of the conceptual types of problems related to the topic of linear functions within the middle grades mathematics textbooks of Singapore and the U. S.? 
3. How are problems related to linear functions in middle grades mathematics textbooks of Singapore and the U.S. different or similar with respect to computational requirement, context, required response, cognitive requirement, and given information?

4. Are the characterizations of problem practices as seen in the problems related to linear functions in middle grades mathematics textbooks from Singapore and from the U.S. the same or different?

5. How do the problem-solving competency types in the problems related to linear functions in middle grades mathematics textbooks from Singapore and from the U.S. compare?

6. How do the types of transfer of representation needed to do the problems pertaining to linear functions in middle grades mathematics textbooks from Singapore compare to the types of transfer of representation needed to do the problems pertaining to linear functions in middle grades mathematics textbooks from the U.S.?

\section{Theoretical Framework}

The theoretical grounding for this study comes from sociocultural theory. From the work of Vygotsky (Scherba de Valenzuela, 2002), sociocultural theory contains the idea that human cognition and learning is social and cultural. Lantolf (1994) discussed Vygotsky's major theoretical insight that higher forms of human thought are continually mediated by symbols. This can be observed in mathematics as "functions are the mathematical tools used to describe the relationships between variable quantities" (O’Callaghan, 1998, p. 24). Mediation is defined as the "introduction of an auxiliary 
device into an activity that then links humans to the world of objects or to the world of mental behaviors" (Lantolf, 1994, p. 418). Symbols in textbooks represent these auxiliary devices. Thus, functions serve as an example of Vygotsky's symbolic mediation as they demonstrate how symbolic tools organize and control mental processes. The graphs, diagrams, and algebraic symbols seen in mathematics are themselves examples of these symbolic tools through which higher forms of thought are gained. A textual analysis allows an examination of the use of symbolic tools in a text. Due to the fact that the symbolic tools in mathematics textbooks are the same in the student edition and teacher edition, the researcher examined only student editions of the textbook.

\section{Potential Usefulness of Textbook Research}

The benefits of textbook analysis on different areas of the education process including (a) alignment of textbooks to standards documents, (b) textbook content, and (c) student achievement is presented. The first section contains the historical call to action to change U.S. mathematics achievement through changing the curriculum including the textbook. An analysis of the merits of performing a textual comparison follows.

\section{Historical Background}

The idea that textbooks affect mathematics achievement is nothing new (Stanic \& Kilpatrick, 2003). At the same time, there has been disagreement over what should be contained in the textbook. Periodically there have been events that have served as a catalyst for change in the curriculum such as the Russian's launch of Sputnik in 1957, the publishing of A Nation at Risk in 1983 and the publishing of the Curriculum and Evaluation Standards for School Mathematics in 1989 and the Principles and Standards of School Mathematics in 1999 (Stanic \& Kilpatrick, 2003). In the 1990s, the results of 
the TIMSS-95 (Beaton et al., 1996) and TIMSS-99 (Gonzales et al., 2000) served as a catalyst for a desire to change the U.S. curriculum. In President Clinton's (1998) Call to Action for American Education in the $21^{\text {st }}$ Century, he specifically addressed needed changes in the curriculum, including in textbooks, as he discussed that the U.S. does not expect enough of students and only offers a "watered-down and boring curriculum" (p. 7) and called for a standard of excellence. This call for higher standards was reiterated by President Bush's No Child Left Behind Act (NCLB) of 2001 (U.S. Department of Education, 2001) and continued by President Obama's Blueprint for Reform: the Reauthorization of Elementary and Secondary Education Act of 2010 (U.S. Department of Education, 2010a). Thus, the call for improvement in mathematics achievement scores through changing the curriculum including in textbooks has been highlighted in the political arena.

\section{Merits of the Study}

The usefulness of the results of a textbook comparison is manifold and is reflected in past research. Fan (2011) states that the first step toward improving the quality of mathematics education is to know what is in the textbook. The results of the current textual analysis assessed the "breadth and depth of the 'intended curriculum' as suggested by Porter (2002, p. 11) and the opportunities to learn (OTL) the topic of linear functions within the textbooks. Knowing the content in a textbook can (a) allow taxpayers and parents to know what content students are taught in U.S. public schools (Porter, 2002), (b) assist with reconciling state standard documents and textbooks (Porter, 2002), and (c) be helpful in understanding the differences in scores on international tests such as the TIMSS and the PISA (Ferrini-Mundy, 2004). Also, research has shown that textbooks (a) 
affect instruction (Fan \& Kaeley, 1998; Reys, Reys, \& Chavez, 2004 ), (b) are widely used guides by most teachers (Schmidt, Houang, \& Cogan, 2002) including middleschool teachers (Henning, 1996) and Singaporean teachers (Zhu \&Fan, 2002), (c) affect student achievement (Österholm, 2005; Tieso, 2005), and (d) affect the content and sequence of the content (Reyes, Reyes, \& Chavez, 2004). Hence, a change in textbooks could theoretically affect the majority of educators within a nation.

Also, Porter (2002) posited that the "content of instruction is an essential variable in research on factors affecting student achievement" (p. 3). This idea is echoed by the National Mathematics Advisory Panel's recommendations to facilitate increased mathematics proficiency by U.S. students (Fennell et al., 2008). They suggested that "a focused, coherent progression of mathematics learning, with an emphasis on proficiency with key topics" (p. 22) for school algebra should be the norm in middle school. Thus, this textual analysis examined the key topic of linear functions as a first step in evaluating the progression of mathematics learning in the textbook.

Research has suggested the possibility of student mathematics achievement being affected by the text. In her study concerning changing the mathematics textbook and groupings within classes containing gifted students, Tieso (2005) found that student achievement increased when the textbook was changed. Also, Österholm (2005) saw a difference in reading comprehension in his study of students' readings of mathematics texts with and without symbols. Thus, the differences found in mathematics textbooks may lead to determining features of the text that may contribute to increased mathematics achievement. 
To summarize, the merits of the study consist of the information gleaned concerning the curriculum and OTL as seen within the textbooks. The study highlighted aspects of the textbook which may affect student achievement. The findings of this study should be valuable to educators, curriculum developers, publishers, and textbook authors who wish to improve the mathematics achievement of students in the U.S.

\section{Delimitations of the Study}

The researcher chose to de-limit this study to an examination of the textbook, particularly focusing on the problems pertaining to linear functions as recommended by Li (2000). The student textbook was chosen as the focus because both student and teacher texts contain the same problems. An examination of the textbook without considering other factors such as the classroom environment or instruction allowed the researcher to focus on the concepts and their presentation as laid out in the problems of the text. This deliberate focus on problems and a few general features of the text served to yield new information about textbooks.

Another delimitation to the study was the use of averages within the Welch's $t$ tests rather than the individual values obtained from each textbook. Similarly, another delimitation was that the values obtained from the general features of the textbook in the study would change depending upon whether one kept or eliminated a textbook which did not contain any linear function problems. The researcher chose to keep the textbooks containing no linear functions in the study because that is what was seen in the textbooks and because both countries each had a textbook with no linear function problems. The researcher also chose to examine each textbook in a series as an individual book instead of grouping the textbooks in a series as one group. 
The researcher examined eight mathematics textbooks from Singapore and nine textbooks from the U.S. The eight Singaporean textbooks represent three different text series in the two grade levels, Secondary 1 and Secondary 2, that is seventh and eighth grade, which contain the topic of linear functions. The nine U.S. textbooks represent three different text series in Grades 6-8 which contain the topic of linear functions. A discussion of how these textbooks were selected is contained in the methodology section in Chapter 3.

The content analysis was used to compare background features of the text and general and specific features of the problems. The parameters were (a) 13 background features of the text, (b) six general classifications for the problems, (c) characterization of problem practices, (d) characterization of problem-solving competency type, and (e) characterization of transfer of representation type. The background features were represented by such things as the number of types of images, the number of problems pertaining to linear function, and the total number of pages in the text. Lists and descriptions of all 13 general features, as well as the other features examined, are in Appendices C and D. The problems were designated by a mathematical feature, a contextual feature, a response-type feature, a cognitive requirement feature, a given-information feature, and an application type feature. More specific characterization of the problems addressed problem practices, problem-solving competency types, and transfer of representation types.

The next section contains definitions that were important to this study. Following these definitions is an overview of the study. The chapter concludes with a description of the content of the remaining chapters. 


\section{Definition of Constructs}

International comparison test. This is a test that is taken by several countries for the purpose of comparing the achievement of students on an international level. The TIMSS test consisted of a 90 minute test containing problems created by experts from each country participating in the study. The problems consisted of multiple choice and free-response items which represented a wide range of mathematics topics and skills. (Beaton et al., 1996)

East Asian countries. Countries that share a geographic location, a similar cultural tradition, and have done well on the TIMSS tests are the East Asian countries referred to in this study. The cultural traditions stem from the Chinese/Confucian tradition (Graf \& Leung, 2000). These countries are Singapore, Korea, Japan, Hong Kong, China, and sometimes Taiwan. (Beaton et al., 1996).

Treatments of the topic. The ways linear functions are presented in the text. This includes how the topic is presented in general in the text and how the topic is represented in the problems of the text particularly with regard to the 22 features the researcher has chosen to examine in the study. There are 13 background features and six general classifications of problems, and three conceptual types that will be examined. See Appendix $\mathrm{C}$ for more details.

Conceptual types. Types of concepts the students are asked to use within the problems in the text in order to answer the problem. These specifically refer to the problem practices, problem-solving competency types, and the transfer types that will be classified for each problem in the text. The problem practices are delineated into six types of practice inherent in the form the linear function as given in the problem. These 
problem practices are (a) symbolic rule, (b) ordered pair, (c) social data, (d) physical phenomena, (e) controlling image, or (f) other. The problem-solving competency types refer to what the student must know how to do to solve the problem. The problem-solving competency types are (a) modeling, (b) interpreting, (c) translating, (d) reifying, or (e) does not apply. The transfer types refer to the type of transfer necessary as a student moves from one type of mathematics representation in the question to a different mathematical representation for the answer. Descriptions of these transfer-types are in Appendix D.

Spiral approach. Spiral approach is the practice of covering a topic in successive years. One can use this procedure to deepen the understanding of a concept.

Linear functions. A linear function is a function with the property that each number for one variable (usually the $\mathrm{x}$ ) has exactly one value for the other variable (usually the y) of the form $y=a x+b$, where $a$ and $b$ are real numbers. An alternate form is $f(x)=a x+b$, where $a$ and $b$ are real numbers, which is used to emphasize that $y$ is a function of $x$ and $y$ is replaced with $f(x)$. There are many ways of representing a function: (a) symbolically (an equation), (b) graphically (a line), (c) numerically (table, patterns, or ordered pairs), and (d) verbally (written or spoken explanation of linear relationship). Figure 4 provides an example of a linear function, $f(x)=2 x-2$, in three different representations. A second alternative form of a linear function is the linear equation $A x+B y=C$ where $A, B$, and $C$ are real numbers such that not both $A$ and $B$ are zero. To use the second form, there must be an explicit understanding that there is a relationship between $x$ and $y$ such that for every $x$ there is exactly one $y$. Thus, 


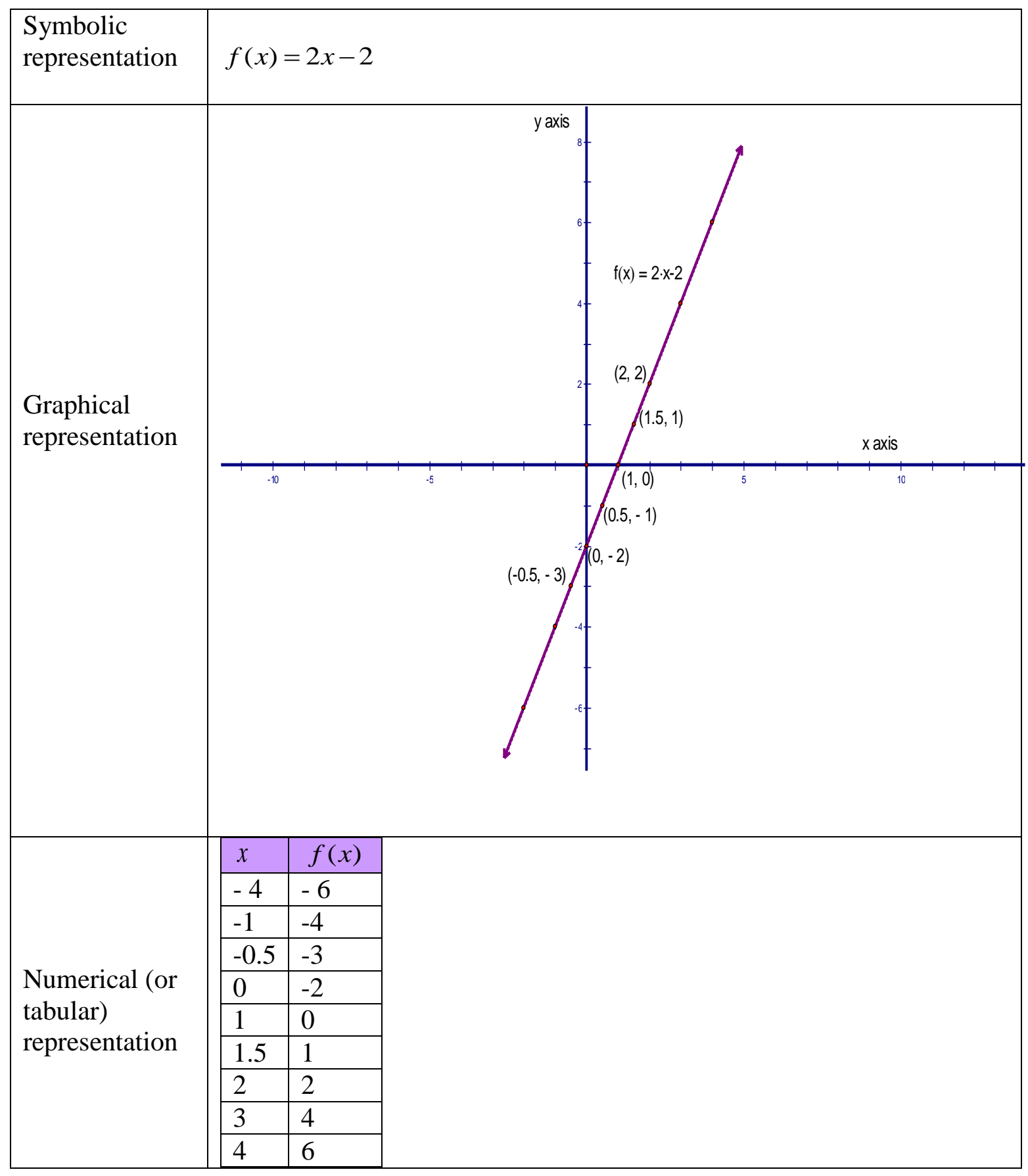

Figure 4. Example of a Linear Function in Different Representations. 
$8 x+7 y=5$ is not considered a linear function unless the text has already defined the equation to be an equation in two variables and the context is clear that $y$ is a function of $x$.

\section{Overview of the Study}

The research on textbooks has demonstrated that the textbook affects mathematics achievement directly (Österholm, 2005; Tieso, 2005) and potentially (Fan \& Kaeley, 1998; Schoen \& Clark, 2007). From the TIMSS results (Schmidt et al., 2001), President Clinton's (1998) address, Bush's NCLB (U.S. Department of Education, 2001), and Obama's ESEA: Blueprint for Reform (U.S. Department of Education, 2010a), the need for improved mathematics achievement of students in the United States has been documented. The purpose of the study was to compare treatments of the topic of linear functions in Singapore and U.S middle grades mathematics textbooks. The sections pertaining to the topic of linear functions were examined in 14 Singaporean mathematics textbooks (five titles in two grade levels) and nine mathematics U.S. textbooks (three titles in three grade levels). Thirteen general features were assessed in the textbooks. The individual problems were classified in terms of six general problem features. Also, problems were characterized in terms of practices, competency type, and transfer of representation type.

\section{Overview of Remaining Chapters}

In Chapter 2, the researcher presents a review of literature that is pertinent to a textbook comparison focused on the topic of linear functions. The methodology is presented in Chapter 3. Within Chapter 4, the researcher presents the findings. A 
discussion pertaining to the findings of the study and suggestions for future research on textbook comparisons is presented in Chapter 5. 


\section{CHAPTER II}

\section{REVIEW OF LITERATURE}

In this study, the researcher compared the treatments of the topic of linear functions in middle grades mathematics textbooks within the countries of Singapore and

the U.S. This chapter begins with background information pertaining to the details of the textbook comparison. Next, four categories of research most pertinent to the mathematics textbook comparison are highlighted. The four areas are (a) textbook features, (b) textbooks within a larger mathematics system, (c) textbook use, and (d) textbooks and learning comprehension. The chapter ends with a summary of the literature with respect to the study. A synopsis of the textbook comparison literature including (a) the characteristics examined, (b) the countries involved, (c) the level of schooling examined, (d) the name of the researcher(s), and (e) the publication date is in Appendix B.

\section{Background}

During the 1970s, 1980s, and 1990s, research and state, national, and international assessments demonstrated a weakness in the mathematics performance of U.S. students (Beaton et al., 1996; Gonzales et al., 2000; Gonzales et al., 2004; Kilpatrick et al., 2001). Students in pre-K through eighth grade struggled to obtain proficiency with rational numbers, proportions, and transitioning from arithmetic to algebra (Kilpatrick et al., 2001). This weakness in mathematics continued into the twenty-first century as is demonstrated in results from various assessments. For example, the Program for International Student Assessment (PISA) 2009 revealed that the average score of U.S. 15year-olds in the mathematics assessment was below the average score of the 34 countries belonging to the Organization for Economic Cooperation and Development (OECD) 
(Fleischman, Hopstock, Pelczar, \& Shelley, 2010). Also, Fleishman and colleagues (2010) presented the fact that the U.S. average scores in mathematics have been below the OECD average scores in previous PISA assessments in 2003 and 2006. In 2009, the percent of U.S. 15-year-olds who could perform higher level mathematics was $27 \%$ which was less than the $32 \%$ of students in the OECD countries who on average could perform at this level. However, the results for 2009 showed that the percentage of students in the U.S. and the other OECD countries who performed at a "baseline level" (Fleishman et al., 2010, p. iv.) of mathematics literacy was the same, $23 \%$.

The results of another international comparison test, the Third International Mathematics and Science Study of 1995 (TIMSS-95) showed that U.S. eighth graders had a mediocre average mathematics achievement score below the international mean among the 37 nations that took the test (Beaton et al., 1996; Zhu \& Fan, 2004). Students of the same age in East Asian countries had the highest average mathematicsachievement scores with Singapore students having the highest average of all the countries. On subsequent eighth grade TIMSS tests, the Trends in International Mathematics and Science Study of 1999 (TIMSS-99) and of 2003 (TIMSS-03), Singapore continued to have the top average mathematics achievement scores of all the nations, while the U.S. continued to maintain scores below (Gonzales et al, 2000) or slightly above (Gonzales et al., 2004) the international mean. On the Trends in International Mathematics and Science Study of 2007, U.S. eighth-graders showed an increase in the U.S. average mathematics achievement score as compared to the 47 other nations who participated (U.S. Department of Education, 2009). The U.S. average score was above that of 39 other countries. This improvement on an international scale is 
tempered by results from the Nation's Report Card - the National Assessment of Educational Progress (NAEP) from 2009 which showed that while the percentage of students in eighth grade at or above proficiency levels was the largest ever in mathematics, this percentage was only 34\% (U.S. Department of Education, 2010b). In 2011, the percentage of eighth graders at or above proficiency levels on the NAEP had increased to 35\% and remained the same in 2013 (National Center for Education Statistics. 2013).

Another test taken nationally, the ACT, examines college readiness, particularly with regard to algebra topics. In 2004, the ACT found that, based upon meeting ACT's college readiness benchmarks, only $40 \%$ of high school graduates were ready for their first course in algebra, while only $34 \%$ of eighth graders were estimated to be ready for college Algebra upon high school graduation (ACT, 2004). By 2009, the number of high school graduates ready for college algebra was $42 \%$ (ACT, 2009). Thus, while U.S. students may be improving in relation to other nations, the fact remains that the majority of students struggle with algebra topics.

Results from the Nation's Report Card: Mathematics 2007 (Lee et al., 2007) reveal U.S. middle school students struggle with the topic of linear functions within the area of algebra. Although 54\% of eighth graders correctly determined a symbolic representation of a linear function when given the function in table form, only $25 \%$ of them were able to identify the graph of a linear equation. On the 2013 Nation's Report Card assessment, U.S. students showed improvement in being able to find the symbolic representation of a line as $67 \%$ were able to find the equation of a line when given a table of values (National Center for Educational Assessment, 2013). However, students still 
struggled with some problems pertaining to linear functions as only $20 \%$ of students were able to interpret slope from a verbal description. This difficulty with the topic of linear functions persists into future mathematics classes as evidenced by the finding that students in AP Calculus continue to struggle with the concept of linear rate of change (Teuscher \& Reys, 2010).

Although U.S. students are not proficient in working with linear functions, the topic is considered a "mainstay and an important building block of secondary mathematics" (Garofalo et al., 2000, p. 77). The place of linear functions in secondary mathematics and algebra in particular was presented in Figure 2 within Chapter 1. The importance of algebra, including the topic of linear functions, is also marked by its representation on national assessments (Lee et al., 2007). For example, problems involving algebra topics including linear functions represent $30 \%$ of the problems on the 2009 national eighth-grade mathematics assessment, Nation's Report Card: Mathematics 2009 (NCES, 2009). The representation of linear functions in the algebra curriculum as seen in U.S. Algebra I textbooks (Larson, Kanold, \& Stiff, 1997; Murdock, Kamischke, \& Kamischke, 2002; Hadley, Pflueger, \& Covatto, 2006) underscores the prevalence of linear functions within algebra. For instance, the researcher completed a class project in the spring of 2007 involving the examination of three U.S. Algebra I textbooks, (a) Algebra I: An Integrated Approach (Larson et al., 1997), (b) Discovering Algebra: An Investigative Approach, Teacher's Edition (Murdock et al., 2002), and (c) Cognitive Tutor Algebra I Student Text, (Hadley et al., 2006) with respect to linear functions. The results revealed that $25 \%$ of the pages in each text contained the topic of linear functions. 
Within the middle school Algebra Standards of the NCTM, the topic of linear functions is heavily emphasized (NCTM, 2000). Also, three other national mathematics standards documents, Middle School Model Two-Year Course Sequence (Achieve, Inc., 2008), College Board Standards for College Success: Mathematics and Statistics (College Board, 2006), and Curriculum Focal Points for Prekindergarten Through Grade 8 Mathematics: A Quest for Coherence (NCTM, 2006), present this heavy emphasis on the topic of linear functions in the middle school curriculum. In recent years, the coverage of linear functions in textbooks has expanded to include the "data analysis technique called linear regression" (Garofalo et al., 2000, p. 77). The importance of linear functions in the curriculum seems to be increasing yet, in view of poor national and international assessment scores, the proficiency of U.S. mathematics students on the topic does not appear to be improving.

Historically, the results from TIMSS-95 and TIMSS-99 were the catalyst for a plethora of studies comparing the educational practices of the nations participating in the TIMSS (Kaiser et al., 1999; Zhu \& Fan, 2004). In curriculum research, there are many curricula to consider, such as the intended curriculum, the implemented curriculum and the textbook curriculum; each of which has a different research program. Within the curriculum studies involving these nations, the textbook was examined in an attempt to identify differences that could possibly help explain the disparity in achievement. The results of these studies suggested that textbooks in countries that placed at the top of the TIMSS were different than textbooks in the U.S. (Schmidt et al., 2001). Finding out what is in a textbook and comparing it to other textbooks is the first step in improving the 
quality of mathematics education (Fan, 2011). A synopsis of the research considered in this chapter follows.

The first area of research in this chapter consists of research done on the content of the textbook. Instructional criteria along with depth of coverage (AAAS, 1999), various types of problems (Li, 2000; Zhu \& Fan, 2004), images (Harries \& Sutherland, 2000), specific references to text (Harries \& Sutherland, 2000), arithmetic average (Cai et al., 2002), and lessons (Mayer et al., 1995) have been compared in textbooks. The topic of linear functions is absent from these textbook content comparisons.

The second area of research pertains to textbooks within a larger mathematics system. Some researchers have indicated that taking one feature of a nation's educational system and transplanting that one feature into another culture may not produce increased mathematical learning (Ginsburg et al., 2005; Uttal, 1996). Ahuja (2006), Ginsburg and Leinwand (2008), and Schmidt et al. (2002) concurred that several features within a mathematics system such as "mathematics frameworks, textbooks, assessments, and teachers" (Ginsburg et al., 2005, p. ix), must be addressed if the U.S. is to have a worldclass mathematics system. However, an examination of the studies that looked at mathematics textbooks in connection to a mathematical system reveals differences in U.S. primary/elementary textbooks as compared to other nations' primary textbooks with respect to general features of the text. According to Fan (2011), finding the content in a textbook and comparing content within textbooks is the first step in improving the quality of mathematics education.

The third area consists of studies which examine textbook use in the classroom. Textbook use has been examined in many different ways (Fan \& Kaeley, 1998; Haggarty 
\& Pepin, 2002; Leung, 1995; Porter, 2002; Reys, Reys, \& Chávez, 2004; Schmidt et al., 2002). The research presented demonstrates that teachers' practices can be affected by the textbook (Fan \& Kaeley, 1998).

The last area of research on mathematics textbooks consists of studies that consider the text and learning comprehension. This research demonstrates the different types of learning that can be affected by the textbook. This section contains studies about reading comprehension of mathematical texts (Österholm, 2005), schemata knowledge (Steele, 2005), conceptualizations of functions (Cunningham, 2005; Mesa, 2004; O'Callaghan, 1998), and effects on mathematics achievement due to changing the textbook with or without a change in the classroom grouping (Tieso, 2005). Determining how textbooks affect the learning of mathematical concepts may allow changes in texts that could cause greater mathematical achievement.

\section{Textbook Features}

In part due to the results of the TIMSS of 1995 and 1999 that compared the average mathematics achievement of students in 37 nations and 38 nations, respectively, textbook comparisons were abundant in the late $20^{\text {th }}$ century and early $21^{\text {st }}$ century (Desimone, Smith, Baker, \& Uneo, 2005; Kaiser et al., 1999; Menon, 2000). These comparisons considered different types of textbooks, textbooks within different nations, and different features of the text such as content-topic coverage and individual problems. In these comparison studies, researchers have provided evidence to indicate that U.S. textbooks need to be changed if students are to learn algebra concepts. Also, researchers have tried to determine the factors in the East Asian textbooks that contributed to these 
countries' good showing in the TIMSS (Desimone et al., 2005). An examination of these studies follows.

\section{Project 2061}

The American Association for the Advancement of Science (AAAS) (1999) compared 13 U.S. middle school mathematics textbooks in regard to the depth of coverage and quality of instructional support. The 13 textbooks were delineated into two categories, "best-sellers" and new texts based upon recent research. They examined the texts' treatment of six benchmarks representing three important mathematical content strands: number, geometry, and algebra. These benchmarks were taken from Project 2061's Benchmark for Science Literacy created in 1993. The benchmarks included four concept benchmarks dealing with (a) fractions and operations on them, (b) graphing, (c) equations, and (d) properties of shapes and two skill benchmarks dealing with equivalent forms of numbers and computations of circumference, area, and volume. In order to examine the depth of coverage for each benchmark in the text, analysts identified textbook activities that addressed all or part of the content in a benchmark. Once an activity was recognized as representing one of the benchmarks, the activity was then analyzed in regard to one of 24 instructional criteria divided into seven broad categories. These categories were (a) identifying a sense of purpose, (b) building on student ideas, (c) engaging students in mathematics, (d) developing mathematical ideas, (e) promoting student thinking, (f) assessing student progress, and (g) enhancing the learning environment.

The researchers (AAAS, 1999) found that none of the textbook series covered all of the concepts and skills for the six benchmarks. Only five of the thirteen textbook 
series covered four or more of the benchmarks in depth. Number and Geometry skills were covered in depth in all but one textbook series, while the concept benchmarks were inconsistently and most often insufficiently covered in the textbooks. The Algebra Equation Concepts were covered in depth by seven of the thirteen textbook series while algebra graph concepts were covered in depth by only two of the textbook series. Only four of the textbook series had a median rating in the satisfactory range for all 24 instructional criteria.

The results for the AAAS (1999) study on middle school textbook series indicated the need for continued examination of the U.S. middle school textbooks. Only four series were rated as excellent middle-grades mathematics textbook series. The concept benchmarks in Algebra (Equation and Graph) were found to be inconsistently and most often partially or minimally covered. The study itself only rated the content coverage in general terms, (a) most content, (b) partial content, and (c) minimal content. The proposed study will examine middle grades textbooks with respect to specific content coverage of the topic of linear functions including representations in equation and graph forms.

\section{Aspects of Problems}

Li (2000) examined how the textbooks from a mediocre-performing country and a high-level-performing country, with respect to international comparison tests, differ. He compared U.S. and Chinese mathematics textbooks. Li examined integer addition and subtraction problems that had no accompanying solutions or answers given in five U.S. seventh grade textbooks and four comparable level Chinese textbooks. He did this by considering three aspects of the problems, (a) the mathematical feature - single (s) or 
multiple (m) computation procedure(s), (b) the contextual feature-numerical/word form (pm) versus illustrative, that is, pictorial/story, form (ic), and (c) the two-pronged performance requirements feature that consisted of a response type as well as a cognitive requirement. The response type was divided into numeric answer only (A), numeric expression only (E), and explanation or solution required (ES). The cognitive requirement was one of the four cognitive tasks: procedural practice (PP), conceptual understanding (CU), problem solving, (PS), or special requirement (SR). Li coded each problem from all textbooks in terms of the three dimensions. Coding by a second independent rater yielded a $93 \%$ inter-rater agreement.

Li's (2000) findings were that the two countries had the same percentage of problems $(80 \%)$ that required a single computation procedure and had similar percentages of problems ( $87 \%$ for the U.S. and $90 \%$ for China) that had a purely mathematical context. However, the performance requirement yielded more varied results, as Li determined that U.S. textbook problems contain a wider variety of problem requirements and more conceptual problems than Chinese textbook problems. This observation was made from the percentages of problems requiring explanations, $19 \%$ for the U.S. and $0 \%$ for China, and problems requiring conceptual understanding, $26 \%$ for U.S. and $16 \%$ for China. To do his study, Li had to examine the addition and subtraction problems to see which ones contained integers and which ones did not. He found that $99 \%$ of the U.S. and $64 \%$ of the Chinese addition and subtraction problems contained integers. From this data, he concluded that Chinese texts may contain a higher level of mathematical content due the higher percentage of problems not using integers in the problems. Li suggested that future studies on textbooks should include comparisons of 
both mathematical problems as well as broad aspects of the text such as content-topic coverage.

Also, Zhu and Fan (2004) conducted a study on the types of problem representations in Chinese and U.S. mathematics textbooks from seventh and eighth grade. The most popular series of mathematics textbooks in Junior High in China and the University of Chicago School Mathematics Project (UCSMP) series mathematics textbooks in the U.S. were chosen to be compared. Problems, defined as "a situation that requires a decision and/or answer, no matter [if] the solution is readily available or not" (Zhu \& Fan, 2004, p. 3-4) [I added the "if"]. Zhu and Fan (2004) classified problems with respect to seven variables: (a) routine versus non-routine, (b) traditional versus nontraditional, (c) open-ended versus closed-ended, (d) application versus non-application, (e) single-step versus multi-step, (f) sufficient data, extraneous data, and insufficient data, and (g) pure mathematical form, verbal form, visual form, and combined form. They used content analysis to code the problems into one category for each of the seven variables. Quantitative and qualitative methods were used to identify the similarities and differences within the texts. They found that the total number of problems varied with the U.S. text having almost twice as many problems, 13,286 , as the Chinese text, 6,850 . The ratio of exercise problems, located in the text part, to text problems, located in the exercises section, was 7:1 for China and 10:1 for U.S. The majority of problems in both textbooks were classified as traditional, $96.8 \%$ for the U.S. and $98.8 \%$ for China, while $97.2 \%$ of U.S. problems versus $99.5 \%$ Chinese problems were classified as routine. Closed-ended problems accounted for $98.1 \%$ for Chinese problems and $93.4 \%$ for U.S. problems while $63 \%$ of U.S. problems and $52 \%$ of Chinese problems were one-step problems. Also, $1 \%$ 
of U.S. and $8 \%$ of Chinese problems were classified as authentic application problems. The results indicated that there were not many differences in the types of problems within the countries' textbooks.

\section{Images and Attention-getters}

Another study involving textbook feature comparisons was conducted by Harries and Sutherland (2000). They examined the way images of mathematical operations are represented in primary textbooks from five countries including Singapore and the U.S. They distinguished two categories of images: object-illustrative images and objectanalytic images. Object-illustrative images represent objects in the problem with no relationship to the mathematical structure while object-analytic images represent the mathematical structure of the problem. Examples would be a picture of a birthday cake (object-illustrative) versus using the candles to show that two candles plus three candles makes five candles (object-analytic). They found that while the images in the Singapore texts emphasized the mathematical concepts and structure, the images in the U.S. text did not illustrate the mathematical concept or structure being taught. In fact, they purported that the images in the U.S. text at times seemed to be a distraction for students.

The results concerning the images within the text by Harries and Sutherland (2000) were similar to findings of a study done by Mayer et al. (1995). Mayer et al. (1995) compared lessons on whole number addition and subtraction in Japanese and U.S. seventh grade textbooks. They specifically examined the number of worked-out examples, explanations, relevant illustrations, irrelevant exercises, and exercises in corresponding lessons within three Japanese textbooks and four U.S. textbooks. They found that the U.S. textbooks contained 19\% illustrations that were irrelevant to the 
lessons while the Japanese textbooks contained $0 \%$ illustrations irrelevant to the lessons. Thus, the U.S. seventh-grade mathematics textbooks were found to differ from Japanese textbooks in regards to illustrations. Similarly, Harries and Sutherland showed that U.S. primary texts differed from Singapore texts with respect to illustrations. This difference has not been documented with respect to middle school texts from Singapore and the U.S.

Another observable difference between the U.S. and Singaporean primary texts was the use of specific references to the mathematical concepts that the images were representing (Harries \& Sutherland, 2000). The Singaporean texts made some specific references to the mathematical concepts while the U.S. texts made little direct reference to the mathematical concepts. In discussing research concerning issues involving transfer of learning from one problem to another, Anderson, Reder, and Simon (2000) discussed the importance of drawing the attention of the students to key ideas. They concluded that "instruction and training on the cues that signal the relevance of an available skill might well deserve more emphasis than they now typically receive" (p. 8).

\section{Goals and Development of Concepts}

Cai et al. (2002) studied the treatments of learning arithmetic average in the teacher and student editions of sixth-grade mathematics textbooks in Asian elementary schools and U.S. middle schools. Three East Asian series: a China series, a Japan series, and a Taiwan series, were compared to two NSF-funded reform-based curricula texts and one "commercial" curriculum text. Cai et al. focused on four features within the text. These features were (a) the grade level the concept was introduced, (b) the kinds of learning goals specified, (c) how the concept was introduced and developed, and (d) the kinds of practice problems, worked-out examples, and activities included in the text. In 
this qualitative study, Cai et al. (2002) established categories to describe the types of meaning they observed in the textbook problems.

The practice problems and worked-out problems were classified into three categories (Cai et al., 2002). These categories were distinguished by three types of understanding about the arithmetic average: procedural understanding as an algorithm, conceptual understanding as an algorithm, or conceptual understanding as a statistic (a mean). The analyses and comparisons were done with respect to one curriculum as well as across the curriculum series. The researchers provided appendices with the collected data and examples of how the problems were classified. They then discussed in a narrative manner the approach to arithmetic average they saw in each of the textbooks. They found that all three East Asian texts and the U.S. "commercial" series focused on average as an "'evening out' or 'equal shares process"”, that is, as a computational algorithm. The two U.S. reform texts focused on the statistical meaning: the mean as a statistic, used to describe, make sense of, and compare data sets (p. 398). The U.S. reform texts presented the "evening out" process initially to introduce an algorithm for finding an average before moving to the statistical focus of average. The examples, practice problems, and activities within the texts demonstrated the different types of meaning that each text expected a student to learn. Determining the types of learning contained in the problems in different texts may help delineate the differences in student learning based upon the text itself.

\section{Summary}

The studies presented in this section demonstrate that U.S. textbooks were lacking with regards to helping students learn algebra and differed in approach to various 
mathematics topics as compared to other countries' textbooks. The topic of linear functions was not examined specifically by any of these researchers. Li (2000) and Zhu and Fan (2004) recommended that further research should be done on particular problem features to determine the kind of content in textbooks that may increase mathematical achievement. Two features that have not been examined in middle school textbooks are images and drawing attention to important features in the text, that is, attention-getters. These two features, as well as other features presented in this section, were examined with respect to the topic of linear functions in this study.

Several of the textbook features reviewed in the literature also have been examined in consideration of both the textbooks and the mathematical systems within different nations. The combining of these features gives a more comprehensive understanding of how textbooks affect mathematics achievement. These studies are presented in the next section.

\section{Textbooks within a Larger Mathematical System}

Within curriculum studies involving the nations from the TIMSS studies, the textbook has been examined as only one of many aspects of the mathematical system (Ahuja, 2006; Ginsburg et al., 2005; Schmidt et al., 2002). These researchers contended that if the U.S. wants to have a world-class mathematics system, several features of the system must be addressed. These features were identified as teacher training, teacher practices, textbooks, assessment, and a clear, coherent framework of standards and curriculum. Also, Ahuja (2006) included the need to make teaching a recognized profession with salary and benefits commensurate to other professionals. While these studies examined many aspects of curriculum, the results revealed details concerning the 
textbook curriculum in particular. The results showed that textbooks in countries that placed at the top of the TIMSS were different than textbooks in the U.S. (Ahuja, 2006;

Ginsburg et al., 2005; Schmidt et al., 2001). These studies and their results are discussed below.

\section{TIMSS-95}

Schmidt and colleagues (2001) examined the mathematics curriculum contained in eighth-grade textbooks within the 37 countries, including East Asian countries, that participated in the TIMSS-95 by looking at (a) content standards, (b) textbook space for each topic, (c)"percentage of teachers who cover various topics" (p. 101), and (d) "percentage of time that teachers indicate that they allocate to various topics" (p. 101). They performed a general study of the topics, that is, a categorical grouping of concepts or "subareas within the subject matter" (Schmidt, McKnight, \& Raizen, 1997, p. 2). Their results were summarized in the article "A Coherent Curriculum: The Case of Mathematics" (Schmidt et al., 2002). They found four things to be true of the U.S.'s intended curriculum as is evidenced in their textbooks when compared to other nations in the TIMSS study. The U.S.'s intended content is (a) unfocused, (b) very repetitive, (c) lacking rigor, and (d) "incoherent” (Schmidt et al., 2002, p. 3). Schmidt et al. (2001) coined the description that America's curricula are "a mile wide and an inch deep" (p. 301) due to the vast number of topics contained in the U.S. textbooks and the number of topics that are actually presented in the classroom. The topics were also presented as random "laundry lists of seemingly unrelated, separated topics" in the U.S. curriculum (Schmidt et al., 2002, p. 3). 
There were limitations to the study (Schmidt et al., 2002), however, as the researchers only determined the coverage of 44 topics without delving into the details of the problems within the topics. Another limitation was the countries' abilities to meet the sampling standard requirement for the study (Holliday, 2005); even the U.S. could not meet this requirement. Despite the limitations to the study, the results showed differences in the U.S. textbooks as compared to textbooks from other nations. However, the TIMSS95 study only examined topics generally without considering individual problems within a topic. Research that focuses on the problems pertaining to one particular topic is needed (Li, 2000).

The differences found in the U.S. mathematics educational system by Schmidt et al. (2001) were reiterated by Ahuja (2006) as he discussed the findings in comparisons between U.S. and Singapore primary texts. Ahuja compiled and gave a clear presentation of specific features of the textbooks that have been examined by other researchers. These features included the appearance of the text, that is, illustrations and their use in the text, and issues concerning types of problems, such as process versus conceptual learning and simple routine problems versus deep, multi-step problems. For the overall layout of the curriculum, he reiterated the lack of focus of the curriculum and attributed the difference to state versus national standards. Some of the information that Ahuja compiled came from the comprehensive study of mathematical systems, a discussion of which now follows.

\section{AIR Study}

The American Institutes for Research (AIR) (Ginsburg et al., 2005) completed a thorough comparison of U.S. elementary mathematics texts to Singapore elementary 
mathematics texts. In this study, researchers not only compared the primary textbooks of these two countries but examined their educational systems as well. The textbooks examined were Primary Mathematics, the only elementary text in Singapore, and the Scott-Foresman Addison-Wesley Mathematics (2004) yearbook series for grades 1-6, and the Everyday Mathematics textbook series (Everyday Learning Corporation, 2001) for grades 1-6. Ginsburg et al. (2005) compared the two nations' textbooks with regard to structure, approach, and content. These were examined by looking at the mathematical content at three levels: (a) the textbook level, (b) the lesson level, and (c) the problem/exercises level. Table 1 shows the focus for each level. Singapore had many more pages per lesson, 15 pages versus two to four pages, and fewer lessons per year to cover, 30 lessons versus 150 lessons, than either U.S. text. The examination of the texts at the lesson level revealed the differences in the spiral approach in the two countries. The U.S. goes over the same material again and again, while Singapore revisits material only to increase the depth of knowledge for that concept. Woodward and Ono (2004) described Singapore's spiral approach in the statement, "Over the years, the texts follow a 'concentric ring' pattern, with each new grade level providing greater depth on a topic" (pp. 5-6).

The qualitative discussion of the lesson level began with a general overview of how the Singapore text started with pictorial representations to introduce a concept (Ginsburg et al., 2005). Immediately following was a learning task that also included representations to further teach the mathematical concepts. Abstract teaching came later after students had developed a concrete understanding of the ideas. Ginsburg and Leinwand (2008) has commended this technique, labeled "Singapore's Concrete- 
Table 1

Content Examined in AIR Study

Level Focus

Textbook Space organization by number of pages, of chapters, and of lesson, number of pages by type (development, exercises, other), and average of pages per lesson

Lesson Percentage of content strand coverage by grade, topic coverage by grade comparison of three specific lessons among texts

Problem Comparison of exercises in three topic areas with regard to (a) number of steps to arrive at solution, (b) necessity of the use of an unknown intermediate variable to solve problem, and (c) the use of routine or non-routine strategy or approach to a solve the problem

pictorial-abstract approach" (p. 270), which is used to help students with the learning of mathematical abstractions. The U.S. textbook was unable to give as much exposure to a concept due to the necessity of covering so many topics (Schmidt et al., 2001). The U.S. students were only exposed to a small amount of time for each concept. A detailed examination of three types of selected problems yielded the conclusion that U.S. textbooks contained more routine exercises than the Singapore text (Ginsburg et al., 2005). However, also, they found that the nontraditional U.S. text presented interesting real-world problems and connected the mathematical concepts to practical applications better than the Singapore text did. Thus, there have been clear and definitive differences within the problems and the approaches to them in primary/elementary textbooks of 
Singapore and the U.S. Research has neither confirmed nor denied the difference in the problems within the middle grades textbooks of Singapore and the U.S.

Also, Ginsburg et al. (2005) presented the results of four pilot studies where U.S. schools in Baltimore, Maryland, Massachusetts, and New Jersey used the Singapore text in their classes. The results were variable as only two of the four sites achieved increased mathematical achievement by their students. Sites where teachers received professional development training on how to use the new text demonstrated better results. Three of the four treatment groups where the teacher had greater professional training had greater percentile score increases on national tests than the comparison group by as much as eight percentile points. The percentage of students in the treatment groups scoring at the advanced level rose from $13 \%$ to $45 \%$, while in the comparison group the percentage increase was $1 \%$. The difference in teacher commitment to using the new text seemed to affect the level of success in implementing the program. Teachers at the successful pilot sites were more fully committed to the project. The school in New Jersey did not have higher achievement results due in part to the schools' high student body turnover rate of about $40 \%$. Other factors that affected the results were that the Singapore text did not align fully to the state assessment standards nor to the topics presented in a particular grade level. Bisk's (2008) discussion of his use of the K-8 Singapore textbooks in professional development courses revealed that the North Middlesex Regional School District (NMRSD) in Massachusetts is now using the Singapore books as their primary text in all their K-8 mathematics classrooms.

The results indicated that in order to bring a nation's textbook or any one feature from their educational system into another country, there should be careful, well-thought- 
out planning and preparation. However, these studies, which examined the text as one aspect of a mathematical system, have been observed to have a concrete effect on curriculum. Schoen and Clark (2007) cited results from the TIMSS-95 (Schmidt et al., 2002) and results of the AIR study (Ginsburg et al., 2005) as being influential in the 2007 revisions of the Sunshine State Standards for mathematics in Florida. They reported a reduction of the average number of benchmarks per grade-level for grades K-8 from 83 per grade level to 18 per grade level. In this reduction, Florida addressed the "mile wide, inch deep" label by Schmidt et al. (2001) and the overlap seen in the spiral approach in the U.S. (Ginsburg et al., 2005). Thus, an examination of texts can produce pertinent changes to curriculum. The first step would be to find out the content in a textbook. Knowing the content would then help those involved in curriculum determine what changes, if any, need to be made both within and across the curricula in the system.

\section{Textbook Use}

Textbooks have been noted to "have a direct impact on what schools teach and what students learn" (Reys, Reys, \& Chávez, 2004, p. 62). This direct influence is seen as textbooks (a) influence the content that is taught, (b) influence the sequence of the content, and (c) provide ready-made lesson plans and ideas which affect the instruction in the classroom (Reys et al., 2004). In his examination of how to measure the content of instruction, Porter (2002) mentioned that content analyses of textbooks have "many uses for the improvement of practice" (p. 11). Even though there is some disagreement about the extent that teachers teach from the textbook (Schmidt et al, 2001; Freeman \& Porter, 1989), if a mathematical concept is not in the textbook, few would argue that most 
teachers would have a more difficult time covering that information. Research that examines textbook use in the classroom is presented next.

\section{Textbook Use in the Classroom}

In their investigation of the mathematics textbooks most frequently purchased in grades 7, 8, and 9 in France, Germany, and England, Haggarty and Pepin (2002) compared mathematics textbooks and how the texts were used in the classroom. The research foci were (a) the mathematics present in textbooks, (b) how teachers mediate mathematics in textbooks, and (c) students' access to textbooks. Haggarty and Pepin determined that teachers use the textbook differently in each country. Some teachers in France use the text for problems only; others use it only for activities. In Germany, teachers use it differently based upon the level of the school. In England, all teachers use the textbook prolifically. The researchers then discussed the access pupils have to textbooks and emphasized the unusual result that England's students have limited access to textbooks. In England, students are not able to bring their books home. Haggarty and Pepin looked at this practice as limiting the student's opportunity to learn mathematics. Thus, textbook use and the mathematics available to the student in the text are seen to be affected by culture.

A look at the research pertaining to East Asian countries and/or the U.S. reveals that these countries use the textbooks extensively in the classroom. Leung (1995) observed junior secondary mathematics classrooms within 18 schools in six regions in the cities of Beijing, Hong Kong, and London and found that most teachers followed the textbook closely during lessons presented in the classroom. Data collected from teachers in the 41 nations that participated in the TIMMS-95 indicated that the textbook is a 
widely-used guide for teachers, particularly beginning ones (Schmidt et al., 2002). Zhu and Fan (2002) similarly found that the textbook was by far the most widely used resource among Singaporean lower secondary teachers, even though it was not the only source. Henning (1996) also presented that middle school teachers in the U.S. use the textbook extensively in their teaching. Thus, Singapore and U.S. Middle school teachers use the textbooks widely in the classroom.

\section{Textbook Use and Teaching Strategy}

Fan and Kaeley (1998) compared the effects of traditional textbooks to the effects of University of Chicago School Mathematics Project (UCSMP) textbooks on teachers' teaching strategies in lower secondary mathematics classrooms. They wanted to determine how textbooks affect teaching practices. Their methodology included using data collected from four pilot studies of textbooks conducted at the University of Chicago in 1992/93 and 1993/94 (Fan \& Kaeley, 1998). Thirteen schools across 11 states in the U.S. and 28 teachers within those schools were chosen to participate in the study. There were 615 students, 311 in the 14 classes using UCSMP textbooks and 304 in 14 classes using non-UCSMP textbooks.

For the observation report, teaching strategies were analyzed in terms of " 'Lecture demonstration, Reading of textbook, Seatwork, Small group work, Whole-class discussion, Going over homework, Laboratory work, Other instructional activity, and Non-instructional activity” “(Fan \& Kaeley, 1998, p. 13). The area of "Locus of activity in the class" (p. 13) was also examined for each text. For the interview reports, questions pertained to typical lessons and methods used in the classroom. For the UCSMP group 
only, the researchers included an additional question pertaining to the necessity of adapting teaching style due to the new text.

Fan and Kaeley (1998) used $t$-tests to examine the data on how textbooks affect teaching strategies. They found that the UCSMP group averaged 16\% of class time on lecturing and $30 \%$ on small group work while the non-UCSMP group averaged $36 \%$ of class time on lecturing and 5\% on small group work. These differences were significant with $p=.038$ and $p=.0443$ respectively. Thus, one major finding was that the text affects what goes on in the classroom. The authors recommended that the finding that teaching strategies are affected by textbooks should be used by curriculum designers, textbook authors, teachers, and administrators. They did not mention editors and publishers in this list, although they pointed out that reforming the textbook should accompany any attempt to reform teaching methods.

The researchers in this section examined how textbooks are used in and affect classroom practice. The idea that textbooks affect what goes on in the classroom is supported by several researchers (Fan \& Kaeley, 1998; Leung, 1995; Porter, 2002; Reyes, et al., 2004; Schmidt et al, 2002; Zhu \& Fan, 2002). The next section focuses on the text within the textbook to see how the wording, the use of symbols, and concepts inherent in the text may affect comprehension of the text.

\section{Textbooks and Learning Comprehension}

Mathematics textbooks have been studied in connection to learning and comprehension in several different ways. Six studies that have learning comprehension as the focus are presented in this section (Cunningham, 2005; Mesa, 2004; O'Callaghan, 1998; Österholm, 2005; Steele, 2005; Tieso, 2005). Three of the studies examined 
learning when the textbook was changed while the other three studies examined the kinds of learning inherent in the exercises already in the text.

\section{Effects on Learning When the Textbook is Altered}

Mathematics texts, unlike most texts, use a lot of symbols. The idea of reading comprehension in light of the symbols used in mathematics was examined in a derivation of a study that was done in the 1970s (Österholm, 2005). Österholm performed a study on the reading comprehension of mathematics text to assist in determining "how and what one can and cannot learn through reading mathematical texts" (2005, p. 326). He created two mathematical textbooks, one with symbols and one without symbols, and also used a history textbook for the study. Sixty-one upper secondary level and 34 university level students from Sweden participated in the study. Students took a prior knowledge test in mathematics and history, read one of the mathematics textbooks, answered questions concerning the content of the text, read the history textbook, and answered questions about the content in this second text. Students were divided into four groups based upon level in school, university or secondary level, and the mathematics textbook that was read, the textbook with symbols or the textbook without symbols.

Österholm (2005) found a significant correlation in reading comprehension from the students who read the mathematics textbook without symbols and the history text versus no correlation in reading comprehension from students who read the mathematics text with symbols and the history text. He also found that the students who read the mathematics text without symbols had a better comprehension of the text than students who read the mathematics text with symbols had of their text. From the results, Österholm (2005) concluded that reading mathematical texts requires "some type of 
content-specific literacy skill” (p. 340). However, he stated that the results cannot be generalized. Further research is called for to determine the cause of the difference between reading comprehension of mathematical texts with and without symbols (Österholm, 2005). He also postulated that perhaps the difficulty in comprehending the text with symbols is caused by applying the same process to read two different types of texts. The proposed study will be comparing the textbooks from two countries with regard to competency types and problem practices within the exercises of the texts to reveal the symbolic form the linear function has been given in and what students are asked to do with the function.

Steele (2005) used a teaching experiment research method to examine the effects of writing on students' development of schemata knowledge for algebraic thinking. Her research question was, "In what ways do students write about and use schemata knowledge when solving algebraic problems related in mathematical structure?” A schema allows a person to process events due to similarity to prior experiences. She used Marshall's four types of schemata knowledge: (a) identification knowledge, (b) elaboration knowledge, (c) planning knowledge, and (d) execution knowledge, as the basis for knowing whether students demonstrated schemata knowledge in the study. Steele teamed up with a seventh-grade teacher to use a combination of interviews and teaching to understand students' knowledge of algebraic concepts. During the one month of the study, eight above-average seventh-grade pre-algebra students from a class of 24 solved eight problems. Steele designed these problems to help students generalize results and see relations among problems. 
In the teaching portion, Steele (2005) emphasized the importance of the students' work in solving the problems. The students were required to write down their thinking as they solved a problem first individually and then discussed their solutions in small groups. During the small group time, Steele and the teacher observed and asked questions such as, "How did you reason about the problems? How did your diagram help you?" (p. 145). Steele interviewed each student four times during the duration of instruction for the eight problems. Each student was interviewed with respect to the same four problems. She asked questions concerning how the students did the problem as well as those pertaining to the recognition of similarities between problems. Instruction for the next day was adapted based upon the results of these interviews and the observations made by Steele and the instructor during the small group discussions.

Steele (2005) found that writing demonstrated the schemata knowledge that students were learning. She presented examples from the student interviews and from their problem solutions that revealed how the four types of schemata knowledge were manifested by the students. Steele's study indicated the usefulness of getting students to be aware of their learning, for example, metacognition. Drawing students' attention to the text is one way to help students with their awareness of their learning.

Tieso (2005) studied the changes in student achievement caused by altering the textbook used with and without also changing the groupings within the $4^{\text {th }}$ - and $5^{\text {th }}$-grade mathematics classes of 31 teachers from four New England school districts. Tieso examined two hypotheses for the study: Students who used the revised textbooks would have higher learning gains than students who used the standard textbook and students who used the revised textbook and experienced ability grouping would have higher 
learning gains than students who used the standard textbook. She created curriculum materials for the differentiated textbook classes which included a unit on statistics and probability based upon the standard textbooks from grades 3-8. Tieso verified the content and construct validity for the curriculum-based assessment she created for the unit. The initial 30-item assessment was tested, revised, and tested again to yield a 35-item instrument, which received an alpha reliability of .78 during a second pilot study.

Tieso (2005) randomly divided teachers and students into the comparison group or one of four treatment groups. Each group was further divided into low, medium, and high subgroups with approximately one-third of the students from each group placed in each category based upon pre-test scores. She gave strategies for teaching to each of the differentiated groups, but she did not give any to the comparison groups nor for the revised text, or revision, groups.

Tieso (2005) performed analysis of variance (ANOVA) with post hoc Scheffé comparisons on preassessment scores. She found significant differences among the preassessment scores of students assigned to the low, middle, and high prior-knowledge groupings. She then used a repeated measures analysis of variance (RM-ANOVA) to analyze pre- and post- test data using grouping arrangement and curricular adjustment as the predictor variables. The results showed that there were significant differences between scores among the comparison and the revision groups' post-test scores. Tieso also used a RM-ANOVA to examine the effects of grade level and treatment group membership on student post-test scores. Students in the middle and high subgroups within the treatment groups showed significantly higher posttest scores than students in 
the middle and high comparison subgroups. Thus, a major finding was that changing the textbook may cause a change in mathematics achievement

\section{Types of learning inherent in the text}

While Österholm (2005), Steele (2005), and Tieso (2005) examined the changes in achievement caused in part by altering the text, Cunningham (2005), Mesa (2004), and O'Callaghan (1998) examined the potential learning already contained in a text's problems. All three authors examined how students learn the concept of function, more specifically linear functions, but in the context of different environments, (a) problems in the textbook, (b) problems presented by the teacher, and (c) a Computer Intensive Algebra (CIA) curriculum. Within her study, Mesa (2004) discussed how "variations in the set of problems that learners face, together with the operations, the representations, and the metacognitive and verification strategies needed to organize the work, lead to different characterizations of the conceptions of a function.” (p. 259). Mesa's major question was "What are the conceptions of functions that may be stimulated by the solutions to exercises and problems of the seventh and eighth grade mathematics textbooks in a given sample?” (p. 260) Mesa presented her study as an example of an analysis designed to determine what types of learning occur when students work through a particular mathematical concept, such as linear functions, in the textbook. Cunningham (2005) was concerned about the curriculum being only a potential curriculum due to the problems the teacher presented in the classroom. Cunningham (2005) questioned whether students were being exposed to enough transfer-of-representation linear function problems to learn the material. O'Callaghan's (1998) interest was whether students 
learned the concept of linear functions better when using a Computer Intensive Algebra (CIA) curriculum versus a traditional algebra curriculum.

Mesa (2004) examined the problems dealing with functions that were available to students in $7^{\text {th }}$ - and $8^{\text {th }}$-grade textbooks from 18 countries who had participated in the TIMSS. From the original sample of 35 textbooks from these countries, 24 textbooks were examined because they contained functions or topics closely related to functions. Mesa then counted all the problems, henceforth called tasks, containing function in the texts and found 1,318 tasks. She gave each of the tasks a 4-tuple code (P, O, R, $\Sigma$ ) representing Biehler's characterization of a concept with P representing the use of function in the task, $\mathrm{O}$ representing the operations needed to solve the task, $\mathrm{R}$ standing for the representations needed to solve the task, and $\Sigma$ representing all of the activities available for verifying the correctness of the problem, henceforth called controls. Mesa then presented how she developed the coding categories for each part of the 4-tuple by examining a task from the first section in each book and responding to a question for each one of the four elements of the quadruplet. These responses were the basis for the categories for each element of the 4-tuplet. She then had to merge categories due to the large number of responses obtained. After testing the coding system with other raters, a revision, and another rater test, Mesa ended up with 10 codes for the use of the function, 36 codes for operations, 9 codes for representation, and 9 codes for controls. The interrater agreement ranged from $80 \%$ to $100 \%$ across the 4 groups of codes created to categorize the 4 characteristics of concept examined within each task.

Mesa (2004) then reorganized the codes within each element based on frequency of observations to facilitate data analysis and interpretation. She was able to create 
affinity groups in which to organize the codes into categories; five for uses, five for operations, three for representations, and three for controls. Mesa then used configural frequency analysis (CFA) to determine the configurations of the four elements of the quadruplet where the frequency was larger or smaller than what was expected by chance. She found 28 configurations whose frequencies differed from chance. An examination of these configurations allowed her to characterize the types of learning that take place during the study of functions. She was able to define five practices on functions, which she labeled "symbolic rule, ordered pair, social data, physical phenomena and controlling image" (p. 267). She described each practice in detail before presenting the results.

The results were that $37 \%$ of the tasks suggested a "symbolic rule, an ordered pair, or a controlling image practice" (Mesa, 2004, p. 272), which has no nonmathematical context, while $10 \%$ suggested a "social data or physical phenomena practice" (p. 272), which have an outside-mathematics context. Among the textbooks, $71 \%$ contained symbolic rule and ordered-pair practices, about $50 \%$ contained social data tasks, $33 \%$ contained physical phenomena practices, and $38 \%$ contained controlling images practices. Twenty-five percent of the textbooks contained only one type of practice, and about $20 \%$ of the textbooks contained four or all of the practices. Thus, Mesa only presented the percentage of textbooks which contained the classifications she created.

Mesa ended by discussing how determining the types of learning that takes place as students work through a concept in the textbook may be useful in helping students grasp a concept more completely and avoid conflicting conceptualizations of 
mathematical notions. She also reiterated that teaching students how to check the appropriateness of the method used should be in the text. Mesa suggested that a similar analysis such as the one she carried out would indicate whether textbooks contain multiple representations for the construction of meaning for mathematical notions and explicit directions for students to use metacognitive strategies. She emphasized that control strategies should be introduced explicitly in mathematics textbooks. The proposed study will be comparing the textbooks with respect to Mesa's five practices on functions and attention getters/signposts to the important concepts in the text.

O’Callaghan (1998) developed a conceptual model for learning functions which consisted of four competencies, (a) modeling - ability to represent a problem situation using a representation for a function, (b) interpreting - ability to change the representation of a function into terms of a real world situation, (c) translating - ability to move from one representation of a function to another, and (d) reifying- "creation of a mental object from what was initially perceived as a process or procedure" (25). He used these competencies to categorize problems on a function test to assess students' knowledge of functions. He and other instructors gave the test through a department final exam to 802 students in 40 classes. O'Callaghan focused on three classes in particular, (a) a class which he taught using a computer-intensive approach (CIA), (b) a class he taught using a traditional approach (TA1), and (c) a class taught by another professor using a traditional approach (TA2). He also interviewed six students from each group using problems similar to the ones on the final exam. The qualitative results demonstrated that students in the CIA curriculum enjoyed the curriculum more and had a different conception of what was a function. An ANOVA among the three focal groups suggested 
that the students in the CIA curriculum had made no less progress than the traditional classes even though the CIA students had lower scores on the final exam. O'Callaghan (1998) demonstrated that it is possible to categorize linear function problems with respect to problem-solving competency types. The next researcher, Cunningham (2005) used the same three core representational systems for functions that $\mathrm{O}^{\prime} \mathrm{Callaghan}$ called equation or symbol, tables, and graphs, but only focused on the competency that O'Callaghan called translating.

Cunningham (2005) examined the amount of class time teachers devote to problems of transfer between algebraic $(A)$, numeric $(\mathrm{N})$, and graphic $(\mathrm{G})$ representations of linear functions and the number of transfer problems on teacher made assessments. Cunningham examined the six transfer problems (a) $A \rightarrow N$, (b) $A \rightarrow G$, (c) $N \rightarrow A$, (d) $\mathrm{N} \rightarrow \mathrm{G}$, (e) $\mathrm{G} \rightarrow \mathrm{A}$, and (f) $\mathrm{G} \rightarrow \mathrm{N}$. The importance of transfer between representations is highlighted in the NCTM standards (2000) not only as a part of the Algebra strand but as a separate strand known as the Representation strand. One of Cunningham's (2005) major results was that teachers spend less time on the type of transfer problems, $\mathrm{G} \rightarrow \mathrm{N}$, which students find most difficult to master. Also, he found that transfer problems requiring moving from an algebraic representation to a numeric representation had the second lowest number of assessments and second lowest amount of class-time. Comparing the number of transfer problems pertaining to linear functions in textbooks in Singapore to the number of transfer problems pertaining to linear functions in the U.S. may provide useful information in determining if a text covers an adequate number of problems for the student to gain mastery of transfer of representation problems. 
Cunningham (2005) and O'Callaghan (1998) only considered the three most common types of mathematical representations, (a) algebraic, (b) numeric, and (c) graphic, in their studies on functions. However, Cunningham (2005) suggested that a fourth representation, written or verbal, should be included in future research pertaining to transfer of representation problems. Within the definitions of the competencies of modeling and interpreting used in his study, O'Callaghan (1998) considered going from verbal to one of the three core representational systems and vice versa, but he did not call the verbal terms a representational system nor did he consider these to be a transfer of representation or a translating competency. However, Brenner et al. (1995) used a fourth representation in her research on students' understanding of algebra. They called this representation a "verbal" representation (p. 12) which involves being able to explain the relationships in word problems and being able to "explain in words the functional relationships represented in the other representations" (p. 12). Thus, this fourth representation is needed when considering problems involving transfer of representational types. This representation would be general enough to include either a written description or a verbal, that is, spoken, description of a problem.

The literature review highlights some of the ways that learning and comprehension changes due to the textbook. The changes caused by reading a text and writing down answers to problems were examined by Österholm (2005) and Steele (2005) respectively. Changes in achievement due to changing the textbook with and without changing school grouping were studied by Tieso (2005). The concepts learned when taught the topic of functions, specifically linear functions, through a text (Mesa, 2004), a CIA curriculum (O'Callaghan, 1998), and problems in class (Cunningham, 
2005), have also been examined. These studies illustrated that the text is an important part of student learning.

\section{Summary}

U.S. students are weak in mathematics as is seen through state, national, and international assessments (Beaton et al., 1996; Gonzales et al., 2000; Gonzales et al., 2004; Kilpatrick et al., 2001). The results from the landmark international comparison study, TIMSS of 1995, served as the catalyst for a plethora of studies comparing the educational practices of the nations participating in the TIMSS (Kaiser et al., 1999; Zhu \& Fan, 2004). Within curriculum studies involving these nations, the textbook has been examined in an attempt to identify differences that could possibly help explain the disparity in achievement. The results of these studies suggested that textbooks in countries that placed at the top of the TIMSS were different than textbooks in the U.S. (Schmidt et al., 2001).

Schmidt and colleagues (2001) examined the mathematics curriculum contained in eighth-grade textbooks within the 37 countries, including East Asian countries that participated in the TIMSS-95. U.S. textbooks and the textbooks of other nations in the study were seen to have general differences in topics covered. However, the TIMSS study only examined topics generally without considering individual problems within a topic. Research that focuses on the problems pertaining to one particular topic is needed (Li, 2000). Thus, the researcher of the present study examined middle-grades textbooks from Singapore and the U.S. with regard to problems using an amalgamation of features examined by Li (2000) and by Zhu and Fan (2004). As suggested by Li, this study also included an examination of broader aspects of the text. 
In a study conducted by the American Institutes for Research (AIR), Ginsburg and colleagues (2005) completed a thorough comparison of U.S. elementary mathematics texts to Singapore elementary mathematics texts. The results of the AIR study showed that primary texts in Singapore and the U.S. have distinct differences. Harries and Sutherland (2000) also found differences in the images and references to the mathematical concepts represented by the images in Singapore and U.S. primary textbooks. Thus, the researcher compared middle school textbooks from Singapore and the U.S. with respect to these features to see if similar results would be obtained for these grades.

Also, research indicated that the topic of linear functions has not been widely emphasized in textbook comparisons. There are not many studies which focus on problems pertaining to the topic of linear functions. Linear functions has been included as one topic among many in some textbook comparisons (Mesa, 2004; Schmidt et al, 2001). However, one researcher focused on characterizing problem types (Mesa, 2004) and only reported the percentage of textbooks which contained these problem types. The other researchers (Schmidt et al., 2001) did not focus on particular problems within the text but examined broad categories of topics within texts. Thus, past research has shown that the differences found in the middle school texts were based upon a general examination of topics without considering individual problems within a topic and that there is a need for further research pertaining to the topic of linear functions.

In the textual analysis, the researcher examined the conceptualizations of the topic of linear functions in the text through the use of a conceptualization model (O'Callaghan, 1998) previously only used on assessment items in class. The researcher also extended 
the transfer of representation types, previously used by Cunningham (2005) and Brenner and colleagues (1995) in research conducted on instructional practice, to textbooks. 


\section{CHAPTER III}

\section{METHOD}

The purpose of the study was to compare the treatment of the topic of linear functions in middle grades student mathematics textbooks of Singapore and the United States. Treatments refer to the ways linear functions are presented in the text including how the topic is represented in the problems of the text. The main focus was on the problems pertaining to linear functions. The research questions motivating the study were as follows:

1. How do the treatments of the topic of linear functions in middle grades mathematics textbooks of Singapore compare to the treatments of the topic of linear functions in middle grades mathematics textbooks of the U.S.?

Treatments of the topic refer to the ways linear functions are presented in general in the text and how the topic is represented in the problems of the text particularly with regard to the 22 features the researcher examined.

2. What are the similarities and differences of the conceptual types of problems related to the topic of linear functions within the middle grades mathematics textbooks of Singapore and the U. S.?

3. How are problems related to linear functions in middle grades mathematics textbooks of Singapore and the U.S. different or similar with respect to computational requirement, context, required response, cognitive requirement, and given information?

4. Are the characterizations of problem practices as seen in the problems related to linear functions in middle grades mathematics textbooks from Singapore and 
from the U.S. the same or different?

5. How do the problem-solving competency types in the problems related to linear functions in middle grades mathematics textbooks from Singapore and from the U.S. compare?

6. How do the types of transfer of representation needed to do the problems pertaining to linear functions in middle grades mathematics textbooks from Singapore compare to the types of transfer of representation needed to do the problems pertaining to linear functions in middle grades mathematics textbooks from the U.S.?

The chapter begins with a detailed description of the textbook selection process. Then, a description of the 22 features that were examined in the 17 textbooks, eight from Singapore and nine from the U.S., is presented in the data collection section. The presentation includes a delineation of the category codes used for each feature. This is followed by an analysis of the coding scheme as informed by the coder training process used to attain inter-rater reliability values. The details of a pre-pilot study that had informed the creation of the coding scheme (Appendix C and Appendix D) are found in Appendix E. A description of the treatment of the data concludes the chapter.

\section{Textbook Selection Process}

Eight mathematics textbooks from Singapore and nine textbooks from the U.S. were examined. The eight Singaporean textbooks represent three different text series in Secondary 1 and Secondary 2, that is, the seventh and eighth year of education, which contain the topic of linear functions. An examination of the Singapore mathematics primary (Ministry of Education Singapore, 2006a) and secondary syllabi (Ministry of 
Education Singapore [MOE], 2006b, MOE, 2012) indicated that linear functions are covered in Secondary 1 and Secondary 2. The nine U.S. textbooks represent three different series in Grades 6-8 which contain the topic of linear function. A description of how these textbooks were selected is next.

\section{Track Determination}

The textbooks were determined by examining the department of education, or equivalent departments', websites for Singapore and the states of Florida, Texas, and California (See Appendix A). The states of Florida, Texas, and California were chosen because they are the three states that drive the mathematics textbook publication market (Seeley, 2003). Information concerning the state adopted textbooks and topics taught in each grade was examined and compared. This information allowed the researcher to determine the grade levels and textbooks used in this study.

After primary school in Singapore, secondary students are placed in one of three tracks, (a) Express (Note, before 2008, this track was two tracks, the Special track and the Express track.), (b) Normal Academic, or (c) Normal Technical (Ministry of Education Singapore [MOE], 2013; Soh, 2008). About 60\% of Singaporean students take Express classes (MOE, 2013). The Express curriculum is designed to prepare students for college upon passing Type O Examinations. The remaining percentage of the Singaporean students are in the Normal Academic or Normal Technical classes and have a curriculum that is similar to the Express track, but is slower paced (MOE, 2013; Soh, 2008). The Normal Academic track allows students to progress to college with an extra year of study to prepare for the Type O Exam. The common middle school mathematics curriculum in the U.S. allows all students to be ready for college depending on the classes taken in high 
school. In light of the facts that a majority (61\%) of Singaporean students is in the Express track and that the curricula in the three tracks are similar but paced differently, the researcher only focused on the Express textbooks.

\section{Year or Level Determination}

The syllabi for grade level and for each track are listed on the Singapore Ministry of Education website (MOE, 2006b; MOE, 2012). Study of the syllabi for the Express track indicated that students are exposed to linear functions primarily in Secondary 1 which is essentially the seventh year of education and in the Secondary 2, the eighth year of education. For that reason, the researcher chose the textbooks in the Secondary 1 and Secondary 2 years to examine.

An extensive review of the state content standards documents of California, Florida, and Texas (see Appendix A) in the summer of 2012 revealed that the topic of linear functions was within Grades 6-8. This factual finding aligned with the NCTM algebra standards for Grades 6-8 as set forth in the Principles and Standards for School Mathematics (NCTM, 2000). There is a difference in the Texas standards, as Texas also has linear functions in grade 9 since Texas prepares students for Algebra 1 to be taken in the ninth grade. The fact that the texts are on the other two states' adoption lists makes this a non-issue. Thus, the texts in Grades 6-8 were chosen to be examined in this study.

\section{Textbook Determination}

Three Secondary 1 (S1) and three Secondary 2 (S2) series mathematics textbooks from Singapore were compared to three middle school series, Grades 6-8, mathematics textbooks from the U.S. 
The researcher examined three textbook series in the Express track used in grades S1 and S2 from Singapore. One of these textbook series, New Syllabus Mathematics, is documented as being used in $80 \%$ of secondary schools in Singapore (SGBox.com, 2014). There were a total of eight Singapore textbooks examined. The two textbooks, Discovering Mathematics $1 A$ and Discovering Mathematics $1 B$, used in secondary $1\left(7^{\text {th }}\right.$ grade) in Singapore was amalgamated to be one textbook in the data collection process. The two text-books, Discovering Mathematics $2 A$ and Discovering Mathematics $2 B$, used in secondary 2 ( $8^{\text {th }}$ grade $)$ in Singapore also were combined to be one textbook in the data collection process. Thus, in the statistical testing for the comparison of the textbooks, there were 6 textbooks for Singapore, three textbook series for each of the two grade levels (See Table 2). See Appendix E for a complete list of these titles.

Table 2

\begin{tabular}{ll} 
Textbook Setup & \\
\hline Textbooks & Grades \\
\hline Singapore & \\
Discovering Math 1A, 1B & Secondary 1 (seventh) \\
Discovering Math 2A, 2B & Secondary 2 (eighth) \\
Math Matters 1 & Secondary 1 (seventh) \\
Math Matters 2 & Secondary 2 (eighth) \\
New Syllabus 1 & Secondary 1 (seventh) \\
New Syllabus 2 & Secondary 2 (eighth) \\
United States & \\
McDougal Math 1 & Sixth \\
McDougal Math 2 & Seventh \\
McDougal Algebra 1 & Eighth \\
Glencoe Math Connects 1 & Sixth \\
Glencoe Math Connects 2 & Seventh \\
Glencoe Math Connects 3 & Eighth \\
Pearson Connected Math 1 & Sixth \\
Pearson Connected Math 2 & Seventh \\
Pearson Connected Math 3 & Eighth \\
\hline
\end{tabular}


In the U.S., each grade uses only one textbook. Three texts within each grade level of grades 6 to 8 were used for the textbook comparison for a total of nine texts from the U.S. An examination of the department of education websites of California, Florida, and Texas in early summer 2012 revealed that there were three textbooks that had the same or similar title on the adoption lists of all three states. Examining publisher websites and talking with customer service representatives clarified that a similar title is basically the same textbook but with a state title. For example, a personal communication with a customer representative for Glencoe revealed that while the titles, Glencoe Florida: Math Connects and Glencoe Math Course, are different; they are simply state versions of the same text and therefore virtually the same. While there is an emphasis on algebra in the eighth grade, these texts covered this emphasis as the eighth grade texts reflect this emphasis that began before 2009. Three U.S. series titles were chosen for a total of nine books. Table 2 shows the set-up of the Singapore texts and the U.S. texts. A complete list of these texts with their titles, authors, publication date, and publishers is found in Appendix E.

\section{Data Collection}

In this study, Singapore textbooks and U.S. textbooks were compared with respect to 22 characteristics. The researcher performed a content analysis to examine the general features of the text with a more concentrated look at the sections pertaining to linear functions. Using these sections, the researcher compared (a) background features of the texts, (b) general features of the problems pertaining to linear functions, and (c) specific characterizations of problem practices within the texts. The features were coded using a coding scheme with codebook (Appendix C, Appendix D) developed by the researcher. 
The coding scheme was an amalgamation of coding symbols and ideas from past studies (Anderson et al., 2000; Cunningham, 2005; Ginsburg et al., 2005; Harries \& Sutherland, 2000; Li, 2000; Mayer et al., 1995; Mesa, 2004; O’Callaghan, 1998; Tieso, 2005; Zhu \& Fan, 2004). The creation of the coding scheme and codebook was informed by the work of Neuendorf (2002).

Thirteen background features of the text were compared. The comparison included finding the (a) number of pages in text, (b) number of chapters, (c) number of sections, (d) number of sections pertaining to linear functions, (e) number of pages pertaining to linear functions, (f) number of pages for development, (g) number of pages for exercises, (h) number of other pages, (i) number of problems pertaining to linear functions, (j) average number of pages per section pertaining to linear functions, $(\mathrm{k})$ number of object-analytic images, (l) number of object-illustrative images, and (m) number of signposts or attention-getters. For 12 of the 13 features, the codes were the number of occurrences for that item while the code for the remaining feature was an average number of pages. The categories of images came from the work of Harries and Sutherland (2000). The designations objective-analytic images (OA) and objectillustrative images (OI) distinguish whether the image facilitates understanding of the text or not. The work of Ginsburg et al. (2005) inspired the examination of the number of pages and problems. From the research by Harries and Sutherland (2000) and discussion by Anderson et al. (2000), the importance of drawing students' attention to important features to assist in student achievement was emphasized. This emphasis was the inspiration for the examination of road-signs or attention-getters feature. See Appendix D for a more complete description of these features. 
Also, the researcher used the content analysis to compare general classifications of features within problems pertaining to linear functions. A merger of classifications of problem features from the works of $\mathrm{Li}$ (2000) and Zhu and Fan (2004) was used to distinguish problems through six feature classifications (a) computational feature, (b) contextual feature, (c) response-type feature, (d) cognitive requirement feature, (e) giveninformation feature, and (f) application type feature. For the computational feature, the researcher determined the number of mathematical procedures required to arrive at an answer and coded each problem as requiring (a) a single computation procedure, $S$; (b) multiple computation procedures, $\mathrm{M}$; or (c) other, ot.

For the contextual feature, the researcher looked at the context in which the problem was presented and coded each problem as either (a) numerical, nu; (b) visual, vi; (c) verbal, ve; (d) combined form, co; or (e) other, ot. The researcher also examined the type of answer that the question requires and coded the problems as requiring one of the following types: (a) numeric answer only, A; (b) algebraic expression or equation only, E; (c) explanation or solution required, ES; (d) Graph only, G, (e) Multiple response types, M, or (f) other response, OP. The researcher reported the type of cognitive level required to do the problem and coded this cognitive requirement feature as (a) procedural practice, PP; (b) conceptual understanding, CU; (c) problem solving, PS; (d) special requirement, SR; or (e) other, ot. For the given-information feature, the researcher reported the amount of information given in the problem as either (a) sufficient, SF; (b) extraneous, EX; or (c) insufficient, ISF. Lastly, for the general classification of features within problems, the researcher reported the amount of information given in the problem 
statement as either applied, AP, or nonapplied, NA. See Appendix D for a more detailed description of these features.

Problems were also classified as one of the five characterizations of problem practices associated with functions as developed by Mesa (2004). The researcher coded the type of practices seen in problems pertaining to linear functions as (a) symbolic rule, sr; (b) ordered pair, op; (c) social data, sd; (d) physical phenomena, ph, (e) controlling image, ci; or (f) other, ot. See Appendix D for a more detailed description of this feature. O'Callaghan's (1998) problem-solving competency types for functions were used to analyze the problems in the text. The researcher classified the component competency type required to solve the problem as (a) modeling, mod; (b) interpreting, int; (c) translating, tran; (d) reifying, reif; or (e) does not apply, dna. See the Codebook in Appendix D for a detailed description of these codes. Cunningham's (2005) descriptions of transfer of representation types combined with Brenner et al.'s (1995) fourth representation were used to analyze the problems within the texts. The researcher coded the type of transfer necessary as a student moves from one type of mathematics representation in the question to a different mathematical representation for the answer. These types of transfer types going from one representation to another representation were coded as (a) $\mathrm{A} \rightarrow \mathrm{N}$, algebraic to numeric; (b) $\mathrm{A} \rightarrow \mathrm{G}$, algebraic to graphical; (c) $\mathrm{A} \rightarrow \mathrm{V}$, algebraic to verbal; (d) $\mathrm{N} \rightarrow \mathrm{A}$, numeric to algebraic; (e) $\mathrm{N} \rightarrow \mathrm{G}$, numeric to graphical; (f) $\mathrm{N} \rightarrow \mathrm{N}$, numeric to numeric, (g) $\mathrm{N} \rightarrow \mathrm{V}$, numeric to verbal; (h) $\mathrm{G} \rightarrow \mathrm{A}$, graphical to algebraic; (i) $\mathrm{G} \rightarrow \mathrm{N}$, graphical to numeric; (j) $\mathrm{G} \rightarrow \mathrm{V}$, graphical to verbal; (k) $\mathrm{V} \rightarrow \mathrm{A}$, verbal to algebraic, (l) $\mathrm{V} \rightarrow \mathrm{N}$, verbal to numeric; (m) $\mathrm{V} \rightarrow \mathrm{G}$, verbal to graphical; 
(n) Multiple transfer types , m, or (o) Does not apply, dna. Detailed descriptions of this feature are in Appendix D.

\section{Analysis of Coding Scheme}

The coding scheme was checked for validity and inter-rater reliability. In preparation for this study, the researcher conducted a pre-pilot study on the first draft of the coding scheme and codebook (Fowler, 2008). See Appendix F for more details on the pre-pilot study. The goal of the pre-pilot study was to find ways to improve the codebook before using it in the textbook comparison study. The pre-pilot study was beneficial in pinpointing things that need to be changed in the codebook and the coder training process

and revealed sources of potential problems in the future textbook comparison study. Also, the pre-pilot study highlighted how important coder-training is to the process of achieving inter-rater reliability. Neuendorf's (2002) 15 step process of coder-training is explained in the next paragraph.

Neuendorf (2002) presented a 15-step process to use when creating a coding scheme. This process involves (a) creating the codebook, (b) three iterations of coder training, coder practice, coder discussion, and codebook revision, (c) the final coding, and (d) analysis of the experience (Neuendorf, 2002). These 15-steps are (a) create the codebook, (b) train coders with discussion, (c) practice coding together to reach consensus, (d) make codebook revisions, if needed, (e) train coders on revisions, (f) practice training independently, (g) discuss results, (h) revise codebook if needed, (i) train coders on revisions, (j) code subsample for measures of reliability, $(\mathrm{k})$ check reliability values, (l) revise codebook if needed, (m) coder training on revisions, (n) independent coding, and (o) coder debriefing. For this study the researcher conducted this 
15-step training process to determine ways to improve the coding scheme and the appropriateness of the category choices.

After creating a coding scheme and a codebook defining the aspects of the mathematics text book, the researcher conducted the 15-step coder training/codebook development process with a second coder as suggested by Neuendorf (2002). The second coder is an assistant professor of mathematics at an accredited university who has a Ph.D. in mathematics. First, the two coders examined the initial codebook and discussed changes that needed to be made. Also, training involved studying Mesa's (2004) and Li's (2000) works. Then, the coders practiced coding together using College Algebra: Graphs and Models (Barnett et al., 2009). Revisions were made with regard to number of pages and more details about the characterization of problem practices, specifically the symbolic rule and social data practices. Once revised, the researcher trained the second coder on the new definitions. Next, the coders coded problems independently. An Excel program was used to facilitate the recording of the coding selections while a coding form was used to record the numbers with the general feature categories. Due to the ease of using the Excel program, the coding form was added to the Excel worksheet. A sample of this rubric listing all problems as columns and the feature categories as rows is found in Appendix G. Then the coders discussed results together. Definitions for procedural practice and conceptual understanding were the main issues of discussion and change in the codebook. Details about the transfer types were clarified and another category of multiple transfer types was included in the codebook. The second coder was trained on revisions to the codebook. Then the coders went over more problems together and then 
coded independently before making more revisions in preparation for testing inter-rater reliabilities.

For the features which required a choice of code, the desired value for the interrater reliability coefficient was chosen to be +0.75 for Cohen's kappa which is the level acceptable in most situations (Lombard, Snyder-Duch, \& Bracken, 2005; Neuendorf, 2002). For the initial test for inter-rater reliability values, the coders used the odd problems from chapter tests 2, 3, and 7 from Beginning and Intermediate Algebra (Lial, Hornsby, \& McGinnis, 2012) for a total of 39 problems. Three features had the appropriate Cohen's Kappa values: a) given-information type with perfect agreement, b) application type with 0.86 , and c) characterization of problem practices type with 0.75 . The coders examined the problems they had coded and discussed the coding scheme. Then, the coders did a second check for inter-rater reliability values using the 36 even problems on chapter tests 2, 3, and 7 in Beginning and Intermediate Algebra. All but one of the 9 features had the necessary +0.75 Cohen's Kappa. The cognitive requirement feature had an inter-rater reliability value of 0.51 for Cohen's kappa and 0.72 for percent agreement

The coders discussed the cognitive requirement type, particularly procedural practice versus conceptual understanding. The realization that conceptual understanding requires one to make relationships among features in the problem while procedural practice requires little connection to relationships was key in distinguishing the difference between the two types of cognitive requirement. The following examples may help illustrate a problem that requires making connections between multiple features in the 
textbook versus one that does not. See Figure 5. After delineating these two cognitive requirements into categories based upon relationship between more than one features, or no or little relationship among features, in the problem, the coders examined every fifth problem in the chapter reviews for chapter 2, 3 and 7 in Beginning and Intermediate Algebra (Lial et al., 2012). They obtained an inter-rater reliability value of 0.82 for Cohen's kappa and 0.90 for percent agreement for the Cognitive Requirement feature. See Table 3.

Conceptual Understanding

1. Use the graph, which shows two pay rates for baby-sitting. Use the points to find each person's pay rate.

2. Use the points and slope of the line to Find the value of a.

Slope $=\frac{a}{2},(-2,-1),(2,5)$
Procedural Practice

1. Use the graph, which shows two pay rates for baby-sitting.

Find two points on each line.

2. Copy and complete the statement using $<$, $>$, or $=$.

Line a: passes through $(1,-3)$ and $(2,0)$

Line b: passes through $(1,1)$ and $(7,3)$

Slope of line $a$ ? slope of line $b$

\section{McDougal Littell Math Course 1}

Figure 5. Cognitive Requirement Sample Problems

The general features of the text did not require a choice of code categories except for the images, which required a count for each type of image, object-illustrative and object-analytic. Thus, Cohen's kappa and percent agreement were not found for these characteristics. The results consisted of a comparison of the two coders' assessments of the features as listed on their coding forms. These values are listed in Table 4. Revisions were made to the codebook to address the discrepancies in the number of object illustrative images, object analytic images, signposts, and number of linear function 
problems. Illustrations used to set up a problem, such as geometrical figures which were used to show the reader which angle they were asked to find, and graphs were excluded from the count of images. Also, the second coder did not realize that the problems in the review sections were not going to be examined in the study, so the description of problems to be examined was detailed more specifically in the codebook.

Table 3

Final Inter-rater Reliability Coefficients for Categories Coded in Text

Feature

Cohen's kappa

Percent Agreement

Problems $(N=36)$

Computational

Contextual

Response-Type

Cognitive Requirement

Given Information

Application Type

Problem Practices

Problem-Solving Competencies

Transfer Type

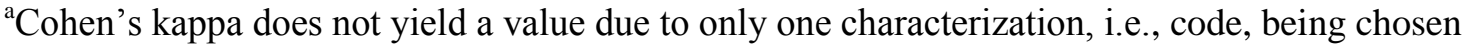
for all problems. All problems were coded with the same code, so the coders agreed on the characterization of every problem in this category.

To address validity of the coding scheme, the researcher completed a literature review on textbook comparisons and how problems have been examined in the past. This 
past research was beneficial in creating the codebook which defines the features that were examined and contains a coding scheme for each feature that encompasses all the important aspects of the feature. Also, the coder-training helped ensure that the coding scheme contains all essential component parts for each feature. Thus, the researcher addressed the somewhat subjective content validity issue by defining the codebook to reflect the entirety of the feature being examined. Also, she calculated a content validity index (CVI), or agreement proportion, for each code of a specific feature (Wynd, Schmidt, \& Schaeffer, 2003). To be an acceptable level of inter-rater proportion agreement, the CVI needed to be $80 \%, 0.80$, as this value is deemed adequate by Wynd et al. (2003).

\section{Table 4}

Comparison of Data for General Characteristics of the Text

\begin{tabular}{lrr} 
Feature & Coder 1 & Coder 2 \\
\hline Pages in Text & 1054 & 1057 \\
Number of Chapters & 14 & 14 \\
Number of Sections & 94 & 84 \\
Number of Linear Sections & 16 & 16 \\
Linear Function Pages & 209 & 188 \\
Pages for Development & 116 & 113.5 \\
Pages for Exercises & 89 & 70.5 \\
Other Pages & 4 & 4 \\
Number of Linear Problems & 1233 & 1591 \\
Average Pages/Linear Function & 12.06 & 11.75 \\
Object-Illustrative Images & 77 & 19 \\
Object-Analytic Images & 44 & 20 \\
Signposts/Attention-Getters & 46 & 50 \\
\hline
\end{tabular}

After the codebook had appropriate inter-rater reliability levels for each characteristic, the researcher and two other judges, the second coder and an assistant professor of mathematics at an accredited university with a Ph.D. in Mathematics 
Education, classified each code for a specific feature as to how relevant the code is to defining/describing the feature being examined. The three coders, each an experienced university professor of mathematics familiar with teaching linear functions, examined each code and judged them as (a) essential, (b) somewhat essential, (c) somewhat nonessential, or (d) nonessential to the definition of the feature being examined. All coders found the codes to be essential to the feature being examined. Thus, the CVI values were 1 across the board, and no changes to the codebook were needed at this point.

\section{Treatment of the Data}

The two coders examined the 17 textbooks, eight textbooks, amalgamated into six textbooks, from Singapore and nine textbooks from U.S., and coded them with regard to the 22 features described in the codebook. An Excel program was used to facilitate the recording of the coding selections for the nine features concerning a choice of code for each problem. A rubric listing all the problems in each section by section heading was created for each book. The researcher added row- and column- sums as a check to decrease human error during the coding process. Also, the coders used the Excel program to record the numbers obtained for the general features from each textbook.

For the statistical testing for the general features, the average values for the features were used in the statistical testing used for the comparison of the data. Welch's $t$ test was used to compare the values for each of the general features obtained from the Singapore textbooks to the values for the corresponding general features obtained from the U.S. textbooks. The null hypothesis for each feature was that the two sample means were equal. The alternate hypothesis was that the sample means were different, i.e. that the textbooks from the two countries were different in regard to that feature. Welch's $t$ - 
test was used because the two samples, that is, the values obtained from the two countries' textbooks, had different numbers of values, six for Singapore and nine for U.S., and the samples were assumed to have unequal variances. The two sets of values obtained from the two countries' sets of textbooks were used to find the statistic $t$ using the formula

$$
t=\frac{\overline{x_{1}}-\overline{x_{2}}}{\sqrt{\frac{s_{1}^{2}}{N_{1}}+\frac{s_{2}^{2}}{N_{2}}}}
$$

where $\overline{x_{i}}=i^{\text {th }}$ sample mean, $s_{i}^{2}=i^{\text {th }}$ sample variance, and $N_{i}=\mathrm{i}^{\text {th }}$ sample size. The degrees of freedom $v$ was approximated by the Welch-Satterthwaite equation which has the formula

$$
v \approx \frac{\left(\frac{s_{1}^{2}}{N_{1}}+\frac{s_{2}^{2}}{N_{2}}\right)^{2}}{\frac{s_{1}{ }^{4}}{N_{1} v_{1}}+\frac{s_{2}{ }^{4}}{N_{2}^{2} v_{2}}}
$$

where $\mathrm{v}_{\mathrm{i}}=N_{i}-1$ is the degrees of freedom associated with the $\mathrm{i}^{\text {th }}$ variance estimate. An Excel program was used to compute the values for $t, v$, and to run the two-tailed $t$-tests for the collected data. Probability values of 0.05 or less for the test are values that represent that there is a significant difference between the two sets and the null 
hypothesis that the textbooks from the two countries are the same for that feature should be rejected.

For the nine features for the problems that required a choice of code, the researcher first found the percentages that each code was used in the problems pertaining to linear functions in each textbook. For each code of the feature, the percentages from the two countries' textbooks became the two sample sets used to find the statistic $t$ which was used to perform Welch's $t$-test to compare the textbooks with respect to the codes for each feature. The Null hypothesis for each code was that the means for the sample sets was equal. The alternative hypothesis was that the means for the two sample sets was different, that is the two countries' textbooks were different with respect to the percentages that a particular code was seen in the textbook. The significance level was 0.05 .

However, the fact that there was one or two codes different for a feature containing a choice of many codes may not have been enough to determine if the two sets of textbooks were different. Thus, the researcher also decided to do a chi-square test of independence for each feature to determine if the choices of codes for a particular feature for the two sets of textbooks were independent (not related) or not independent (related) to the country of origin. The chi-square test of independence was used to determine if the choice of code for a feature was related to the countries' textbooks. The Null hypothesis was that the choice of codes for one feature is independent of the country from which the textbooks came, that is, the country the textbook came from has no significant effect on the choice of code for that feature. The alternative hypothesis was that the two variables, "codes chosen for one feature" and "country", are related (not independent), that is, the 
country that the textbook came from has an effect on the choice of code for that feature. There were nine chi square tests that were done, one for each feature. For the computational feature, the set "country" which includes U.S. and Singapore, and the set of "codes" which includes (a) single, (b), multiple, and (c) other, are the two variables which were tested for independence. The Null hypothesis was that the country did not have a significant effect on the choice of codes, (a) single, (b) multiple, and (c) other, for the problems; the alternative hypothesis was that the country did have an effect on the choice of codes. For each of the eight other features which required a choice of code, a similar chi square test of independence was performed. The expected frequencies necessary for this test were found by combining both countries' textbook codes and using these numbers to find the percentage of problems expected from each individual countries' textbooks as seen by the observed percentages. The total number of problems was 4547. An Excel program was used to compute the chi-square statistics, $\chi^{2}$, and determine the associated probabilities for the chi square tests for independence. The Null hypothesis was rejected when the calculated probability was less than 0.05 .

\section{Summary}

In this section, the methods for the study were presented. The work of Neuendorf (2002) influenced the creation of the codebook and coding scheme used in the quantitative study. As presented, several past research studies (Anderson et al., 2000; Cunningham, 2005; Ginsburg et al., 2005; Harries \& Sutherland, 2000; Li, 2000; Mayer et al., 1995; Mesa, 2004; O’Callaghan, 1998; Tieso, 2005; Zhu \& Fan, 2004) also influenced the coding scheme. Thus, the study is based upon prior research and theory. Because the study is an amalgamation of ideas from several studies, the study was 
designed to give a broad look at how the textbooks from Singapore and the U.S. compare, particularly with respect to the topic of linear functions. The use of two raters to test the coding scheme reduced possible researcher bias. The validity of the coding scheme was checked by the careful delineation of coding categories used to capture all aspects of the feature being examined and by the calculation of a content validity index value for each feature. Thus, the study was designed to contribute to research in the area of linear functions. Next, Chapter 4 contains the results of the textual analysis completed on the 17 textbooks from Singapore and the U.S. 


\section{CHAPTER 4 \\ RESULTS OF STUDY}

The purpose of the study was to compare treatments of the topic of linear functions in Singapore and U.S middle grades mathematics textbooks. The textbooks were examined with respect to 13 general features of the textbook and nine features related to the problems pertaining to linear functions. In this chapter, the researcher first presents the data obtained for the 13 general features with the corresponding results from Welch's $t$-tests for each feature. Then the researcher reports the data for the nine problem features with the corresponding results of the Welch's $t$-tests and chi-square tests of independence for each feature.

\section{Results from Data Collection}

The two coders examined the 17 textbooks, eight textbooks, amalgamated into six textbooks, from Singapore and nine textbooks from U.S., and coded them with regard to the 22 features described in the codebook. An Excel program was used to facilitate the recording of the coding selections for the nine features concerning a choice of code for each problem. A rubric listing all the problems in each section by section heading was created for each book. The total number of problems examined for each textbook is in Table 5. The number of problems was one of the big differences between the Singapore textbooks and the U.S textbooks. The Singaporean textbooks have far fewer homework problems than the U.S. textbooks.

\section{General Features}

The coders used the Excel program to record the numbers obtained for the general features from each textbook. The data for the general features from Singapore is seen in 
Table 6 and the data for the general features from the U.S. are in Table 7. A comparison of the values from Table 6 and Table 7 showed that the most apparent difference between the two countries' values was the number of pages in the text, which in turn made the number of pages for the other features different between the two countries' textbooks. The other apparent differences shown in the two tables are the number of object analytic images and number of object illustrative images. These differences are indicated more clearly in the averages of the textbooks from each country in Table 8 . The average values for the features were used in the statistical testing used for the comparison of the data.

Table 5

Number of Problems in each Text

\begin{tabular}{lc}
\hline Textbook & Number of Problems \\
\hline Singapore & 175 \\
Discovering Math 1 & 85 \\
Discovering Math 2 & 162 \\
Math Matters 1 & 0 \\
Math Matters 2 & 192 \\
New Syllabus 1 & 210 \\
New Syllabus 2 & \\
United States & 297 \\
McDougal Math 1 & 481 \\
McDougal Math 2 & 1058 \\
McDougal Algebra 1 & 357 \\
Glencoe Math Connects 1 & 395 \\
Glencoe Math Connects 2 & 498 \\
Glencoe Math Connects 3 & 0 \\
Pearson Connected Math 1 & 481 \\
Pearson Connected Math 2 & 234 \\
Pearson Connected Math 3 & \\
\hline
\end{tabular}

For the statistical testing for the general features, Welch's $t$-test was used to compare the values for each of the general features obtained from the Singapore textbooks to the values for the corresponding general features obtained from the U.S. The 
null hypothesis for each feature was that the two sample means were equal. The alternate hypothesis was that the sample means were different, that is, that the textbooks from the two countries were different in regard to that feature. Welch's $t$-test was used because the two samples, that is, the values obtained from the two countries' textbooks, had different numbers of values, six for Singapore and nine for U.S., and the samples were assumed to have unequal variances. The two sets of values obtained from the two countries' sets of textbooks were used to find Welch's $t$ statistic.

Table 6

Singapore Numbers for General Features

\begin{tabular}{lrrrrrr}
\hline Feature & DM1 $^{\text {a }}$ & DM2 & MM1 & MM2 & NS1 & NS2 \\
\hline Number of & & & & & & \\
$\quad$ Pages in Text & 428 & 382 & 417 & 311 & 420 & 399 \\
Chapters & 16 & 11 & 12 & 12 & 16 & 12 \\
Sections & 61 & 57 & 58 & 37 & 126 & 73 \\
$\quad$ Linear Sections & 7 & 3 & 11 & 0 & 14 & 12 \\
$\quad$ Pages for & & & & & & \\
$\quad$ Linear Functions & 41 & 20 & 46.5 & 0 & 46.5 & 54 \\
$\quad$ Development & 22.75 & 13.5 & 34.25 & 0 & 32 & 37.25 \\
$\quad$ Exercises & 11.75 & 5.5 & 11.75 & 0 & 12 & 15.75 \\
$\quad$ Other & 6.5 & 3.25 & .5 & 0 & 2.5 & 1 \\
Linear Problems & 175 & 85 & 162 & 0 & 192 & 210 \\
Avg. pages/section & 6.04 & 3.33 & 4.23 & 0 & 3.32 & 4.5 \\
Images: Object & & & & & & \\
$\quad$ Analytic & 8 & 1 & 7 & 0 & 2 & 2 \\
$\quad$ Illustrative & 8 & 2 & 7 & 0 & 2 & 2 \\
Signposts & 15 & 2 & 16 & 0 & 2 & 4 \\
\hline
\end{tabular}

${ }^{a}$ Key for abbreviations: DM1: Discovering Mathematics 1, DM2: Discovering Mathematics 2, MM1: Mathematics Matters 1, MM2: Mathematics Matters2, NS1: New Syllabus Mathematics 1, NS2: New Syllabus Mathematics 2 textbooks.

An Excel program was used to compute the values for $t, v$, and to run the twotailed $t$-tests for the collected data. Probability values of 0.05 or less for the test indicated a significant difference between the two sets. Thus, the null hypothesis that the textbooks 
Table 7

United States Numbers for General Features

\begin{tabular}{|c|c|c|c|c|c|c|c|c|c|}
\hline Feature & $\mathrm{ML1}^{\mathrm{a}}$ & ML2 & HMA & GM1 & GM2 & GM3 & PM1 & PM2 & PM3 \\
\hline \multicolumn{10}{|l|}{ Number of } \\
\hline Pages in Text & 759 & 757 & 798 & 753 & 827 & 605 & 603 & 658 & 679 \\
\hline $\begin{array}{c}\text { Chapters } \\
8\end{array}$ & 13 & 13 & 12 & 13 & 14 & 13 & 8 & 8 & \\
\hline Sections & 99 & 98 & 92 & 155 & 158 & 128 & 125 & 118 & 120 \\
\hline Linear Sections & 7 & 8 & 21 & 18 & 22 & 18 & 0 & 17 & 8 \\
\hline \multicolumn{10}{|l|}{ Pages for } \\
\hline Linear Functions & 50 & 62 & 180 & 85 & 95 & 110 & 0 & 96 & 46 \\
\hline Development & 24 & 30 & 98 & 46.75 & 53.75 & 58 & 0 & 47 & 10.75 \\
\hline Exercises & 26 & 32 & 79 & 37.25 & 41.25 & 52 & 0 & 48 & 28.5 \\
\hline Other & 0 & 0 & 3 & 1 & 0 & 0 & 0 & 1 & 6.75 \\
\hline Linear Problems & 297 & 403 & 1058 & 357 & 395 & 498 & 0 & 481 & 234 \\
\hline Avg. pages/section & 7.14 & 7.75 & 8.57 & 4.72 & 4.32 & 6.11 & 0 & 5.65 & 5.75 \\
\hline \multicolumn{10}{|l|}{ Images: Object } \\
\hline Analytic & 9 & 8 & 24 & 23 & 23 & 17 & 0 & 9 & 0 \\
\hline Illustrative & 19 & 21 & 55 & 36 & 25 & 31 & 0 & 46 & 21 \\
\hline Signposts & 12 & 14 & 40 & 12 & 10 & 16 & 0 & 11 & 0 \\
\hline
\end{tabular}

${ }^{a}$ Key for abbreviations: ML1: McDougal Little Math Course 1, ML2: McDougal Little Math Course 2, HMA: Holt McDougal Algebra 1, GM1: Glencoe Math Connects 1, GM2: Glencoe Math Connects 2, GM3: Glencoe Math Connects 3, PM1: Pearson Connected Math 1, PM2: Pearson Connected Math 2, PM3: Pearson Connected Math 3 
Table 8

\begin{tabular}{lcc}
\multicolumn{3}{l}{ Average Values for General Features from Each Country } \\
\hline Feature & Singapore & United States \\
\hline Number of & 392.8 & 715.44 \\
Pages in Text & 13.17 & 11.33 \\
Chapters & 68.67 & 121.44 \\
Sections & 7.83 & 13.22 \\
Linear Sections & & \\
Pages for & 34.67 & 80.44 \\
Linear Functions & 23.29 & 40.92 \\
Development & 9.46 & 38.22 \\
Exercises & 2.29 & 1.31 \\
Other & 137.33 & 413.67 \\
Linear Problems & 3.57 & 5.56 \\
Avg. pages/section & & \\
Images: Object & 3.33 & 12.56 \\
Analytic & 3.50 & 28.22 \\
Illustrative & 6.50 & 12.78 \\
Signposts &
\end{tabular}

from the two countries are the same for that feature was rejected for $p<0.05$. See Table

9. There were seven features that had probability values that were significant at the $5 \%$ level which indicated that the Null Hypothesis should be rejected. Thus, there were seven general features in which the countries' textbooks differed. These features were (a) number of pages in text, (b) number of sections, (c) number of pages for linear functions, (d) Number of pages for exercises, (e) Number of linear function problems, (f) number of object illustrative images, and (g) number of object analytic images.

\section{Problem Features}

For the nine features for the problems which required a choice of code, the researcher performed Welch's $t$-tests to compare the textbooks with respect to the codes for each feature. The Null hypothesis for each code was that the means for the sample sets were equal. The alternative hypothesis was that the means for the two sample sets 
Table 9

Welch's t-test Numbers for General Features

\begin{tabular}{|c|c|c|c|c|c|c|c|c|}
\hline \multirow[b]{2}{*}{ Feature } & \multicolumn{2}{|c|}{ Singapore } & \multicolumn{2}{|c|}{ United States } & \multirow[b]{2}{*}{$t$} & \multirow[b]{2}{*}{$d f$} & \multirow[b]{2}{*}{$p$} & \multirow[b]{2}{*}{ Decision } \\
\hline & $M$ & $S D$ & $M$ & $S D$ & & & & \\
\hline \multicolumn{9}{|l|}{ Number of } \\
\hline Pages in Text & 392.83 & 43.38 & 715.44 & 81.98 & -9.91 & 13 & $0000^{*}$ & Reject \\
\hline Chapters & 13.17 & 2.23 & 11.33 & 2.55 & 1.47 & 12 & 0.167 & Do not Reject \\
\hline Sections & 68.67 & 30.39 & 121.44 & 23.59 & -3.59 & 9 & $0.006^{*}$ & Reject \\
\hline Linear Sections & 7.83 & 5.49 & 13.22 & 7.63 & -1.59 & 13 & 0.136 & Do not Reject \\
\hline \multicolumn{9}{|l|}{ Pages for } \\
\hline Linear Functions & 34.67 & 20.55 & 80.44 & 50.23 & -2.44 & 11 & $0.032^{*}$ & Reject \\
\hline Development & 23.29 & 14.35 & 40.92 & 29.10 & -1.56 & 12 & 0.145 & Do not reject \\
\hline Exercises & 9.46 & 5.69 & 38.22 & 21.51 & -3.82 & 10 & $0.004^{*}$ & Reject \\
\hline Other & 2.29 & 2.40 & 1.31 & 2.27 & 0.80 & 10 & 0.443 & Do not Reject \\
\hline Linear Problems & 137.33 & 79.87 & 413.67 & 284.49 & -2.76 & 10 & $0.021^{*}$ & Reject \\
\hline Avg. pages/section & 3.57 & 2.01 & 5.56 & 2.50 & -1.70 & 12 & 0.114 & Do Not Reject \\
\hline \multicolumn{9}{|l|}{ Images: Object } \\
\hline Analytic & 3.33 & 3.33 & 12.56 & 9.55 & -2.66 & 11 & $.023^{*}$ & Reject \\
\hline Illustrative & 13.50 & 3.21 & 28.22 & 16.19 & -4.45 & 9 & $.002^{*}$ & Reject \\
\hline Signposts & 6.50 & 17.09 & 12.78 & 11.68 & -1.29 & 13 & .218 & Do not reject \\
\hline
\end{tabular}

*Significant when $p<0.05$

Note: $M=$ Mean, $S D=$ Standard Deviation 
were different. Using a significance level of 5\%, the researcher found that out of the 50 codes for the nine features, there were eight codes different with respect to the percentage of problems containing those codes within the two countries' sets of textbooks. These included (a) "single" computation, (b) "multiple" response type, (c) "other" response type, (d) "other" problem practice, (e) "interpreting" problem solving competency type, (f) "does not apply" problem solving competency type, (g) "multiple" transfer type, and (h) "does not apply" transfer type. See Table 10 for a complete listing of the values obtained in the statistical testing. Thus, the researcher found the specific codes for the features which were represented differently in the two countries textbooks.

A chi-square test of independence was used to determine if the choice of code for a feature was independent of the countries' textbooks. For each feature, the Null hypothesis was that the choice of codes for that feature was independent of the country from which the textbooks came. The alternative hypothesis was that the two variables, "codes chosen for that feature" and "country", were related (not independent). There were nine chi square tests that were done, one for each feature. The Null hypothesis was rejected when the calculated probability was less than 0.05 . For all nine chi square tests, the probabilities were less than 0.05 , and the Null hypotheses were rejected. The values associated with these nine tests are found in Table 11. These results indicated that the selection of codes for each of the nine features was dependent upon the country from which the textbook came. Thus, the textbooks from Singapore and the U.S. were seen to be different with respect to the problems. These results suggested that the differences found among the specific codes in Table 11, showed how the countries' textbooks were indeed different with regard to specific codes. A discussion of these results in Chapter 5 
Table 10

Welch's t-test Values for Codes of Problem Features

\begin{tabular}{|c|c|c|c|c|c|c|c|c|}
\hline \multirow[b]{2}{*}{ Feature } & \multicolumn{2}{|c|}{ Singapore } & \multicolumn{6}{|c|}{ United States } \\
\hline & $M$ & $\overline{S D}$ & $M$ & $S D$ & $t$ & $d f$ & $p$ & Decision \\
\hline \multicolumn{9}{|l|}{ Computational } \\
\hline Single & 0.046 & 0.032 & 0.256 & 0.193 & -3.19 & 9 & $0.012^{*}$ & Reject \\
\hline Multiple & 0.493 & 0.267 & 0.337 & 0.170 & 1.27 & 8 & 0.241 & Do Not Reject \\
\hline Other & 0.294 & 0.193 & 0.296 & 0.136 & -0.02 & 8 & 0.985 & Do Not Reject \\
\hline \multicolumn{9}{|l|}{ Contextual } \\
\hline Numerical & 0.245 & 0.186 & 0.200 & 0.134 & 0.51 & 8 & 0.626 & Do Not Reject \\
\hline Visual & 0.012 & 0.024 & 0.005 & 0.008 & 0.61 & 6 & 0.564 & Do Not Reject \\
\hline Verbal & 0.167 & 0.112 & 0.207 & 0.112 & -0.68 & 11 & 0.509 & Do Not Reject \\
\hline Combined & 0.410 & 0.264 & 0.473 & 0.245 & -0.47 & 10 & 0.651 & Do Not reject \\
\hline Other & 0.000 & 0.000 & 0.003 & 0.009 & -1.00 & 8 & 0.347 & Do Not Reject \\
\hline \multicolumn{9}{|l|}{ Response-Type } \\
\hline Numeric Answer & 0.463 & 0.272 & 0.323 & 0.156 & 1.14 & 7 & 0.289 & Do Not Reject \\
\hline Numeric Expression & 0.110 & 0.113 & 0.111 & 0.084 & -0.02 & 9 & 0.988 & Do Not Reject \\
\hline Explanation/Solution & 0.018 & 0.027 & 0.054 & 0.044 & -1.97 & 13 & 0.070 & Do Not Reject \\
\hline Graph Only & 0.121 & 0.110 & 0.041 & 0.019 & 1.76 & 5 & 0.136 & Do Not Reject \\
\hline Multiple Response & 0.062 & 0.058 & 0.196 & 0.090 & -3.49 & 13 & $0.004^{*}$ & Reject \\
\hline Other Response & 0.059 & 0.083 & 0.163 & 0.074 & -2.50 & 10 & $0.032^{*}$ & Reject \\
\hline \multicolumn{9}{|l|}{ Cognitive Requirement } \\
\hline Procedural Practice & 0.513 & 0.254 & 0.449 & 0.197 & 0.52 & 9 & 0.614 & Do Not Reject \\
\hline Conceptual & 0.206 & 0.105 & 0.272 & 0.128 & -1.08 & 12 & 0.300 & Do Not Reject \\
\hline Problem Solving & 0.084 & 0.061 & 0.131 & 0.079 & -1.31 & 13 & 0.213 & Do Not Reject \\
\hline Special Requirement & 0.000 & 0.000 & 0.003 & 0.004 & -2.11 & 8 & 0.068 & Do Not Reject \\
\hline Other & 0.030 & 0.045 & 0.0 .034 & 0.035 & -0.18 & 9 & 0.864 & Do Not Reject \\
\hline \multicolumn{9}{|l|}{ Given Information } \\
\hline Sufficient & 0.828 & 0.406 & 0.884 & 0.332 & -0.28 & 9 & 0.783 & Do Not Reject \\
\hline
\end{tabular}


Welch's t-test Values for Codes of Problem Features

\begin{tabular}{|c|c|c|c|c|c|c|c|c|}
\hline \multirow[b]{2}{*}{ Feature } & \multicolumn{2}{|c|}{ Singapore } & \multicolumn{6}{|c|}{ United States } \\
\hline & $M$ & $S D$ & $M$ & $S D$ & $t$ & $d f$ & $p$ & Decision \\
\hline Extraneous & 0.000 & 0.000 & 0.001 & 0.001 & -1.50 & 8 & 0.171 & Do Not Reject \\
\hline Insufficient & 0.006 & 0.010 & 0.004 & 0.013 & 0.26 & 13 & 0.800 & Do Not Reject \\
\hline \multicolumn{9}{|l|}{ Application Type } \\
\hline Applied & 0.223 & 0.122 & 0.294 & 0.156 & -0.99 & 13 & 0.343 & Do Not Reject \\
\hline Non Applied & 0.610 & 0.304 & 0.595 & 0.249 & 0.10 & 9 & 0.919 & Do Not Reject \\
\hline \multicolumn{9}{|l|}{ Problem Practices } \\
\hline Symbolic Rule & 0.471 & 0.240 & 0.441 & 0.174 & 0.27 & 8 & 0.793 & Do Not Reject \\
\hline Ordered Pair & 0.116 & 0.105 & 0.079 & 0.042 & 0.80 & 6 & 0.451 & Do Not Reject \\
\hline Social Data & 0.167 & 0.096 & 0.188 & 0.097 & -0.40 & 11 & 0.695 & Do Not Reject \\
\hline Physical Phenomena & 0.000 & 0.000 & 0.001 & 0.003 & -1.54 & 8 & 0.161 & Do Not Reject \\
\hline Controlling Image & 0.069 & 0.056 & 0.090 & 0.060 & -0.69 & 11 & 0.506 & Do Not Reject \\
\hline Other & 0.010 & 0.018 & 0.090 & 0.068 & -3.35 & 10 & $0.008^{*}$ & Reject \\
\hline \multicolumn{9}{|l|}{ Problem-Solving } \\
\hline Modeling & 0.165 & 0.096 & 0.184 & 0.092 & -0.38 & 11 & 0.712 & Do Not Reject \\
\hline Interpreting & 0.003 & .005 & 0.037 & 0.030 & -3.29 & 9 & $0.010^{*}$ & Reject \\
\hline Translating & 0.606 & 0.308 & 0.493 & 0.204 & 0.79 & 8 & 0.451 & Do Not Reject \\
\hline Reifying & 0.025 & 0.062 & 0.018 & 0.020 & 0.27 & 6 & 0.795 & Do Not Reject \\
\hline Does Not Apply & 0.034 & 0.065 & 0.157 & 0.078 & -3.30 & 12 & $0.006^{*}$ & Reject \\
\hline \multicolumn{9}{|l|}{ Transfer Type } \\
\hline Algebraic to Numeric & 0.325 & 0.206 & 0.271 & 0.133 & 0.57 & 8 & 0.586 & Do Not Reject \\
\hline Algebraic to Verbal & 0.012 & 0.029 & 0.023 & 0.020 & -0.83 & 8 & 0.429 & Do Not Reject \\
\hline Algebraic to Graphical & 0.083 & 0.087 & 0.028 & 0.018 & 1.50 & 5 & 0.192 & Do Not Reject \\
\hline Numeric to Algebraic & 0.020 & 0.032 & 0.026 & 0.027 & -0.40 & 10 & 0.697 & Do Not Reject \\
\hline Numeric to Verbal & 0.002 & 0.005 & 0.004 & 0.006 & -0.88 & 13 & 0.396 & Do Not Reject \\
\hline
\end{tabular}


Table $10 \quad$ (Continued)

Welch's t-test Values for Codes of Problem Features

\begin{tabular}{|c|c|c|c|c|c|c|c|c|}
\hline \multirow[b]{2}{*}{ Feature } & \multicolumn{2}{|c|}{ Singapore } & \multicolumn{2}{|c|}{ United States } & \multirow[b]{2}{*}{$t$} & \multirow[b]{2}{*}{$d f$} & \multirow[b]{2}{*}{$p$} & \multirow[b]{2}{*}{ Decision } \\
\hline & $M$ & $S D$ & $M$ & $S D$ & & & & \\
\hline Numeric to Graphical & 0.042 & 0.032 & 0.021 & 0.010 & 1.62 & 6 & 0.159 & Do Not Reject \\
\hline Numeric to Numeric & 0.024 & 0.033 & 0.020 & 0.021 & 0.21 & 8 & 0.842 & Do Not Reject \\
\hline Graphical to Algebraic & 0.013 & 0.028 & 0.020 & 0.026 & -0.49 & 10 & 0.633 & Do Not Reject \\
\hline Graphical to Numeric & 0.037 & 0.033 & 0.032 & 0.025 & 0.33 & 9 & 0.747 & Do Not Reject \\
\hline Graphical to Verbal & 0.009 & 0.014 & 0.011 & 0.011 & -0.30 & 9 & 0.771 & Do Not Reject \\
\hline Verbal to Algebraic & 0.051 & 0.065 & 0.067 & 0.049 & -0.53 & 9 & 0.611 & Do Not Reject \\
\hline Verbal to Numeric & 0.099 & 0.064 & 0.051 & 0.031 & 1.70 & 7 & 0.135 & Do Not Reject \\
\hline Verbal to Graphical & 0.023 & 0.041 & 0.004 & 0.005 & 1.07 & 5 & 0.333 & Do Not Reject \\
\hline Multiple Transfer Types & 0.034 & 0.037 & 0.133 & 0.073 & -3.47 & 12 & $0.004^{*}$ & Reject \\
\hline Does Not Apply & 0.060 & 0.078 & 0.175 & 0.096 & -2.55 & 12 & $0.025^{*}$ & Reject \\
\hline
\end{tabular}

*Significant when $p<0.05$

Note: $M=$ Mean, $S D=$ Standard Deviation 
Table 11

Values for $\chi^{2}$ Test of Independence for Problem Features

\begin{tabular}{|c|c|c|c|c|c|c|}
\hline Feature & $\frac{\text { Singapore }}{n}$ & $\frac{\text { United States }}{n}$ & $\chi^{2}$ & $d f$ & $p$ & Decision \\
\hline Computational & 824 & 3723 & 199.38 & 2 & $0.000^{*}$ & Reject \\
\hline Single & 50 & 991 & & & & \\
\hline Multiple & 504 & 1463 & & & & \\
\hline Other & 270 & 1269 & & & & \\
\hline Contextual & & & 43.21 & 4 & $0.000 *$ & Reject \\
\hline Numerical & 264 & 821 & & & & \\
\hline Visual & 7 & 21 & & & & \\
\hline Verbal & 179 & 815 & & & & \\
\hline Combined & 374 & 2058 & & & & \\
\hline Other & 0 & 8 & & & & \\
\hline Response Type & & & 953.71 & 5 & $0.000 *$ & Reject \\
\hline Numeric Answer & 477 & 1355 & & & & \\
\hline Numeric Expression & 116 & 509 & & & & \\
\hline Explanation/Solution & 17 & 202 & & & & \\
\hline Graph Only & 104 & 182 & & & & \\
\hline Multiple Response & 68 & 765 & & & & \\
\hline Other Response & 0 & 8 & & & & \\
\hline Cognitive Requirement & & & 15.19 & 4 & $0.006^{*}$ & Reject \\
\hline Procedural Practice & 502 & 2019 & & & & \\
\hline Conceptual & 204 & 1070 & & & & \\
\hline Problem Solving & 90 & 499 & & & & \\
\hline Special Requirement & 0 & 9 & & & & \\
\hline Other & 28 & 126 & & & & \\
\hline Given Information & & & 3.37 & 2 & $0.186^{*}$ & Reject \\
\hline Sufficient & 819 & 3712 & & & & \\
\hline
\end{tabular}

(Continued) 
Table $11 \quad$ (Continued)

Values for $\chi^{2}$ Test of Independence for Problem Features

\begin{tabular}{|c|c|c|c|c|c|c|}
\hline Feature & $\frac{\text { Singapore }}{n}$ & $\frac{\text { United States }}{n}$ & $\chi^{2}$ & $d f$ & $p$ & Decision \\
\hline Extraneous & 0 & 2 & & & & \\
\hline Insufficient & 5 & 9 & & & & \\
\hline Application Type & & & 4.48 & 1 & $0.034 *$ & Reject \\
\hline Applied & 216 & 1114 & & & & \\
\hline Non Applied & 608 & 2609 & & & & \\
\hline Problem Practices & & & 95.34 & 4 & $0.000 *$ & Reject \\
\hline Symbolic Rule & 476 & 1858 & & & & \\
\hline Ordered Pair & 99 & 322 & & & & \\
\hline Social Data & 171 & 713 & & & & \\
\hline Physical Phenomena & 0 & 5 & & & & \\
\hline Controlling Image & 69 & 419 & & & & \\
\hline Other & 9 & 406 & & & & \\
\hline Problem-Solving & & & 132.14 & 4 & $0.000^{*}$ & Reject \\
\hline Modeling & 169 & 694 & & & & \\
\hline Interpreting & 3 & 134 & & & & \\
\hline Translating & 586 & 2152 & & & & \\
\hline Reifying & 32 & 86 & & & & \\
\hline Does Not Apply & 34 & 657 & & & & \\
\hline Transfer Type & & 0.133 & 254.57 & 14 & $0.000 *$ & Reject \\
\hline Algebraic to Numeric & 338 & 1136 & & & & \\
\hline Algebraic to Verbal & 6 & 82 & & & & \\
\hline Algebraic to Graphical & 66 & 140 & & & & \\
\hline Numeric to Algebraic & 19 & 152 & & & & \\
\hline Numeric to Verbal & 2 & 15 & & & & \\
\hline Numeric to Graphical & 39 & 81 & & & & \\
\hline
\end{tabular}

(Continued) 
Table $11 \quad$ (Continued)

Values for $\chi^{2}$ Test of Independence for Problem Features

\begin{tabular}{|c|c|c|c|c|c|c|}
\hline Feature & $\frac{\text { Singapore }}{n}$ & $\frac{\text { United States }}{n}$ & $\chi^{2}$ & $d f$ & $p$ & Decision \\
\hline Numeric to Numeric & 22 & 92 & & & & \\
\hline Graphical to Algebraic & 8 & 126 & & & & \\
\hline Graphical to Numeric & 40 & 143 & & & & \\
\hline Graphical to Verbal & 8 & 46 & & & & \\
\hline Verbal to Algebraic & 55 & 253 & & & & \\
\hline Verbal to Numeric & 102 & 201 & & & & \\
\hline Verbal to Graphical & 14 & 19 & & & & \\
\hline Multiple Transfer Types & 38 & 499 & & & & \\
\hline Does Not Apply & 67 & 738 & & & & \\
\hline
\end{tabular}

*Significant when $p<0.05$.

Note: $N=4547$, For Singapore, $n=824$, for U.S. $n=3723$. 
will further clarify concrete ways in which the countries' textbooks appear to differ, as well as distinguishing ways they are similar. The researcher will also discuss how the results relate to the six research questions on which the study was based. 


\section{CHAPTER V}

\section{DISCUSSION}

In this study, the researcher compared treatments of the topic of linear functions in Singapore and U.S middle grades mathematics textbooks. Specifically the researcher addressed the following research questions:

1. How do the treatments of the topic of linear functions in middle grades mathematics textbooks of Singapore compare to the treatments of the topic of linear functions in middle grades mathematics textbooks of the U.S.?

Treatments of the topic refer to the ways linear functions are presented in general in the text and how the topic is represented in the problems of the text particularly with regard to the 22 features the researcher examined.

2. What are the similarities and differences of the conceptual types of problems related to the topic of linear functions within the middle grades mathematics textbooks of Singapore and the U. S.?

3. How are problems related to linear functions in middle grades mathematics textbooks of Singapore and the U.S. different or similar with respect to computational requirement, context, required response, cognitive requirement, and given information?

4. Are the characterizations of problem practices as seen in the problems related to linear functions in middle grades mathematics textbooks from Singapore and from the U.S. the same or different?

5. How do the problem-solving competency types in the problems related to linear 
functions in middle grades mathematics textbooks from Singapore and from the U.S. compare?

6. How do the types of transfer of representation needed to do the problems pertaining to linear functions in middle grades mathematics textbooks from Singapore compare to the types of transfer of representation needed to do the problems pertaining to linear functions in middle grades mathematics textbooks from the U.S.?

In this chapter, the discussion has two parts: (a) examining the general features of the textbook and (b) examining the general features of problems and the specific characterizations of problem features. The researcher has included possible reasons for findings within these sections before addressing (a) areas of future research, (b) significance of the study, (c) implications for practice, and (d) limitations of the study.

\section{Research Questions}

The first research question was a general question concerning the entire study and focused on both general features of the textbooks and also on features pertaining to the problems in the textbooks of the two countries. Research questions 2 through 6 focused specifically on the features pertaining to the linear functions problems in the textbooks. Thus, the researcher chose to divide the discussion of the research questions up into two parts, an examination of the general features of the textbook and then an examination of the features pertaining to problems.

\section{Examination of General Features}

To address research question 1 with respect to the general features of the textbook, the researcher used Welch's $t$-test for the 13 general features. The Welch's $t$ - 
tests conducted on the general features showed that the two countries' textbooks were different with respect to seven general aspects of the text and were not significantly different with respect to six features of the text. A compilation of the general features that were significantly different versus not significantly different, according to Welch's $t$ tests, showed the general trends in the two countries' textbooks. See Figure 6. The greater number of pages, of problems, and of images in the U.S. textbooks coincided with what has been noted in research about primary textbooks from Singapore and the U.S. (Ginsburg et al., 2005). While the number of pages in the two countries' textbooks was different, the number of chapters in the two countries' textbooks was similar. Thus, chapters were longer in the U.S. textbooks compared to Singapore textbooks. Also, while the number of sections was different in the two countries' textbooks, the number of sections pertaining to linear functions was not significantly different. However, the number of pages pertaining to linear functions was significantly different between the two countries' textbooks with the U.S. textbooks averaging over twice the Singapore average, 80.44 pages versus 34.67 pages respectively.

\begin{tabular}{ll} 
Similar & Different \\
\hline Number of Chapters & Number of Pages in Text \\
Number of Linear Function Sections & Number of Sections \\
Number of Pages for Development & Number of Pages for Linear Functions \\
Number of Other Pages & Number of Pages for Exercises \\
Average Pages per Section & Number of Linear Function Problems \\
Number of Signposts & Number of Object Analytic Images \\
& Number of Object Analytic Images \\
\hline
\end{tabular}

Figure 6. Similarities and Differences of General Features of Textbooks.

An examination of the breakdown of number of pages for linear functions into "development", "exercises", and "other" pages, revealed that the U.S. and Singapore 
textbooks had similar numbers of pages for "development" and for "other" but differed significantly in regard to the number of pages for exercises. The U.S. average for number of pages for exercises in the linear functions sections was over 4 times greater than the Singapore average, 38.22 versus 9.46 , respectively. When calculating the percentage of exercise pages in the textbooks using the average of the number of exercise pages divided by the average of the number of pages in the text, Singapore textbook averages yielded $2.4 \%$ of the pages for exercises while the U.S. textbook averages yielded $5.3 \%$ of the pages were for exercises. The fact that U.S. textbooks had a greater number of pages for exercises corresponds to the fact that there were a greater number of exercises in U.S. textbooks.

The greater number of exercises in the U.S. textbooks may be partly explained by the type of student being taught. In Singapore, the students come with a known skill set established by a national curriculum and high stakes testing, which ensure that students know prerequisite information (Soh, 2008). The U.S. has had state established curricula that have been documented as being quite different between states (Reys, Dingman, Nevel, \& Teuscher, 2007). Thus, U.S. students in the same grade level may not have the same curriculum as other students from different states. Having different state curricula affects the exercises contained in the textbook as publishing companies cater to the widest market available and include problems for the standards from many states (Seeley, 2003). Thus, the researcher suggests that this has the two-pronged effect of increasing the number of problems in the textbook and causing repetition of similar problems in different sections. 
An additional reason for the difference in the number of exercises in the countries' textbooks may be due to Singapore's reduction in content that has been developed over years of examining the scope and sequence of the mathematics curriculum in an effort to ensure that students learn the concepts well and are prepared for future learning (Soh, 2008). The carefully planned Singapore curriculum also has a built-in spiral approach that calls for a revisiting of material but only at a deeper level. This reduces the number of exercises that a textbook contains because the publisher does not feel pressure to include all concepts every time the topic is presented.

An examination of the U.S. textbooks shows that this is not the case for the U.S. Comparing the $6^{\text {th }}$ grade and $7^{\text {th }}$ grade textbooks shows that there are problems which cover the very same material in both years. A very clear example of this overlap in material is seen in Glencoe's Math Connects Course 1 and Course 2 textbooks for sixth and seventh grades. There is a chapter where the section headings are almost the same, and the problems are very similar within these sections. See Table 12 for an example. There is little spiral approach and little discernable difference between some of the topics covered in the two grades. Thus, differences in the scope and sequence of the countries' mathematics curricula seem to be one cause of differences in the textbooks. In 2001, Schmidt et al. described the U.S. mathematics curricula as being "a mile wide and an inch deep" (p. 301) and noted the repetitiveness of the content covered. Although changes have been made to state curricula as a direct result of this description (Teuscher \& Reyes, 2010) and there is an awareness of the problem (National Governors Association Center for Best Practices, 2010), more needs to be done to address this issue. 
Table 12

Overlap in Glencoe Math Connects Textbooks

Feature Course 1 (Sixth Grade) Course 2 (Seventh Grade)

$\begin{array}{lll}\text { Chapter } & \text { 7 Solve Equations } & \text { 3 Linear Equations } \\ \text { Section } & \text { Addition and Subtraction Equations } & \text { Addition and Subtraction Equations } \\ \text { Problem } & \begin{array}{l}\text { 5. Number Sense: A number is } \\ \text { multiplied by 4, and then } 6 \text { is }\end{array} & \begin{array}{l}\text { 5. Number Theory: A number is } \\ \text { multiplied by }-3 \text {. Then } 6 \text { is } \\ \text { added to the product. The }\end{array} \\ \begin{array}{l}\text { result is } 18 . \text { What is the } \\ \text { number? }\end{array} & \begin{array}{l}\text { adding }-7, \text { the result is }-25 . \text { What } \\ \text { is the number? }\end{array}\end{array}$

Until some policy is in place to ensure that all students are taught the same content in the same year, U.S. students will continue to have the different levels of preparedness (Reys, 2014; Reys, Dingman, Nevel, \& Teuscher, 2007). In 2009, the U.S. began the process of establishing a voluntary national curriculum known as the Common Core State Standards for Mathematics. The task of changing the 50 individual state curricula and creating one national curriculum is in the beginning stages. The number of states that have adopted the Common Core has fallen from 45 states to 42 states (Standards in Your State, 2015) within the past year. Several states have legislation pending regarding repealing or delaying the Common Core and/or the testing associated with the Common Core (Bidwell, 2014). The curriculum is so new that it is unclear what the effects will be on student learning.

The 2014-2015 school year is scheduled to be when assessments designed specifically for the Common Core will be used to make sure students are progressing 
appropriately (Frequently Asked Questions, 2015). The recent advent of the Common Core and the upcoming test scores present an opportune time for curriculum developers to make a concerted effort to follow Singapore's example. Curriculum developers and those who create curriculum materials should examine the scope and sequence of the mathematics curriculum meticulously to make sure it is doing what is expected, allowing teachers to teach and students to learn the concepts well.

Concerning the number of images, object analytic and object illustrative, Singapore textbooks had few images while the U.S. textbooks contained an abundance of images. Many pages in the U.S. textbooks seemed to be full not just of images but of text and patterns. Singapore textbooks, on the other hand, had pages which contained a lot of blank space. This openness and simplicity seemed to increase the readability of the Singapore textbooks. One could describe the two presentations of images as orderly and bare for Singapore versus full and busy for the U.S. See Appendix H for a sample textbook page from each country. A future study would be to measure and compare the amount of space covered by images and text in each textbook.

The difference that was seen in the number of images in the textbook may be rooted in sociocultural theory which has as its premise that all learning is affected by one's beliefs and values which come from the surrounding culture (Cherry, 2015). The number of images seen in the text may be due to differences in culture as described by Leung (2001) when he described the western countries' culture of "pleasurable learning" seen in the U.S. versus a culture of "hard work" seen in East Asian countries (p. 41). U.S. publishers and textbook authors seem to fill the book with something to entertain and get students interested in the subject while Singapore publishers and textbook authors seem 
to stick with an all-business, no frills approach. This could also be indicative of the difference noted between students' intrinsic motivation to learn mathematics in East Asian countries and students' extrinsic motivation to learn mathematics in the U.S. (Leung, 2001). Chen and Uttal (1988) also determined that Chinese students have "a belief system that focuses on internal goals" (p. 357) that has been passed down from their culture. This intrinsic motivation to learn is also seen in Singapore as $74 \%$ of the population is classified as Chinese (Department of Statistics Singapore, 2013). Thus, Singapore students seem to have an inner drive to learn mathematics while U.S. students seem to need an outward source to motivate them to learn. In an age where many students are often bombarded by an array of technological distractions, if one believes that students are mainly motivated to learn through external stimuli, then the textbook should look "busy" in an attempt to keep the student's attention. Of course, the next step would be an electronic form of the textbook, but that is beyond the scope of this discussion. Interestingly, both countries' textbooks contain similar numbers of signposts/attentiongetters such as caution or connection boxes. However, the signposts in the Singapore textbooks typically had a smaller font and were positioned so they did not detract from the main text.

\section{Examination of Problem Features}

To determine how the two countries' textbooks compared in regard to the nine problem features, chi-square tests for independence indicated that the choice of code for each problem feature was dependent upon the country of origin. Welch's $t$-tests revealed the individual codes for each feature that were significantly different within the two countries' textbooks. Interestingly, out of the 50 codes for the nine features, eight of them 
were found to be significantly different and 42 of them were found to be similar. See

Figure 7.

\begin{tabular}{ll} 
Problem Feature & Significantly Different Codes \\
\hline Computational & Single \\
Contextual & No Codes \\
Response-type & Multiple, Other \\
Cognitive Requirement & No Codes \\
Given Information & No Codes \\
Application-type & No Codes \\
Problem Practices & Other \\
Problem-solving Competency & Interpreting, Does Not Apply \\
Transfer Type & Multiple, Does Not Apply \\
\hline
\end{tabular}

Figure 7. Significantly Different Codes for Problem Features.

For research question 2, "What are the similarities and differences of the conceptual types of problems related to the topic of linear functions within the middle grades mathematics textbooks of Singapore and the U.S.?", the countries' textbooks initially looked as if they were very similar. The statistical testing showed that both countries had similar percentages of applied problems versus non-applied problems. Similarly with the Cognitive Requirement feature, the types of cognitive level required to do the problems was similar in both countries. However, for the Response-Type feature, the codes "Multiple Response" and "Other Response" were found to be different with the U.S. textbooks containing a higher percentage of these response types than the Singapore textbooks. The Problem Practices feature differed in the code "Other" with the U.S. textbooks containing more of this type of practice. For the Problem-Solving feature, the categories "Interpreting" and "Does Not Apply" were found to be different with the U.S. textbooks containing more problems with these features. The Transfer-type feature differed in the codes "Does Not Apply" and "Multiple" with the U.S. textbooks 
containing more of each of these codes. Thus, the two countries' textbooks did differ in some way with respect to the conceptual types of problems.

The textbooks differed in the way the problems directed students to demonstrate conceptual learning. The codes which were different for each of these categories mostly occurred when U.S. problems directed students to (a) define or explain a definition or rule, (b) state the name of the rule being used in the problem, or (c) create a problem that uses a particular concept. These problems were designed to make sure that students gained conceptual knowledge. When a problem has a code of "Multiple" response type or representation, these problems were also designed to make certain that students could make connections between multiple concepts in a problem. Singapore textbooks had very few of these problems. Thus, the textbooks differed in the way that students were asked to show they have conceptual understanding of the problem.

The lack of definition problems in Singapore textbooks may be influenced by sociocultural factors as seen by the difference in the importance given to rote learning by Eastern culture versus the importance given to "meaningful learning" (p. 39) by Western culture as presented by Leung (2001). This is also supported by the averages of the percentage of procedural practice problems and the conceptual understanding problems in the Cognitive Requirement feature. While not evidencing a significant difference, the procedural practice averages, 0.513 vs. 0.449 , and the conceptual understanding averages, 0.206 vs. 0.272 , for Singapore and the U.S. respectively, seem to hint at this tendency. The inter-play of the importance of memorization and of intrinsic motivation to learn and do well, which has been documented as a part of East Asian culture (Leung, 1995; Chen \& Uttal, 1988), may help explain why there are not as many definition problems in the 
Singapore textbooks. Singaporean students are assumed to learn definitions and rules without problems to help them do so. Another reason may be the differentiated mathematics curriculum by ability that Singapore has in place starting in primary 5 which may assume that students who want to advance will know the material adequately (Soh, 2008). Another reason for this difference may also stem from the carefully delineated curriculum that Singapore has in place which has been meticulously examined to reduce the number of problems and skills in the textbook (Soh, 2008). This would eliminate the need to repeat definitions as problems.

For research question 3, "How are problems related to linear functions in middle grades mathematics textbooks of Singapore and the U.S. different or similar with respect to computational requirement, context, required response, cognitive requirement, and given information?", the two countries' textbooks differed with respect to the Computational Requirement feature. The code "Single computations" was significantly different in the countries' sets of textbooks. U.S. textbooks contained a much higher percentage of problems requiring only a single computation to answer the question than the Singapore textbooks, an average percentage of $25.6 \%$ versus $4.6 \%$ respectively. The difference in number of single vs. multi-computation problems may affect results on international comparison assessments like the TIMSS. An examination of the released items from the TIMSS 2011 (Foy, Arora, \& Stanco, 2013) revealed that more than one computation is typically required to answer the problem. With fewer single computation problems, Singapore students are able to practice problems which are more similar to those seen on these assessments. 
There are a few reasons why U.S. textbooks contain more single computation problems. U.S. schools have students with a more varied knowledge base due to lack of conformity to the same curriculum (Reys et al. 2007; Seeley, 2003). Thus, one of the reasons why U.S. textbooks have more single computation problems may be to help students who are lacking in prior knowledge get caught up to other students. Another reason may well be due to Singapore's spiral approach which delineates the topics in the curriculum in such a way that repetitiveness is unnecessary. Singapore students only revisit a topic to go into further depth with the topic. This is not the case for U.S. textbooks. Glencoe's Florida Math Connects 1 and Glencoe's Florida Math Connects 2 has a chapter where the sections are called almost the same name. The intent seemed to be to revisit the old material with new terminology and a little more depth, but the attempt of the use of the spiral approach falls short. There was no evidence of a proper usage of the spiral approach in Ginsburg et al.'s (2005) examination of U.S. primary textbooks.

There were features relating to problems that were similar in the countries' textbooks. There were no codes that were different for the Contextual feature, so how the problem statement was presented in the text was similar in both countries. Similarly, for the Computational Requirement feature, the countries' textbooks had a similar proportion of problems that require no computations such as "graph the line". Also, the two countries' textbooks were similar in the information given in the problem with almost all of the problems containing sufficient information to do the problem. Thus, the textbooks were similar in regard to the general appearance of the problems. 
The discussion of the Required Response feature will now be done as a larger discussion of research questions 4-6 concerning the three classifications of problem practices. The differences that were seen in the two countries' textbooks concerning these four problem features all related to the same observances between the two countries' textbooks. Both the Required Response feature and the Problem Practices feature differed in the code "Other" between the two countries" textbooks. Also, the Problem-Solving Competency feature and the Transfer of Representation Type feature differed in the code "Does not apply". The codes "Other" and "Does not apply" occurred when U.S. textbook problems contained directions which indicated that students were to use a definition, state a rule, or create a problem in which the concept they were learning could be used. See Figure 8 for examples of these types of problems. The Singapore textbooks had very few problems that asked students to explain definitions, state which definition or theorem is being used, or create a problem which must be solved using the concept they were learning. This may well stem from the differences in the two countries' curriculum and in the attitudes concerning rote learning, memorization, and motivation as postulated previously within the discussion of Research Question 2. Another reason may be that Singapore teachers discuss these types of problem in the classroom.

Other

Write a real-world problem that could be represented by a relation.
Use Rule to Find the Error

Daniella is finding the output when the function rule is $10 \div x$ and the input is 2 . Find her mistake and correct it. $2 \div 10=0.2$

Figure 8. U.S. "Other" and "Does Not Apply" Problems. 
The Response type feature and the Transfer of representation feature also had the appearance of the code of "Multiple" being different in the countries' textbooks. In U.S. textbooks, students were asked for several different responses for one problem, while Singapore students were only asked for one response. The U.S. textbooks also directed students to perform multiple transfer of representation types in a single problem, while Singapore textbooks only required at most one transfer of representation type to obtain the answer. Many problems in the U.S. textbooks required students to do multiple things within one problem, so a question would require multiple response types and/or multiple transfer types in order for the student to answer the problem. Problems from the textbooks from Singapore, however, typically contained only one thing for students to do, and, usually, there was a whole set of problems where students were directed to find just this one thing. See Figure 9 for sample problems from each country.

\section{United States}

You spend 39 minutes walking and brushing your dog. Brushing takes 15 minutes. Write and solve an addition equation to find the number of minutes you spend walking your dog. Explain another method you could use to find your walking time. McDougal Littell Math Course 1

Figure 9. Response Type Sample Problems.

The U.S. seemed to emphasize making connections between different representations as this is deemed a necessary mathematics skill particularly by the NCTM (2000). The transfer of representation types is also established as a standard in eighth grade in the Common Core Mathematics States Standards (National Governors 
Association Center of Best Practices, 2010). U.S. textbooks had several questions which asked for several transfer of representation types in one problem. In Singapore, the problems seemed to be designed for students to concentrate on one objective at a time before moving on to a different representation type or different response type in a different problem. This may be directly related to the established sequence in the curriculum of Singapore designed to ensure that students learn the concepts well and are prepared for future learning (Soh, 2008). Having students, many of whom struggle with mathematics, focus on only one aspect of a problem at a time seems like a good approach to help students learn a topic well. Another reason for the lack of multiple response or transfer of representation types in Singapore textbooks may stem from differences in cognitive complexity or cognitive demand of the problem which this study did not specifically examine. The two examples in Figure 9 seem to indicate that there is a difference in cognitive complexity. Examining cognitive complexity within the exercises in Singapore versus U.S. textbooks would be an interesting future study.

An examination of the released test items from TIMSS-2011 (Foy, Arora, \& Stanco, 2013) revealed that the problems do require a transfer of representation type to get the answer as set forth as important by NCTM (2000) and CCMSS (National Governors Association Center of Best Practices, 2010). However, the questions are formatted in such a way that more closely aligns to the problems in the Singapore textbooks. There are no directions which guide the student in how to go about thinking through the problem. The directions are formatted as find $\mathrm{x}$, find area or similar wording. For example, when given a rectangle whose sides are labeled $\mathrm{x}$ and $\mathrm{x}+2$ respectively, the directions are, "What is the area of this rectangle?" (Foy, Arora, \& Stanco, 2013) Another 
example is as follows: "A piece of wood was $40 \mathrm{~cm}$ long. It was cut into 3 pieces. The lengths in $\mathrm{cm}$ are $2 x-5, x+7, x+6$. What is the length of the longest piece?" (Foy, Arora, \& Stanco, 2013). Thus, the problem directions in the Singapore texts may help prepare the students better for international assessments.

All forms of transfer of representation types as seen in the Concept Map from Figure 3 in Chapter 1 are contained in the U.S. problems. In Singapore, however, there is a dearth of transfer of representation problems going to the verbal representation. This difference is also seen in the Problem-solving Competency feature, as the two countries' textbooks were also found to be different with regard to the code "Interpreting". Interestingly, many of the problems from the U.S. required a student to interpret an answer into words, while very few problems within the Singapore textbooks had this requirement. This seemed to be a surprising revelation until one begins to consider that the careful planning of the curriculum in Singapore uses the spiral approach (Soh, 2008) that allows for students to master one aspect of a topic before revisiting the topic at greater depth in a future class. An examination of the Mathematics Syllabus in Singapore indeed showed that interpretation is covered in Secondary 3 and Secondary 4, that is, ninth and tenth grade (Ministry of Education Singapore, 2006b). Thus, the Singapore curriculum is designed for students to master solving equations and application problems before being introduced to the additional concept of interpreting what a numeric answer means in words. This delay in introducing every aspect of solving a word problem to the student may help some students who need to learn one aspect of solving the problem well before proceeding on to another aspect. 
Interestingly, an examination of the released items for the PISA-2012 showed that the PISA contains all four of the transfer of representation types which includes interpreting (OECD, 2013). This test is given to students who are 15 years old. Singapore's curriculum aligns with the timing of this international test.

While the discussion thus far has addressed mainly differences, the two countries' textbooks were similar in many respects. Both contained the typical problems that one would expect to see in a beginning algebra program: (a) solve the equation, (b) solve the application problem, (c) find the slope, (d) graph the line or point, (e) find the equation of the line, (f) evaluate $\mathrm{y}$ when given a $\mathrm{x}$, and many others. With respect to the problem features, of the 50 codes, 42 of them were similar. The main similarities in the problems were that the problems were similar in how they were presented in the text, the information contained in the problem, and the number of applied versus non-applied problems. The main differences seemed to be in the assessment of conceptual learning through the use of definitions, multiple representations, multiple response types, and interpreting problems and in the number of computations needed to solve the problem.

\section{Future Research}

This study revealed several areas for potential research. Broadly, these areas include (a) multiple response types, particularly in relation to cognitive complexity, (b) number of pages and problems, (c) spiral approach in U.S. textbooks, (d) meticulous examination of U.S. curricula and (e) measuring the amount of space or amount of images on a page.

The first area of study would be studies concerning multiple responses or representations versus single responses or representations in a problem. Does asking one 
question per problem affect student learning differently than asking more than one question per problem? One possible study would be to examine the cognitive complexity within the single- versus multi- response types. Is the single-response question more challenging than the multi-response question? Perhaps, asking students to do one thing per problem may be a useful technique to help students who are struggling in mathematics. Another interesting study would be to look at problems with regard to cognitive complexity without any connection to the computation requirement.

Another study would be try to determine why there is such a difference in the number of pages and the number of problems in the textbook between the two countries? Which problems and pages are actually assigned in the classroom? Are there more multiple computation problems assigned than single computation problems? The number of pages and problems in the U.S. textbook is much greater than the number of pages and problems in Singapore textbooks. A closer examination of Singapore's reduction in content that developed over years and the process of attaining the reduction as mentioned by Soh (2008) should be useful.

Another follow-up study to what has been seen in this study is a study concerning the spiral approach. Should the spiral approach be used in U.S. textbooks? At what level is the spiral approach already seen in U.S. textbooks? The spiral approach may be a useful way to eliminate repetitive problems in the U.S. mathematics curriculum. Does a spiral approach more similar to that used in Singapore produce higher student achievement in the US?

Another area of potential research involves studies which facilitate a meticulous examination of the developing U.S. mathematics curriculum, presumably the Common 
Core. The Common Core begins with stating that a focus of the document is to create a "greater focus and coherence" (National Governors Association Center for Best Practices, 2010, p. 3) in the U.S. mathematics curriculum. Further studies will continue the process of creating a well-delineated curriculum that allows teachers to teach each concept completely and with rigor and allows students to learn the concepts well and be prepared for future learning. Soh (2008) described such a task as a necessary process when Singapore changed its curriculum. Similarly, Usiskin (2014) recommended continued examination and revision of the Common Core mathematics curriculum. Within this examination should be attention to textbooks with respect to (a) number of pages and number of problems, (b) multiple tasks within one problem, and (c) the spiral approach.

The final area of potentially valuable research includes studies which measure the space on the page. Similar to past studies on primary textbooks from Singapore and the U.S. (Ginsburg et al., 2005), the current study found the number of images in middle school textbooks in the U.S. to be greater than the number of images in middle school textbooks from Singapore. The difference in appearance of the two countries' textbooks went beyond just the number of images in the text. U.S. textbooks were full of text, pictures, even colors and patterns while Singapore's textbooks were sparse with little extra text, pictures, and colors and patterns. A future study would be to measure and compare the amount of space covered by images and text in each textbook.

The idea of measuring the white space on a page or web page is known as measuring text density and is thought to affect search time of a webpage (Weller, 2004). Weller discusses the differences between overall density, "a percentage of the characters 
present in relation to overall space available" (p. 1), local density, "number of other characters in proximity to a character... a measure of how tightly packed the information is on the screen" (p. 1), and white space, "blank space on a screen that does not contain text” (p. 1) in her study on the effects of white space on visual search time.

The appearance of the textbooks examined in this dissertation along with the finding that the two countries' textbooks differ in the number of object-illustrative and object-analytic images lead the researcher to suggest that a study comparing the densities of the pages within the textbooks from Singapore and the U.S. would be worthwhile. The appearance of the page may affect readability of the text which in turn may affect comprehension of the concepts presented. Alacaci, Bulut and Erbaş (2012) classified text density as an examination of visual design and readability in their comparison of $6^{\text {th }}$ grade textbooks from Turkey, Singapore, and the U.S. However, no details were given in the article about how they measured this feature. If the empty space can be quantified and compared, this would be the first step in developing studies to determine if the amount of empty space on textbook pages affects student learning.

\section{Significance of Study}

The textual analysis was a comparison of the breadth and depth of the mathematics curriculum pertaining to linear functions as seen in the middle grades mathematics textbooks from Singapore and the U.S. The textbooks from the two countries were found to be similar in many aspects. One interesting similarity was that the problem statements, that is, the context of the problems, were similar in both countries' textbooks. However, the U.S. texts contained significantly more problems requiring (a) the use of a definition in some way, (b) a single computation, (c) 
interpreting, and (d) multiple responses or representations within one problem. The U.S. textbooks contained many more problems and pages than the Singapore textbooks. Knowing the similarities and differences in the two countries' textbooks will allow those involved with curriculum and educational materials to focus on these aspects and determine which features, if any, need to be changed to affect the content and sequence of the content in the textbooks. Additionally, knowing about the textbook features and these similarities and differences can inform individuals providing professional development to teachers to help U.S. teachers think more deeply about the problems they are selecting for their students to complete. The similarities and differences also provide avenues for further research toward improvement of U.S. student mathematics learning and achievement.

During the 2014-2015 school-year, assessments made specifically for the Common Core are scheduled to be used to check student progress (Frequently Asked Questions, 2015). The upcoming Common Core assessments present an opportune time for curriculum developers to make a concerted effort to examine textbooks to see if there are any features that may need to be altered. This would include checking for a possible reduction in number of problems. At the Annual Conference of the Association of Mathematics Teacher Educators in February, 2014, Barbara Reys said, “To be successful, the Common Core and the aligned assessments must be partnered with content-rich curriculum materials...", “...there is an immediate need for new curriculum materials" (p. 9). There is also the need for constantly assessing the materials and curriculum currently being used. The process of changing the Common Core and subsequently 
changing the curriculum materials, including textbooks, will not be an easy one (Usiskin, 2014).

In An Overview of Mathematics Education in Singapore, Soh (2008) discussed the careful and painstaking process that Singapore goes through in creating and changing the mathematics curriculum. In particular, he points out the need to make sure that extraneous content is culled but essential content is kept in order to make sure that teachers have time to teach without losing rigor and that students have time to learn the content well in each grade level. Indeed, he surmised that the process of reducing quantity while keeping core skills and concepts necessary for future learning is a long, arduous process. A process which necessarily has feedback from all groups involved, (a) curriculum specialists, (b) curriculum planning officers, (c) teachers from every level, (d) mathematicians and mathematics educators from all levels of education above secondary level, and (e) representatives from the Singapore Examination and Assessment Board and other assessment groups. This process of enacting change is something that those involved with curriculum development and implementation in the U.S., including textbook writers and publishers, should be aware of. With the upcoming Common Core assessments, all involved with curriculum need to begin the process of re-assessing the scope and sequence of the U.S. mathematics curriculum and make changes where needed.

The results of this study revealed examples of where having a well-thought out sequence and plan for the curriculum affects the problems in the textbook. For example, the lack of "interpret" problems in the Singapore textbooks shows how the curriculum is set up so students learn how to solve equations one year and then are introduced to the 
new concept of interpreting the equations they solve in the next grade level. This revisiting of a concept only to deepen knowledge is the spiral approach that Singapore uses to reduce the number of concepts learned each year. U.S. students are exposed to all parts of a concept all at once and then repeat the same concept the next year. Such repetition is one reason for the greater number of problems seen in the U.S. textbooks. The discrepancy in the numbers of problems between the two countries' textbooks was another result which demonstrated the need for a more well-planned-out curriculum in the U.S. Without a clear-cut sequence of skills and concepts to teach at each grade level in the U.S. mathematics curriculum, U.S. textbooks present a wide collection of problems encompassing the curriculum in as many states as possible (Seeley, 2003). Thus, the need to have a clear-cut sequence of skills and concepts at each grade level is seen from differences found in the two countries' textbooks. This was an unexpected conclusion based upon the results of the study. Mathematics curricula described as "a mile wide and an inch deep" (Schmidt et al., 2002, p. 301) continues to be a problem in the U.S.

Examining the textbook is a natural accompaniment to the change in mathematics curriculum that is set to take place with the Common Core. This study highlighted some things that need to be examined further which may lead to changes that are needed in the textbooks. The amount of space covered on a page by images and print needs to be examined in greater detail with regard to readability. The readability of the text is one aspect of the textbook which may affect student achievement. The two countries' textbooks differed greatly in regard to the appearance of the page. Another aspect of the textbook which may affect student achievement is problems that require more than one response or transfer of representation to answer the question. U.S. students were asked 
for multiple responses while Singapore students were only asked for one. Further research is needed to see if requiring multiple responses helps, hinders, or does not affect student learning. The researcher suggests that publishers and textbook writers should carefully re-consider putting problems with multiple responses or multiple transfers of representation types in one problem. An examination of exercises with respect to cognitive complexity is also recommended.

\section{Implications for Practice}

The coding process used in this study may be beneficial as a tool to assist textbook adoption committee members in examining textbooks before adopting a textbook. The codebook not only provides a way to compare problems between textbooks but also provides a way to determine the features in a single textbook. Being able to systematically examine problems in a textbook for content can be helpful in the adoption process as well as in the writing and publication of a textbook. The codebook provides a way for publishers to ensure that the textbooks contain the content educators desire.

The coding process could also be used as a tool to scientifically examine how textbooks align to international comparison assessments. By using the codebook to code released items from the international tests, one could get a better understanding of how the problems from the textbooks align with the problems from international assessments.

\section{Limitations of Study}

Some limitations to this study related to the coder training. While two textbooks and at least 210 problems were used in the coder training for this dissertation, future researchers should use more than two textbooks for the coder training process. This will allow the coders to see a greater variety of problems and have enough experience with 
coding to determine if there needs to be a new code added to the codebook before starting to code in the actual study. The study was limited due to the Transfer of Representation Types feature needing to be split into more detailed categories. For example, the numeric representation should have been split into three different categories, (a) numeral, (b) ordered pair, and (c) table. The graphical representation could also have been split into the two categories graphical and image as there was not a separate category for geometric diagrams. Geometric diagrams were addressed in the study in the characterization of problem practices feature under the code "controlling image".

Another limitation to the study was human error. During the coder training process, there were errors made in the entry of the codes into the Excel worksheet. Because the errors were found in the coder-training process, for the actual study, column sums and row sums were added to the Excel worksheet as a check for human error.

A final limitation was the fact that as many states are moving toward the Common Core, textbooks are in a time of transition. The U.S. textbooks that were examined for this study are already changing. There is a need for continued study of the new textbooks that are being made for the Common Core.

\section{Summary Remarks}

The researcher found some ways in which the textbooks from Singapore and the United States were similar and some ways in which they were different. In general, the two countries' textbooks were similar in the number of (a) chapters, (b) linear function sections, (c) pages for development, (d) other pages, and (e) signposts. However, the overall appearance of the page was quite different in the two countries' textbooks. The different number of object-illustrative images and object-analytic images in the two 
countries' textbooks supported a more distinct difference seen in the overall appearance of the page. This difference could be described as bare for the Singapore texts and busy for the U.S. texts. The U.S. texts also contained a greater number of (a) pages, (b) exercises, (c) sections, (d) linear function pages and (e) pages for exercises. Thus the general overall appearance of the countries' textbooks was quite different.

However, the two countries' textbooks were quite similar with regard to the way the problems were presented. Both contained typical problems that one would expect to see in a beginning algebra program. The main similarities were that the problems were similar in how they were presented in the text, the information contained in the problem, and the ratio of applied versus non-applied problems. The main differences seemed to be in the assessment of conceptual learning through the use of definitions, multiple representations, multiple response types, interpreting problems and in the number of computations needed to solve the problem. Thus, the U.S. textbooks contained a greater variety of problems than the textbooks from Singapore.

Areas of future research include studies on (a) the density of the textbook page, (b) the number of assigned pages and problems, (c) the spiral approach, (d) multiple responses, and (e) the Common Core mathematics curriculum. The researcher also suggests that all involved in U.S. mathematics curricula should make a concerted effort to examine the scope and sequence of the current curricula and proposed Common Core State Standards for mathematics in order to develop a carefully delineated curriculum designed so teachers may teach each concept completely and with rigor and students can learn the concepts well and be prepared for future learning. An examination of curricula 
necessitates an examination of the textbook. Thus, the researcher concludes by asserting the need for more textbook examination studies as well as textbook comparison studies. 


\section{References}

Achieve, Inc. (2008). Middle school model two-year course sequence. Washington, D.C., Achieve, Inc. 1-12. Retrieved from http://www.achieve.org/files/MiddleSchoolModelTwo-YearSequence.pdf

ACT. (2004). Crisis at the core: Preparing all students for college and work. Iowa City, IA: Author.

ACT (2009). ACT Profile Report-National. Graduating Class 2009. Retrieved from http://www.act.org/news/data/09/pdf/National2009.pdf

Ahuja, O. P. (2006). World-class high quality mathematics education for all K-12 American students. The Montana Mathematics Enthusiast, 3(2), 223-248.

Alacaci, C., Bulut, \& M., Erbaş, A.K. (2012). A comparison of mathematics textbooks from Turkey, Singapore and the United States. Educational Sciences: Theory and Practice, 12(3), 2324-2329.

American Association for the Advancement of Science. (1999). Project 2061 textbook evaluations: Middle grades mathematics textbooks. Retrieved from http://project2061.aaas.org./publications/textbook/default.htm

Anderson, J. R., Reder, L. M., \& Simon, H. A. (2000). Applications and misapplications of cognitive psychology to mathematics education. Texas Educational Review. [Online] http://act-r.psy.cmu.edu/papers/misapplied.html

Baldi, S., Jin, Y., Skemer, M., Green, P. J., \& Herget, D. (2007). Highlights from PISA 2006: Performance of U.S. 15-year old students in science and mathematics literacy in an International Context. Retrieved from http://nces.ed.gov/pubsearch/pubsinfo.asp?pubid=2008016

Barnett, R. A., Ziegler, M. R., Byleen, K. E., \& Sobecki, D. (2009). College algebra: Graphs and models ( $3^{\text {rd }}$ ed.). Boston, MA: McGraw-Hill.

Beaton, A. E., Mullis, I. V. S., Martin, M. O., Gonzalez, E. J. Kelly, D. L., \& Smith, T. A. (1996). Mathematics achievement in the middle school years: IEA's Third International Mathematics and Science Study (TIMSS). International Association for the Evaluation of Educational Achievement. Center for the Study of Testing, Evaluation, and Educational Policy. Chestnut Hill, MA: Boston College.

Bidwell, A. (2014). Common Core in flux as states debate standards, tests. U.S. News and World Report. Retrieved February 27, 2015 from http://www.usnews.com/news/articles/2014/07/15/common-core-status-in-fluxas-states-debate-standards-tests 
Bisk, R. (2008). Singapore math: perspectives and experiences of a college professor. In Z. Usiskin and E. Willmore (Eds.), Mathematics curriculum in Pacific rim countries-China, Japan, Korea, and Singapore: Proceedings of a Conference. (pp. 283-290). Charlotte, NC: Information Age Publishing.

Brenner, M. E., Brar, T., Durán, R., Mayer, R. E., Moseley, B., Smith, B. R., et al. (1995, October). The role of multiple representations in learning algebra. Presented at the Annual conference of the North American Chapter of the International Study Group for the Psychology of Mathematics Education. Columbus, $\mathrm{OH}$.

Cai, J., Lo, J. J., \& Watanabe, T. (2002). Intended treatments of arithmetic average in U.S. and Asian school mathematics textbooks. School Science and Mathematics, 102(8), 391-404.

Center for the Study of Mathematics Curriculum. (2007, February). K-12 Mathematics: What Should Students Learn and When Should They Learn It? Conference Proceedings. Arlington, VA: Author.

Chen, C. \& Uttal D.H. (1988). Cultural values, parents' beliefs, and children's achievement in United States and China. Human Development, 31, 351-358.

Cherry, K. (2015). What is sociocultural theory?: Definition and information. Retrieved on February 28, 2015 from http://psychology.about.com/od/developmentecourse/f/sociocultural-theory.htm

Clinton, W. (1998). President Clinton's call to action for American education in the $21^{\text {st }}$ Century. Washington, DC: Department of Education. (ERIC Document Reproduction Service No. ED468585).

College Board. (2006). College Board standards for college success: Mathematics and Statistics, adapted for integrated curricula. New York, NY: College Board.

Cunningham, R. F. (2005). Algebra teachers' utilization of problems requiring transfer between algebraic, numeric, and graphic representations. School Science and Mathematics, 105(2), 73-81.

Department of Statistics Singapore. (2013). Table 3.4 Singapore Residents by Age Group, Ethnic Group and Sex, End June 2013 (Cont.). Retrieved on February 28, 2015 from http://www.singstat.gov.sg/statistics/browse-by-theme/populationand-population-structure 
Desimone, L. M., Smith, T., Baker, D., \& Ueno, K. (2005). Assessing barriers to the reform of U.S. mathematics instruction from an international perspective. American Educational Research Journal, 42(3), 501-535.

Fan, L. (2011, October). Textbook research as scientific research: Towards a common ground for research on mathematics textbooks. Paper presented at the 2011 International Conference on School Mathematics Textbooks. Shanghai, China.

Fan, L., \& Kaeley, G. S. (1998, April). Textbooks use and teaching strategies: An empirical study. Paper presented at the annual meeting of the American Educational Research Association. San Diego, CA.

Fennell, F. S., Faulkner, L. R., Ma, L., Schmid, W., Stotsky, S., Wu, H., et al. (2008). Report of the task group on conceptual knowledge and skills. Foundations for Success: The Final Report of the National Mathematics Advisory Panel. Washington, DC: U.S. Department of Education.

Ferrini-Mundy, J. (2004). Invited commentary: The TIMSS 2003 and PISA 2003 reports: Sustaining focus and concern for about the state of mathematics education in the United States. Educational Statistics Quarterly, 6(4), 26-28.

Fleischman, H. L., Hopstock, P.J., Pelczar, M. P., \& Shelly, B. E. (2010). Highlights from PISA 2009: Performance of U.S. 15-Year Old Students in Reading, Mathematics, and Science Literacy in an International Context (NCES 2011-004). U.S. Department of Education. National Center for Education Statistics. Washington DC: U.S. Government Printing Office.

Fowler, L. D. (2008, April). Examination and Critique of Codebook for Textual Analysis. Presented at The Seventh Annual College of Education Research Conference. Miami, FL. Retrieved from http://digitalcommons.fiu.edu/cgi/viewcontent.cgi article=1117\&context=sferc

Foy, P, Arora, A., \& Stanco, G. M. (2013). TIMSS 2011 User guide for the international data base: Mathematics eighth grade released items. International Association for the Evaluation of Educational Achievement (IEA). Publisher: TIMSS \& PIRLS International Study Center, Lynch School of Education, Boston College, Chestnut Hill, MA and International Association for the Evaluation of Educational Achievement (IEA), IEA Secretariat, Amsterdam, the Netherlands. Retrieved April 14, 2015 from http://timss.bc.edu/timss2011/international-released-items. html

Freeman, D. J., \& Porter, A. C. (1989). Do textbooks dictate the content of mathematics instruction in elementary schools? American Educational Research Journal, 26(3), 403-421. 
Frequently Asked Questions: Implications and Future Work/Will common assessments be developed? (2015) Retrieved January 21, 2015 from

http://www.corestandards.org/about-the-standards/frequently-asked-questions/ Common Core State Standards Initiative.

Garofalo, J., Drier, H., Harper, S., Timmerman, M.A., \& Shockey, T. (2000). Promoting appropriate uses of technology in mathematics teacher preparation. Contemporary Issues in Technology and Teacher Education [Online serial], 1(1). Available: http://www.citejournal.org/vol1/iss1/currentissues/mathematics/article1.pdf

Ginsburg, A., \& Leinwand, S. (2008). Singapore math: Can it help close the U.S. mathematics learning gap? In Z. Usiskin and E. Willmore (Eds.), Mathematics curriculum in pacific rim countries-China, Japan, Korea, and Singapore. (pp. 265-282). Charlotte, NC: Information Age Publishing.

Ginsburg, A., Leinwand, S., Anstrom, T., \& Pollock, E. (2005) What the United States can learn from Singapore's world-class mathematics system (and what Singapore can learn from the United States): An exploratory study. American Institutes for Research. Retrieved from http://www.air.org/files/Singapore_Report_Bookmark_Version1.pdf

Gonzales, P., Calsyn, C. Jocelyn, L., Mak K., Kastberg, D., Arafeh, S., et al. (2000). Highlights from the Third International Mathematics and Science Study-Repeat (TIMSS-R) (NCES 2001-027). U.S. Department of Education, Office of Educational Research and Improvement. Washington, DC: U.S. Government Printing Office.

Gonzales, P., Guzman, J. C., Partelow, L., Pahike, E., Jocelyn, L., Kastberg, D., et al. (2004). Highlights from the Trends in International Mathematics and Science Study (TIMSS) 2003 (NCES 2005-005). U.S. Department of Education, National Center for Education Statistics. Washington, DC: U.S. Government Printing Office.

Graf, K., \& Leung, F. K. S. (2000). The thirteenth ICMI study on mathematics education in different cultural traditions. Educational Studies in Mathematics, 43(1), 95-116.

Hadley, W. S., Pflueger, J., \& Covatto, M. (2006). Cognitive tutor algebra I student text. Pittsburgh, PA: Carnegie Learning.

Haggarty, L., \& Pepin, B. (2002). An investigation of mathematics textbooks and their use in English, French and German classrooms: Who gets an opportunity to learn what? British Educational Research Journal, 28(4), 567-590. 
Harries, T., \& Sutherland, R. (2000). The representation of mathematical concepts in primary mathematics textbooks: A focus on multiplication. In A. Rogerson (Ed.) Mathematics for living: The mathematics education into the $21^{\text {st }}$ century project, (pp. 142-146). Amman, Jordan: Third World Forum.

Henning, C. A. (1996). Overcoming the limitations of mathematics textbooks in the middle school classroom. (ED401102). Retrieved February 26, 2015 from http://files.eric.ed.gov/fulltext/ED401102.pdf

Holliday, W. G. (2005). Slowing the influence of flawed mathematics and science education studies. School Science and Mathematics, 105(1), 1-4.

Kaiser, G., Luna, E., \& Huntley, I. (Eds.). (1999). International comparisons in mathematics education. Philadelphia, PA: Falmer Press.

Kelly, D., Xie, H., Nord, C.W., Jenkins, F., Chan, J.Y., \& Kastberg, D. (2013). Performance of U.S. 15-year-old students in mathematics, science and reading literacy in an international context (NCES 2014-024). National Center for Education Statistics. U.S. Department of Education.

Kilpatrick, J, Swafford, J, \& Findell, B. (2001). Adding it up: Helping children learn mathematics. Washington, DC: National Academies Press.

Lantolf, J. P. (1994). Sociocultural theory and second language learning: Introduction to the special issue. The Modern Language Journal, 78(4), 418-420.

Larson, R. E., Kanold, T. D., \& Stiff, L. (1997). Algebra I: An integrated approach. Lexington, MA: D.C. Heath.

Lee, J., Grigg, W., \& Dion, G. (2007). The Nation's Report Card: Mathematics 2007 (NCES 2007-494). National Center for Education Statistics, Institute of Education Sciences. U.S. Department of Education. Washington, D.C.

Leung, F. K. S. (1995). The mathematics classroom in Beijing, Hong Kong, and London. Educational Studies in Mathematics, 29, 297-325.

Leung, F. K. S. (2001). In search of an East Asian identity. Educational Studies in Mathematics, 47(1), 35-51.

Li, Y. (2000). A comparison of problems that follow selected content presentations in American and Chinese mathematics textbooks. Journal for Research in Mathematics Education, 31(2), 234-241.

Lial, M. L., Hornsby, J. I., \& McGinnis, Jr., T. (2012). Beginning and intermediate algebra (5th ed.). Boston, MA: Pearson-Addison Wesley. 
Lombard, M, Snyder-Duch, J., \& Bracken, C. C. (2005). Practical resources for assessing And reporting intercoder reliability in content analysis research projects.

Retrieved March 2, 2015 from http://matthewlombard.com/reliability/index_print $\underline{. h t m l}$

Mayer, R. E., Sims, V., \& Tajika, H. (1995). A comparison of how textbooks teach mathematical problem solving in Japan and the United States. American Educational Research Journal, 32(2), 443-460.

Menon, R. (2000). Should the United States emulate Singapore's education system to achieve Singapore's success in the TIMSS? Mathematics Teaching in the Middle School, 5(6), 345-347.

Mesa, V. (2004). Characterizing practices associated with functions in middle school textbooks: An empirical approach. Educational Studies in Mathematics, 56, 255-286.

Ministry of Education Singapore. (2006a). Mathematics Syllabus Primary. Retrieved February 21, 2015 http://www.moe.gov.sg/education/syllabuses/sciences/files/ maths-primary-2007.pdf

Ministry of Education Singapore. (2006b). Secondary Mathematics Syllabuses.

Retrieved June 22, 2011 from

http://www.moe.gov.sg/education/syllabuses/sciences/files/maths-secondary.pdf

Ministry of Education Singapore. (2013). The Education Statistics Digest 2013.

Retrieved February 28, 2015 from http://www.moe.gov.sg/education/educationstatistics-digest/files/esd-2013.pdf

Ministry of Education Singapore (2012). O- \& N(A)- Level Mathematics Teaching and Learning Syllabus. Retrieved February 21, 2015 from http:/www.moe.gov.sg/ education/syllabuses/sciences/files/ordinary-and-normal-academic-level-maths2013.pdf

Murdock, J., Kamischke, E., \& Kamischke, E. (2002). Discovering algebra: An investigative approach, Teacher's Edition. Emeryville, CA: Key Curriculum Press.

National Center for Education Statistics. (2009). The Nation's Report Card: Mathematics 2009 (NCES 2010-451). Institute of Education Sciences. U.S. Department of Education, Washington, DC.

National Center for Education Statistics. (2013). The Nation's Report Card A First Look: 2013 Mathematics and Reading (NCES 2014-451). Institute of Education Sciences. U.S. Department of Education, Washington, DC. 
National Council of Teachers of Mathematics. (2000). Principles and standards for school mathematics. Reston, VA: NCTM.

National Council of Teachers of Mathematics. (2006). Curriculum focal points for prekindergarten through grade 8 mathematics: A quest for coherence. Reston, VA: NCTM.

National Governors Association Center for Best Practices, Council of chief State School Officers. (2010). Common Core State Standards Mathematics. Washington D.C.: Author. Copyright Date: 2010.

Neuendorf, K. A. (2002). The content analysis guidebook. Thousand Oaks, CA: Sage.

O'Callaghan, B. R. (1998). Computer-intensive algebra and students' conceptual knowledge of functions. Journal for Research in Mathematics Education, 29, 21-40.

OECD (2013). PISA 2012 Assessment and analytic framework: Mathematics reading, science, problem solving and financial literacy, PISA, OECD Publishing, Paris. http://dx.doi.org/10.1787/9789264190511-en

Österholm, M. (2005). Characterizing reading comprehension of mathematical texts. Educational Studies in Mathematics, 63, 325-346.

Porter, A. C. (2002). Measuring the content of instruction: Uses in research and practice. Educational Researcher, 31(7), 3-14.

Provasnik, S., Kastberg, D., Ferraro, D., Lemanski, N., Roey, S., \& Jenkins, F. (2012). Highlights from TIMSS 2011: Mathematics and Science Achievement of U.S. Fourth- and Eighth-Grade Students in an International Context (NCES 2013-009 Revised). U.S. Department of Education. National Center for Education Statistics. Washington DC.

Reys, B. J. (2014, February). Curriculum matters! For students, for teachers, for teacher educators. Paper presented at the Annual Conference of the Association of Mathematics Teacher Educators. Irvine, CA.

Reys, B. J., Reys, W. R., \& Chávez, O. (2004). Why mathematics textbooks matter. Educational Leadership, 61(5), 61-66.

Reys, B. J., Dingman, S, Nevel N., \& Teuscher, D. (2007). High school Mathematics: State-level curriculum standards and graduation requirements. Retrieved December 18, 2014 from http://www.mathcurriculumcenter.org/PDFS/HSreport.pdf . Center for the Study of Mathematics Curriculum. 
Riley, R. W. (1997). Mathematics equals opportunity. White paper prepared for U.S. Secretary of Education Richard W. Riley. Washington, DC: Department of Education.

Scherba de Valenzuela, J. (2002). Sociocultural theory. Retrieved November 27, 2007 from http://www.unm.edu/\%7Edevalenz/handouts/sociocult.html

Schmidt, W., Houang, R., \& Cogan, L. (2002). A coherent curriculum: The case of mathematics. American Educator, 26(2), 1-18.

Schmidt, W. H., McKnight, C. C., Houang, R. T., Wang, H., Wiley, D. E., Cogan, L. S., et al. (2001). Why schools matter: A cross-national comparison of curriculum and learning. San Francisco, CA: Jossey Bass.

Schmidt, W. H., McKnight, C. C., \& Raizen. (1997). A splintered vision: An investigation of U.S. Science and mathematics curriculum, Executive Summary. Retrieved on July 1, 2011, http://ustimss.msu.edu/splintrd.pdf

Schoen, R. C., \& Clark, J. T. (2007). Florida's answer to "a mile wide and an inch deep:" Mathematics content standards that allow time for in-depth teaching and learning. Dimensions in Mathematics, 27(2), 6-12.

Seeley, C. L. (2003). Mathematics textbook adoption in the United States. In M. A. Stanic \& J. Kilpatrick (Eds.), A history of school mathematics (pp. 957-988). Reston, VA: National Council of Teachers of Mathematics.

SGBox.com. (2014). Which Singapore math textbooks are Singapore schools using? Retrieved from http://www.sgbox.com/singaporetextbooks.html on December 16, 2014.

Soh, C. K. (2008). An overview of mathematics education in Singapore. In Z. Usiskin and E. Willmore (Eds.), Mathematics curriculum in pacific rim countries-China Japan, Korea, and Singapore: Proceedings of a Conference. (pp. 23-36). Charlotte, NC: Information Age Publishing

Spielhagen, F. R. (2006). Closing the achievement gap in math: The long-term effects of eighth-grade algebra. Journal of Advanced Academics, 18(1), 34-59.

Standards in Your State. (2015). Retrieved February 26, 2015 from http://www.corestandards.org/about-the-standards/frequently-asked-questions/ Common Core State Standards Initiative.

Stanic, G. M. A., \& Kilpatrick J. (Eds.). (2003). A history of school mathematics (pp. 819-842). Reston, VA: National Council of Teachers of Mathematics. 
Steele, D. (2005). Using writing to access students' schemata knowledge for algebraic thinking. School Science and Mathematics, 105(3), 142-154.

Steen, L. A. (1990). On the shoulders of giants: New approaches to numeracy. Washington, DC: National Academies Press.

Teuscher D. \& Reys, R. E. (2010). Slope, rate of change, and steepness: Do students understand these concepts?. Mathematics Teacher, 103(7), 519-524.

Tieso, C. (2005). The effects of grouping practices and curricular adjustments on achievement. Journal for the Education of the Gifted, 29(1), 60-89.

U.S. Department of Education. (2001). No Child Left Behind Act of 2001. Retrieved July 1, 2011 from http://www.ed.gov/policy/elsec/leg/esea02/index.html

U.S. Department of Education. (2009). Highlights from TIMSS 2007. Retrieved on July 1, 2011 from http://nces.ed.gov/pubs2009/2009001_1.pdf

U.S. Department of Education. (2010a). ESEA Blueprint for Reform. Office of Planning, Evaluation, and Policy Development, Washington, D.C. Retrieved on June 30, 2011 from http://www2.ed.gov/policy/elsec/leg/blueprint/blueprint.pdf

U.S. Department of Education. (2010b). National Assessment of Educational Progress. National Center for Education Statistics. Retrieved on June 14, 2010 from http://nces.ed.gov/nationsreportcard/

Usiskin, Z. (2008). Introductions. In Z. Usiskin and E. Willmore (Eds.), Mathematics curriculum in Pacific rim countries-China, Japan, Korea, and Singapore: Proceedings of a Conference. (pp. 1-5). Charlotte, NC: Information Age Publishing.

Usiskin, Z. (2014, April). What changes should be made next for the next edition of Common Core State Standards of Mathematics?. Paper presented at the NCTM Annual Meeting. New Orleans, LA.

Uttal, D. H. (1996). Beliefs, motivation, and achievement in mathematics: A crossnational perspective. In M. Carr (Ed.), Motivation in mathematics (pp. 25-37). Cresskill, NJ: Hampton Press.

Weller, D. (2004). The effects of contrast and density on visual websearch. Posted on July 12, 2004 on Software Usability Research Laboratory. Retrieved December 16, 2014 from http://psychology.wichita.edu/surl/usabilitynews/62/density.htm 
Woodward, J., \& Ono, Y. (2004). Mathematics and academic diversity in Japan. Journal of Learning Disabilities, 37, 74-82.

Wu, H. (2001). How to prepare students for algebra. American Educator, 25(2), 10-17.

Wynd, C. A., Schmidt, B., \& Schaefer, M. A. (2003). Two quantitative approaches for estimating content validity. Western Journal for Nursing Research, 25(5), 508518.

Zhu, Y., \& Fan, L. (2002). Textbook use by Singaporean mathematics teachers at lower secondary school level. Proceedings of ICME-EARCOME 2 (Vol. 2), 94-201.

Zhu, Y., \& Fan, L. (2004, July). An analysis of the representation of problem types in Chinese and U.S. mathematics textbooks. Paper accepted for ICME-10, Discussion group 14, (pp. 4-11). Copenhagen, Denmark. 
Appendix A

Education Websites

General Education Websites (Most go directly to Curriculum and Instruction)

California: DOE Curriculum Frameworks and Instructional Materials:

http://www.cde.ca.gov/ci/cr/cf/index.asp

Florida: DOE Curriculum: http://www.fldoe.org/bii/Instruct_Mat/

Texas: http://www.tea.state.tx.us/index2.aspx?id=3373

Singapore: http://www.moe.gov.sg/

$\underline{\text { Websites of Adopted Texts/ Adoption Schedules }}$

California: Mathematics Publishers List: http://www.cde.ca.gov/ci/cr/cf/mathpub.asp

Current Adoptions: http://www.cde.ca.gov/ci/ma/im/mathprogramnov2007.asp

Florida: Current Adoptions: http://www.fldoe.org/bii/Instruct_Mat/pdf/Adopted0910.pdf

Adoption Schedule: http://www.fldoe.org/bii/curriculum/sss/\#math

Texas Adoptions: http://www.tea.state.tx.us/textbooks/materials/bulletin/programs.pdf

https://faulk.tea.state.tx.us/ematevi/EMATREPORTS/RptInst/EM_CURR_ADPN.pdf

Adoption Schedule:

http://ritter.tea.state.tx.us/textbooks/adoptprocess/adoptioncycle.pdf

Singapore: Adoptions http://atl.moe.gov.sg/Current.aspx

$\underline{\text { Websites for Standards/Skills/Syllabi }}$

California: Mathematics Framework for California Public Schools Kindergarten through

Grade Twelve (2006): http://www.cde.ca.gov/ci/cr/cf/documents/mathfrwk.pdf

Florida: Standards Search website:

http://www.floridastandards.org/Standards/FLStandardSearch.aspx 
Standards by Grade: http://www.corestandards.org/the-standards/mathematics Printable standards: http://www.floridastandards.org/Downloads.aspx

Texas: Standards by grade: http://ritter.tea.state.tx.us/rules/tac/chapter111/ch111b.pdf

General standards: $\underline{\text { http://www.tea.state.tx.us/index2.aspx?id=2147499971 }}$

Singapore: Syllabi:

http://www.moe.gov.sg/education/syllabuses/sciences/files/maths-secondary.pdf 
Appendix B

International Textbook Comparisons

\begin{tabular}{|c|c|c|}
\hline Characteristic & Country/Grade Level & Researcher(s)/Year \\
\hline $\begin{array}{l}\text { Integer addition/ } \\
\text { subtraction }\end{array}$ & China, U.S. $/ 7^{\text {th }}$ grade & $\mathrm{Li} / 2000$ \\
\hline Problems UCSMP & China, U.S. $/ 7^{\text {th }}-8$ th & Zhu \& Fan/2004 \\
\hline Images/specific & Five countries/Singapore & Harries \& \\
\hline references & and U.S./primary & Sutherland/2000 \\
\hline Lessons & Japan, U.S. $/ 7^{\text {th }}$ & $\begin{array}{c}\text { Mayer, Sims, \& } \\
\text { Tajika/1995 }\end{array}$ \\
\hline Arithmetic average & $\begin{array}{l}\text { Korea, Taiwan, Japan } \\
\text { and U.S. } / 5^{\text {th }}-6^{\text {th }}\end{array}$ & $\begin{array}{l}\text { Cai, Lo, \& } \\
\text { Watanabe/2002 }\end{array}$ \\
\hline Instructional criteria & U.S./middle & AAAS/1999 \\
\hline General features & $\begin{array}{l}37 \text { countries in TIMSS } \\
\text { Singapore \& U.S./ 8th }\end{array}$ & Schmidt et al./2001 \\
\hline $\begin{array}{l}\text { Layout/lessons/ } \\
\text { Problems }\end{array}$ & $\begin{array}{c}\text { Singapore \& U.S./ } \\
\text { elementary }\end{array}$ & Ginsburg et al./2005 \\
\hline How text is used & $\begin{array}{c}\text { France, Germany, \& } \\
\text { England } / 7^{\text {th }}-9 \text { th }\end{array}$ & $\begin{array}{l}\text { Haggarty \& } \\
\text { Pepin/2002 }\end{array}$ \\
\hline $\begin{array}{l}\text { Effect on teacher } \\
\text { practices }\end{array}$ & U.S./lower secondary & Fan \& Kaeley/1998 \\
\hline
\end{tabular}




\begin{tabular}{lll} 
Characteristic & Country/Grade Level & Researcher(s)/Year \\
\hline Characteristics of & Beijing, Hong Kong, & Leung/1995 \\
Chinese culture & London/ middle & \\
Reading comprehension & Sweden University & Österholm/2005 \\
Schemata knowledge & U.S./ $7^{\text {th }}$ grade & Steele/2005 \\
Textbook/achievement & U.S./5 ${ }^{\text {th }}$ grade & Tieso/2005 \\
Characterizing & TIMSS countries & Mesa/2004 \\
problem-types & & \\
Problem-solving & U.S./College & O'Callaghan/1998 \\
competency & & Cunningham/2005 \\
Transfer of representation & & \\
\hline
\end{tabular}


Appendix C

Coding Scheme

Part I

Background features

1. Number of pages in text

2. Number of chapters

3. Number of sections

4. Number of sections pertaining to linear functions

5. Number of pages pertaining to linear functions

6. Number of pages for development

7. Number of pages for exercises

8. Number of other pages

9. Number of problems pertaining to linear functions

10. Average number of pages per section pertaining to linear functions

11. Number of object-analytic images

12. Number of object-illustrative images

13. Number of signposts or attention-getters

Part II

General classification of problem

1. Computational feature

(S) single computation procedure $\quad(\mathrm{M})$ multiple computation procedures (ot) other

2. Contextual feature

(nu) numerical (vi) visual (ve) verbal (co) combined form (ot) other

3. Response-type feature

(A) numeric answer only (E) algebraic expression or equation only

(ES) explanation or solution required $\quad(G)$ Graph only 
(M) Multiple response types $\quad$ (OP) other response

4. Cognitive requirement feature

(PP) procedural practice

(PS) problem solving

(CU) conceptual understanding

(SR) special requirement (ot) other

5. Given-information feature

(SF) sufficient $\quad($ EX) extraneous $\quad$ (ISF) insufficient

6. Application type

(AP) applied (NA) nonapplied

Part III

Classification of problem practices

1. Characterization of problem practices

$\begin{array}{lll}\text { (sr) symbolic rule } & \text { (op) ordered pair } & \text { (sd) social data } \\ \text { (ph) physical phenomena } & \text { (ci) controlling image } & \text { (ot) other }\end{array}$

2. Problem-solving competency type

(mod) modeling (int) interpreting (tran) translating

(reif) reifying (dna) does not apply

3. Transfer type

$(\mathrm{A} \rightarrow \mathrm{N})$ algebraic to numeric

$(A \rightarrow G)$ algebraic to graphical

$(\mathrm{A} \rightarrow \mathrm{V})$ algebraic to verbal

$(\mathrm{N} \rightarrow \mathrm{G})$ numeric to graphical

$(\mathrm{N} \rightarrow \mathrm{A})$ numeric to algebraic

$(\mathrm{N} \rightarrow \mathrm{N})$ numeric to numeric

$(\mathrm{N} \rightarrow \mathrm{V})$ numeric to verbal

$(\mathrm{G} \rightarrow \mathrm{A})$ graphical to algebraic

$(\mathrm{G} \rightarrow \mathrm{N})$ graphical to numeric

$(\mathrm{G} \rightarrow \mathrm{V})$ graphical to verbal

$(\mathrm{V} \rightarrow \mathrm{A})$ verbal to algebraic

$(\mathrm{V} \rightarrow \mathrm{N})$ verbal to numeric

$(\mathrm{V} \rightarrow \mathrm{G})$ verbal to graphical

(m) multiple transfer types

(dna) does not apply 
Appendix D

Codebook

Textbook Content Analysis

Textbook ID: Fill in the textbook ID number, as indicated on the textbook list.

Coder ID: Indicate the number of the individual who coded that sheet, according to the coder ID List.

Part I: Background features of the textbook

Unit of data collection: The textbook pages will give us the data for Part I.

Number of pages in text: Report the number of pages in the textbook. Start with the beginning of Chapter 1. Include any "answer to exercises" sections but do not include indices or other appendices. Do not include formula pages in back or front of book. Do not count include Spanish/English or similar glossaries.

Number of chapters: Report the number of chapters in the textbook. This includes any pseudo- chapters which look like a chapter but are not labeled chapters.

Number of sections: Report the total number of sections in the textbook. Chapters are made up of sections, that is, $1.2=$ Chapter 1 section 2 . A pseudo-chapter may have sections with titles but no numbers; include these pseudo-sections in your count. Include extra teaching lessons within the chapter as a new section. Chapter reviews, Review Exercises, Chapter Tests, Summary Exercises, and the like are not included as sections. Optional sections are not counted.

Number of sections pertaining to linear functions: Report the total number of sections pertaining to linear functions/equations. A linear function is an equation of the form $f(x)=m x+b$ where $\mathrm{m}$ and $\mathrm{b}$ are real numbers. An alternative form is the linear equation $A x+B y=C$ where $A, B$, and $C$ are real numbers such that not both $A$ and $B$ are zero. While $8 x+7=5$ is not considered a linear function, knowing how to solve such equations are an integral part of working with linear functions and will also be examined. The pages to include would contain solving linear equations, graphing linear equations, finding linear equations, fitting a line to data, and definition of and concepts related to linear functions/equations.

Number of pages pertaining to linear functions: Report the number of pages in the text pertaining to linear functions/equations. Count the number of pages in each section pertaining to linear functions/equations.

Number of pages for development: Report the fractional number of pages for concept 
development contained within the sections pertaining to linear functions. This does not include exercises at the end of the chapter. If multiple categories, such as development, exercises or other, occur on one page, then round to the most appropriate quarter page.

Number of pages for exercises: Record the fractional number of pages for exercises contained within the sections pertaining to linear functions. Exercises are the problems after the concept development pages. The students work on these problems to further their understanding of the concept. Include pages that contain problems that follow an extra teaching lesson. If multiple categories occur on one page, such as development, exercises, or other, then round to the most appropriate quarter page.

Number of other pages: Record the fractional number of pages that do not contain concept development or exercises within the sections pertaining to linear functions. These pages may contain illustrations, may be blank, give historical information, etc. If multiple categories occur, then round to the most appropriate quarter page.

Number of problems pertaining to linear functions: Record the number of problems within the sections pertaining to the topic of linear functions. These are problems that do not have an answer or solution within the section. Do not include the examples or practice problems in the development pages. Count a problem with multiple questions separated by a, b, c or i, ii, iii, etc. as separate problems. Problems at the end of the chapter referred to as review exercises, mixed review, review, chapter review, self-test, chapter test, and similarly titles problems will not be examined. Group activity problems and summary exercises will not be examined.

Average number of pages per section pertaining to linear functions: Report the average number of pages per section pertaining to linear functions. Calculate by dividing the total number of pages pertaining to linear functions by the total number of sections pertaining to linear functions.

Number of object-analytic images: Count the number of images that represents the mathematical structure in the problems within the sections pertaining to linear functions/equations. An image is any drawing, picture, cartoon, or photo seen in the text. Graphs, tables, and screen-shots of calculator output are not included as an image. Illustrations used to set up a problem, such as geometrical figures which are used to show the reader which angle they were asked to find, and graphs will not be counted.

Number of object-illustrative images: Count the number of images that represents objects with no relationship to the mathematical structure in the problems within the sections pertaining to linear functions. An image is any drawing, picture, cartoon, or photo seen in the text. Graphs, tables, and screen-shots of calculator output are not included as an image. Illustrations used to set up a problem, such as geometrical figures which are used to show the reader which angle they were asked to find, and graphs will not be counted. 
Number of signposts or attention-getters: Within the sections pertaining to linear functions, report the number of signposts or attention-getters in the textbook. Signposts or attention-getters are instances where the text directs the student to look at or to learn a particular formula or definition, warns of common errors, or directs the student to consciously focus on his/her thinking. Examples include Caution Boxes and hints to relate material to previously-learned material. A definition listed is not an example unless the text directly relates it to previously learned material.

Part II: General classification of problems.

Unit of data collection: The problems pertaining to linear functions after the concept developmental pages within the student textbooks will be the source of data collected in Part II. The problems will be those with no solution or answer given within the section.

Computational feature: Report the number (one, more than one, or none) of mathematical operations required to arrive at an answer.

1. Single computation procedure, $S$ : The problem requires a single computation to arrive at an answer. If a problem directs the student to do a simple computation multiple times, for example, Calculate $2 x+3$ when $x=2, x=-2$, this is classified as a single computation procedure.

2. Multiple computation procedures, $M$ : The problem requires multiple computations to arrive at an answer.

3. Other, ot: The problem requires something other than computations.

Contextual feature: Report the main contextual form in which the problem is presented. Many problems have verbal directions before the main contextual form of the problem. When the verbal directions are minimal, the problem may be classified as numerical or visual form.

1. Numerical, nu: The problem is represented in a purely numerical form. A table would be classified under this category.

2. Visual, vi: The problem is only represented in a picture, graph, or diagram form.

3. Verbal, ve: The problem is only represented in word or story form.

4. Combined form, co: The problem is represented by more than one form.

5. Other, ot: The problem is represented by a form not already listed.

Response-type feature: Report the type of answer that the question requires.

1. Numeric answer only, $A$ : The answer only requires a number or an ordered pair.

2. Algebraic expression or equation only, E: The answer only requires an algebraic expression, that is, a letter or any combination of numbers, letters, operation symbols $(+,-, \times, \div)$ and grouping symbols or an algebraic equation, that is, a statement that two algebraic expressions are equal. The single number answer will not be in this category.

3. Explanation or solution required, ES: The answer requires an explanation or the presentation of how a solution is found.

4. Graph only, G: The answer only requires a graph. 
5. Multiple response types, $M R$ : The problem requires more than one type of answer.

6. Other response, $O P$ : The problem requires a response other than the above categories. This may refer to matching, true/false, multiple choice, or comparison/selection problems where no explanation is asked for.

Cognitive requirement feature: Report the type of cognitive level required to do the problem.

1. Procedural practice, $P P$ : The problem requires only processes that use rules and algorithms with little connection to relationships among features in the problem.

2. Conceptual understanding, $C U$ : The problem requires the ability to make relationships among features in the problem in order to solve the problem. These problems do not require but may have multi-step procedures to solve them. Focus is on concepts.

3. Problem solving, PS: Problems in which the situation in the problem must be put in mathematical form before it can be solved. These problems are multi-step. Focus is on solving a problem.

4. Special requirement, SR: The problem may require a higher level of thought such as proving a conjecture.

5. Other, ot: The problem requires some other cognitive requirement.

Given-information feature: Report the amount of information given in the problem statement.

1. Sufficient, SF: The problem has exactly the amount of information to do the problem.

2. Extraneous, EX: The problem contains extra information that is not pertinent to the problem.

3. Insufficient, ISF: The problem does not contain enough information to do the problem.

Application type feature: Report the applicability of the problem to real world or everyday problems.

1. Applied, AP: The problem is based on or has applications to a real life situation.

2. Nonapplied, NA: The problem does not have any practical connection to every day life.

Part III Classification of problem practices

Unit of data collection: The problems pertaining to linear functions after the concept development pages within the student textbooks will be the source of data. The problems will be those with no solution or answer given within each section.

Characterization of problem practices: Report on the type of practice seen in the problems pertaining to linear functions in the textbook.

1. Symbolic rule, sr: The problem emphasizes the use of the function as a rule, that is, an equation. Problem will often start with an equation.

2. Ordered pair, op: The problem emphasizes the use of the function as an ordered pair. 
The ordered pair relationship can be seen through several different representations such as an arrow diagram, Cartesian plane, an equation, and others.

3. Social data, $s d$ : The problem emphasizes the use of the function as a relation. The relation is constructed from given information. The problem rarely starts with an equation. Example: Make a table for the following relation: A shirt costs $\$ 17$ at Costco. Show the relationship of the amount paid to the number of shirts bought. Problem may require using relationship to find values once relationship is found.

4. Physical phenomena, ph: The problem emphasizes the use of the function as a physical relationship, such as cause-effect or time relationships. No symbolic representation is used. Data is usually gathered by the student or is given as data that has been collected. The problem does not ask you to create an equation.

5. Controlling image, ci: The problem emphasizes the use of the function as figural, that is, is defined by graph, pattern, or geometrical figures.

6. Other, ot: The practice is one not previously defined or cannot be determined.

Problem-solving competency type: Report the competency needed to solve the problem.

1. Modeling, mod: The problem requires the student to take a problem situation in words and translate it into a mathematical representation. The most used mathematical representations are algebraic (symbols), numeric (numbers), and graphical (graphs).

2. Interpreting, int: The problem requires the student to translate the mathematical representation (algebraic, numeric, or graphical) of a function into real-life terms.

3. Translating, tran: The problem requires the student to change form one mathematical representation (algebraic, numeric, or graphical) to another mathematical representation.

4. Reifying, reif: The problem requires the student to recognize that a linear function is a mathematical object and not just a process or procedure. Examples would include composition, algebra, and transformations of functions. May include a transfer of representation type.

5. Does not apply, DNA: None of these competencies apply.

Transfer type: Report the type of transfer present as the student moves from the mathematical representation of the question to a different mathematical representation for the answer. Algebraic refers to equation or algebraic expression form. Numeric refers to table or number form, including ordered pair form. Graphical refers to graph, diagram, or picture form.

Verbal form refers to written or verbal word or sentence form.

1. $A \rightarrow N$, Algebraic to numeric: The student is required to move from an algebraic representation to a numeric representation

2. $A \rightarrow G$, Algebraic to graphical: The student is required to move from an algebraic representation to a graphical representation.

3. $A \rightarrow V$, Algebraic to verbal: The student is required to move from an algebraic representation to a verbal representation.

4. $N \rightarrow$ A, Numeric to algebraic: The student is required to move from a numeric representation to an algebraic representation. 
5. $N \rightarrow G$, Numeric to graphical: The student is required to move from a numeric representation to a graphical representation.

6. $\mathrm{N} \rightarrow \mathrm{N}$, Numeric to numeric: The student is required to move from a numeric representation to a numeric representation.

7. $N \rightarrow V$, Numeric to verbal: The student is required to move from numeric representation to a verbal representation.

8. $G \rightarrow A$, Graphical to algebraic: The student is required to move from a graphical representation to an algebraic representation.

9. $G \rightarrow N$, Graphical to numeric: The student is required to move from a graphical representation to a numeric representation.

10. $G \rightarrow V$, Graphical to verbal: The student is required to move from a graphical representation to a verbal representation.

11. $V \rightarrow A$, Verbal to algebraic: The student is required to move from a verbal representation to an algebraic representation.

12. $V \rightarrow N$, verbal to numeric: The student is required to move from a verbal representation to a numeric representation.

13. $V \rightarrow G$, verbal to graphical: The student is required to move from a verbal representation to a graphical representation.

14. Multiple transfer types, $m$ : The student is required to answer multiple questions within one problem using different transfer types. Example: $\mathrm{V} \rightarrow \mathrm{A}$ and $\mathrm{V} \rightarrow \mathrm{N}$ may be used to answer multiple questions in one problem. Note: This does not allow more than one transfer to occur to achieve the final mathematical representation.

15. Does not apply, DNA: None of these transfers apply. 
Appendix E

Textbooks Used in Comparison

Singapore

Title

Discovering Mathematics $1 A$

Discovering Mathematics $1 B$

Mathematics Matters Secondary 1

New Syllabus Mathematics 1 6th Ed

Discovering Mathematics $2 A$

Discovering Mathematics $2 B$

Mathematics Matters Secondary 2

New Syllabus Mathematics 2 6th Ed

United States

Title

Glencoe Florida Math Connects 1

Glencoe Florida Math Connects 2

Glencoe Florida Math Connects 3
Author(s) / Publisher

Victor Chow Wai Keung, 2010 / Starpub

Victor Chow Wai Keung, 2010 / Starpub

Sin Kwai Meng, Ng Song Beng,

Chip Wai Lung, 2008 / Marshall Cavendish

Yeap Ban Har, Teh Keng Seng, Loh

Cheng Yee, 2011 / Shing Lee

Victor Chow Wai Keung, 2010 / Starpub

Victor Chow Wai Keung, 2010 / Starpub

Sin Kwai Meng, Ng Song Beng,

Chip Wai Lung, 2008 / Marshall Cavendish

Yeap Ban Har, Teh Keng

Seng, Loh Cheng Yee, 2011 / Shing Lee

Author(s) / Publisher

Molix-Bailey, Dr. Day, Frey, Howard, 2011 /

School Ed. Group/McGraw-Hill

Molix-Bailey, Dr. Day, Frey, Howard, 2011

School Ed. Group/McGraw-Hill

Molix-Bailey, Dr. Day, Frey, Howard, 2011 / 
School Ed. Group/McGraw-Hill

McDougal Little Math, Course 1

McDougal Little Math, Course 2

Algebra I Concepts and Skills

Florida Math Series: Course 1

Florida Math Series: Course 2

Florida Math Series: Course 3
Larson, 2007 / Holt McDougal

Larson, 2007 / Holt McDougal

Larson, 2010 / Holt McDougal

Lappan et al., 2011 / Pearson Prentice Hall

Lappan et al., 2011 / Pearson Prentice Hall

Lappan et al., 2011 / Pearson Prentice Hall 


\section{Appendix F \\ Highlights of Pre-Pilot Study}

The pre-pilot study (Fowler, 2008) began with a brief training session and slight revision of the codebook. Two coders, then, independently coded two randomly selected sections of text pertaining to linear functions in a mathematics textbook from the U.S. with respect to 23 features. An Excel program was used to facilitate the recording of the coding selections while a coding form was used to record the numbers within the generalfeature categories. Due to the ease of using the Excel program, the coding form will be added to the Excel worksheet. A sample of this rubric listing all problems as columns and the feature categories as rows is found in Appendix G. The total number of problems examined was 54 (Fowler, 2008).

For the features which required a choice of code, inter-rater reliability values were assessed using Cohen's kappa and percent agreement. The general features of the text did not require a choice of code categories but only required a count for each feature. The general features results consisted of a comparison of the two coders' assessments of the features as listed on their coding forms. These values are listed in Table 1. None of the coders' assessments were a perfect match. The coders were most in agreement about the average number of pages per section pertaining to linear functions with values of 5.43 and 5.22.

Cohen's kappa and percent agreement were the inter-rater reliability coefficients calculated for the six problem characteristics and the problem practices pertaining to linear functions. As seen in Table 2, the inter-rater reliability coefficients varied widely 
with respect to problem characteristics and problem practices. These values allowed the Table 1

Comparison of Data for General Characteristics of the Text Feature Coder 1 Coder 2 Pages in Text 794 807

Number of Chapters 12

Number of Sections 109 120

Linear Function Pages 38

Pages for Development 26

Pages for Exercises 32.5 26

Average Pages/Linear Function

Object-Illustrative Images

Object-Analytic Images

Signposts/Attention-Getters

researcher to determine the usefulness of the definitions and categories within the coding scheme.

The researcher was able to use the results of the pre-pilot study to determine changes that needed to be made in the coding scheme. First, the fact that every general feature of the text was classified differently by the coders was an indicator that the definitions of these characteristics should be changed. The pre-pilot study results indicated a need for clarification of the difference between conceptual understanding and 
problem solving and of the effect the directions have on the coding of the contextual feature. The researcher addressed these issues by stating the main focus of each code and Table 2

Inter-Rater Reliability Coefficients for Categories Coded in Text

Feature Cohen's kappa Percent Agreement

$$
\text { Problems }(\mathrm{n}=54)
$$

Computational

Contextual

Response-Type

Cognitive Requirement

Given Information

Application Type

Problem Practices

${ }^{a}$ Cohen's kappa does not yield a value due to only one characterization (i.e., code), being chosen for all problems. All problems were coded with the same code, so the coders agreed on the characterization of every problem in this category. stating that the directions are included as part of the problem. Some discrepancies that were observed and the plans to resolve the issues are as follows:

1. Does one count the introductory pages before the chapters begin? Yes.

2. Can one have half pages or one-quarter pages in the count? Yes. Pages will be counted to the nearest quarter page.

3. Do extra teaching lessons within a section count as a new section? No.

4. Are all problems; oral, written, mixed review, computer, and self-test; counted 
as problems? No. Mixed review and review problems will not be examined.

5. Do graphs count as images to be classified? No, these problems are already mathematical in nature and do not need to be classified as object analytic or object illustrative.

6. What are more explicit examples of signposts? These would include caution boxes and hints to relate information to previously-learned material.

7. Does the number of pages for every lesson, even ones without linear functions, need to be determined? No, the percentage of the textbook that pertains to linear functions should be sufficient.

8. To what extent are linear equations part of the linear functions topic? Linear equations will be included as part of linear functions as long as the relationship between $\mathrm{x}$ and y clearly exists. See Appendix D for more details.

The researcher also decided to leave some sections, such as the number of pages for each section, out of the future comparison study and to alter other categories. The number of features examined in the texts changed from 23 to 22 features. The pre-pilot study also highlighted how important coder-training is to the process of achieving inter-rater reliability. 


\section{Appendix G}

Sample of Excel Program Used in Coding
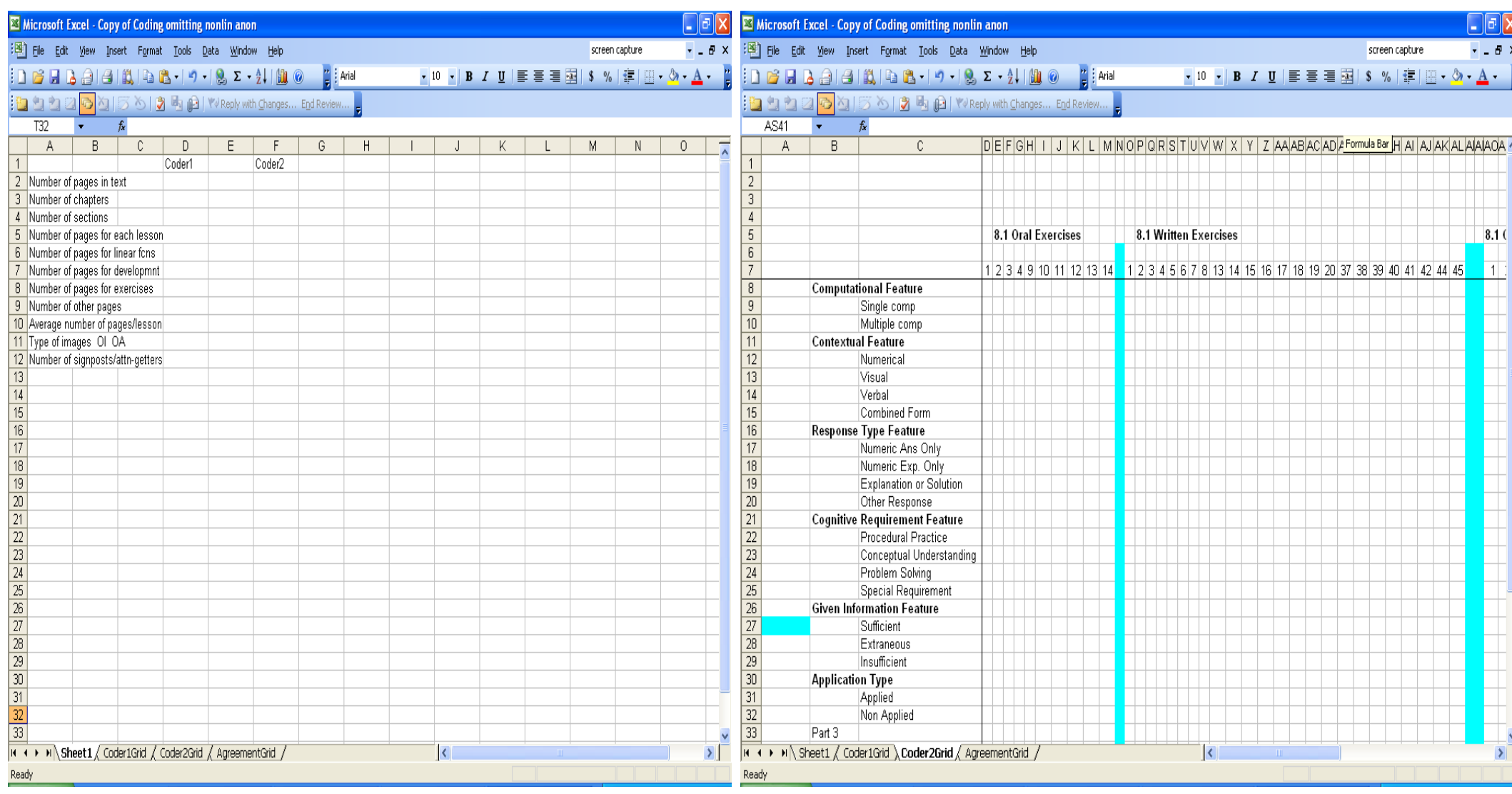

司要

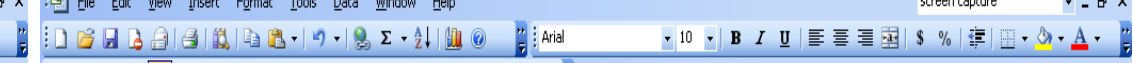
]

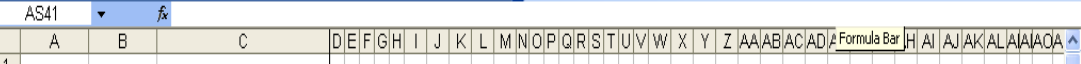

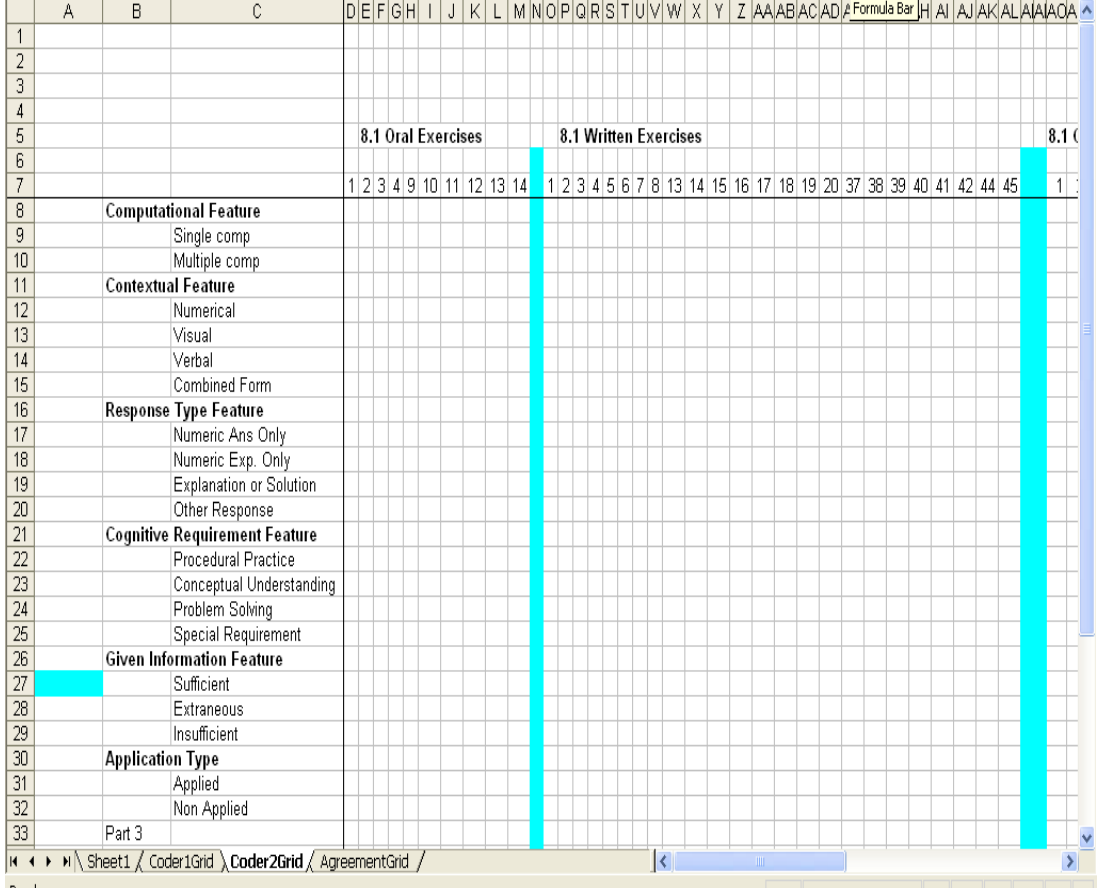

Ready 


\section{Appendix $\mathrm{H}$}

Sample pages from U.S. and Singapore textbooks, respectively

\section{United States: McDougal Little Math, Course 1}

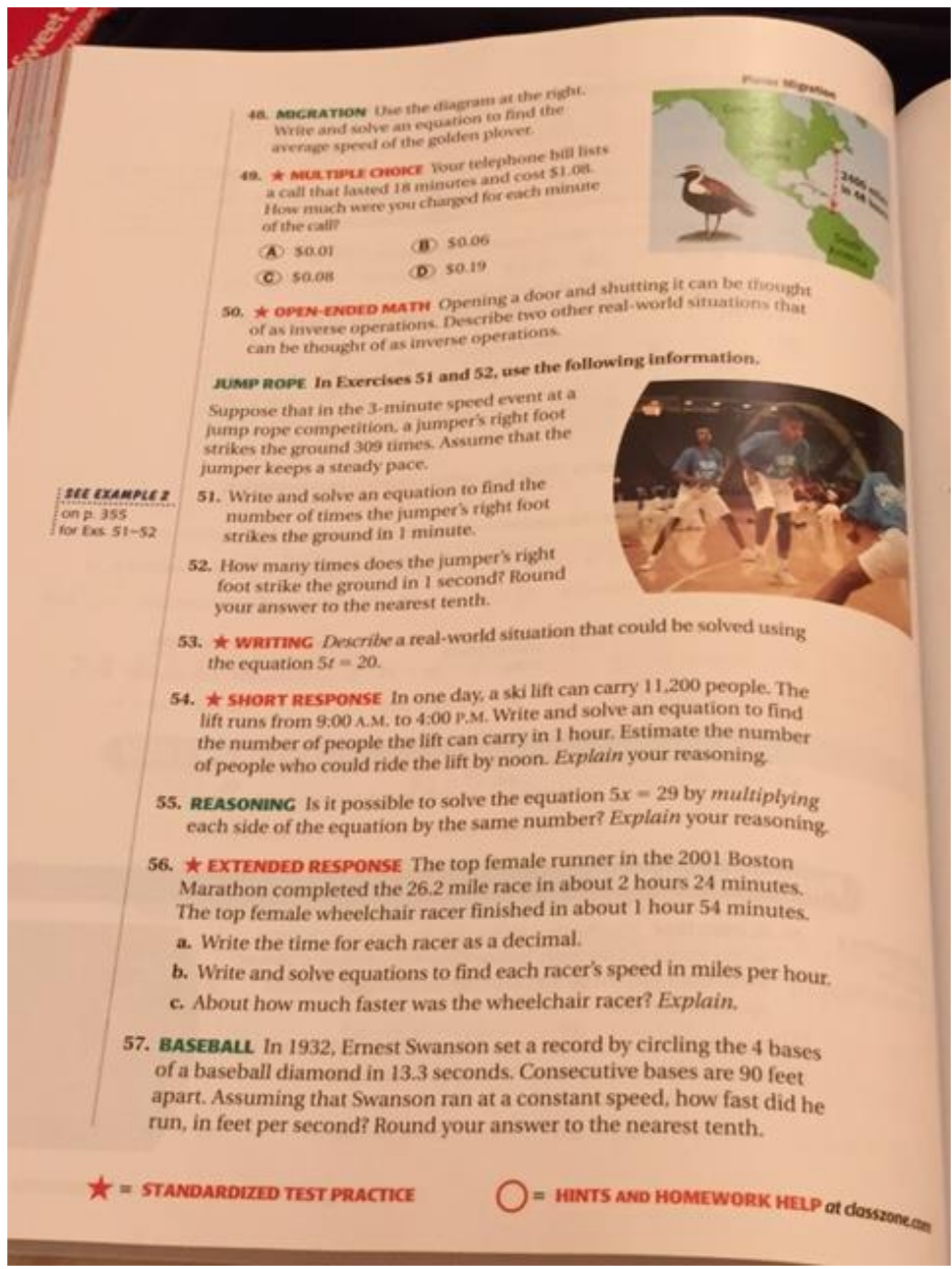


Singapore: Discovering Mathematics $1 A$

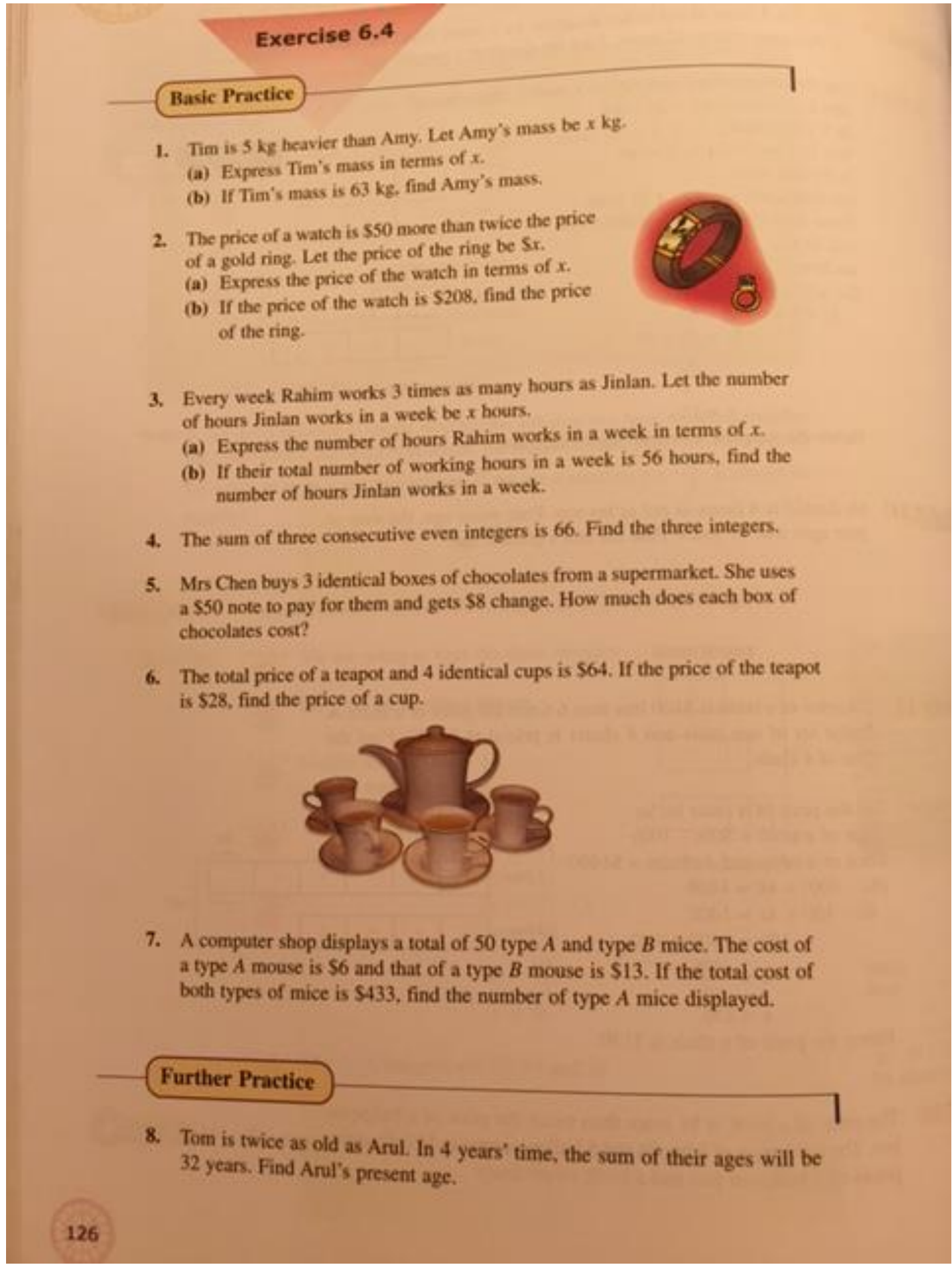


VITA

\section{LINDA DONNELL (DONNA) FOWLER}

1986-1989

B.A. Mathematics, Magna Cum Laude

Carson Newman College

Jefferson City, TN

1989

Substitute Teacher

Hamblen County, TN

1989-1992

M.S. Mathematics

Middle Tennessee State University

Murfreesboro, TN 37132

1989-1993

Teaching Assistant/Adjunct

Middle Tennessee State University

Murfreesboro, TN

1994-Present

Assistant Professor of Mathematics

Palm Beach Atlantic University

West Palm Beach, FL

1998-2009

Work-Study Supervisor for Mathematics Department

Palm Beach Atlantic University

West Palm Beach, FL

Oct. 19-30, 1998 Employee of the Week.

2001-07, '08-‘09 Mathematics Society Faculty Sponsor

2011-present

2011

Ed.S. Curriculum and Instruction

Florida International University

Miami, FL

\section{PUBLICATIONS AND PRESENTATIONS}

Fowler, L. D. (2008, April). Examination and Critique of Codebook for Textual Analysis.

Presented at The Seventh Annual College of Education Research Conference.

Miami, FL.

http://digitalcommons.fiu.edu/cgi/viewcontent.cgi article $=1117 \&$ context $=$ sferc 